\title{
The Role of Ionic Liquids in the Pharmaceutical Field: An Overview of Relevant Applications
}

\author{
Sónia N. Pedro $\left(\right.$, Carmen S. R. Freire, Armando J. D. Silvestre ${ }^{\circledR}$ and Mara G. Freire *(D) \\ Department of Chemistry, CICECO-Aveiro Institute of Materials, University of Aveiro, \\ 3810-193 Aveiro, Portugal; soniapedro@ua.pt (S.N.P.); cfreire@ua.pt (C.S.R.F.); armsil@ua.pt (A.J.D.S.) \\ * Correspondence: maragfreire@ua.pt
}

Received: 25 September 2020; Accepted: 2 November 2020; Published: 5 November 2020

\begin{abstract}
Solubility, bioavailability, permeation, polymorphism, and stability concerns associated to solid-state pharmaceuticals demand for effective solutions. To overcome some of these drawbacks, ionic liquids (ILs) have been investigated as solvents, reagents, and anti-solvents in the synthesis and crystallization of active pharmaceutical ingredients (APIs), as solvents, co-solvents and emulsifiers in drug formulations, as pharmaceuticals (API-ILs) aiming liquid therapeutics, and in the development and/or improvement of drug-delivery-based systems. The present review focuses on the use of ILs in the pharmaceutical field, covering their multiple applications from pharmaceutical synthesis to drug delivery. The most relevant research conducted up to date is presented and discussed, together with a critical analysis of the most significant IL-based strategies in order to improve the performance of therapeutics and drug delivery systems.
\end{abstract}

Keywords: active pharmaceutical ingredients; drug delivery systems; formulations; ionic liquids; solubility; permeability

\section{Introduction}

Pharmaceuticals play a major role in medical care, boosting life quality and expectancy, especially when considering chronic diseases [1]. The global prescription of medicines is forecast to grow up to nearly $\$ 1.2$ trillion by 2022 [2]. Although active pharmaceutical ingredients (APIs) can be commercialized in several dosage forms, crystalline forms have been the preferred option $[3,4]$. However, 40 to $70 \%$ of the drugs under development present low water-solubility, which may compromise the bioavailability and therapeutic efficacy and, thus, fail in the later stages of development $[5,6]$. The irregular gastrointestinal absorption of solid forms, along with the low therapeutic efficiency and possible toxicity and side-effects of polymorphs, are major concerns to overcome [7]. For instance, large differences in bioavailability among different polymorphs require different drug dosages [8]. On the other hand, the therapeutic dosage of a certain API can correspond to a toxic or potential lethal dose if the wrong polymorph is administered. Polymorphism issues result in significant economic losses in sales and in R\&D to enable novel formulations back into the market $[9,10]$.

Beyond the well-known downsides of polymorphism, the APIs' solubility in aqueous solution, dissolution, and bioavailability are also dependent on particle size and properties [11]. Attempting to improve the drugs solubility in water as well as their bioavailability, several strategies have been investigated, especially when the oral route is envisaged [5,6]. Nevertheless, most of these strategies still use large quantities of organic solvents in the manufacturing process of these formulations, particularly to induce the crystallization of a given polymorphic form and particle size, having associated health and environmental concerns [12]. Furthermore, solvent molecules can be incorporated into the crystal structure of the API during the crystallization process [13]. Therefore, when considering the use of 
organic solvents, they must be removed from the API or their levels must be controlled in order to ensure human consumption safety [12]. Despite the existence of extensive literature describing novel and "greener" solvents to this purpose, there is still some reluctance by the pharmaceutical industry to accept and implement these alternatives [14-16].

In the above context, liquid forms of APIs are appealing solutions to avoid both polymorphism and improve low-water solubility constraints, while allowing to reduce organic solvents use. The pharmaceutical industry has relied on eutectic mixtures for this purpose, shortly exploring other options for commercialization $[17,18]$. In addition to these, ionic liquids (ILs) disclose high potential in the pharmaceutical field, which is mainly due to their high versatility in terms of chemical structure design towards a target application. ILs are molten salts that are composed of a large organic cation and an organic/inorganic anion. The large dimensions of their ions lead to charge dispersion, which makes difficult the formation of a regular crystalline structure $[19,20]$. ILs display a set of unique features, from which is possible to highlight, if properly designed, their high thermal and chemical stability and a strong solvation ability for a wide variety of compounds [21]. The proper selection of cation-anion combinations in ILs enables the use of drugs as ion components, allowing for the conversion of solid active pharmaceutical ingredients into liquid forms (API-ILs). Thus, this strategy solves the problem of polymorphism and provides improved bioavailability, and ideally boosts therapeutic properties [3,22].

Because of the unique properties of ILs, their application in the pharmaceutical field has been extended far beyond the development of novel liquid forms (API-ILs), being investigated as well in other stages of drug development and delivery. The number of publications related to the application of ILs in the pharmaceutical field has grown exponentially in the past 20 years, as illustrated in Figure 1. ILs have been applied in the development of purification platforms for pharmaceuticals (an application out of the scope of this review), for which some recent review manuscripts exist [23-25]. Other relevant reviews and book chapters recognizing the advances of ILs in different areas of pharmaceuticals development, spanning from their formulation, biological activity, and application on drug delivery are also available [22,26-34]. However, most of these focus on a specific application of ILs in the pharmaceutical field. On the other hand, this review compiles and discusses the most relevant works and overall applications of ILs in the pharmaceutical field, namely on the role of ILs as solvents, reagents, and/or catalysts in the APIs' synthesis, in the APIs crystallization, as solvents, co-solvents, and emulsifiers to improve drugs solubility, as a way of producing liquid forms of APIs, and in the development of drug delivery systems. Special attention is drawn to the most important achievements reported so far on the use of ILs in the described applications and the resulting benefits in terms of pharmaceutical formulations and pharmacological activity.

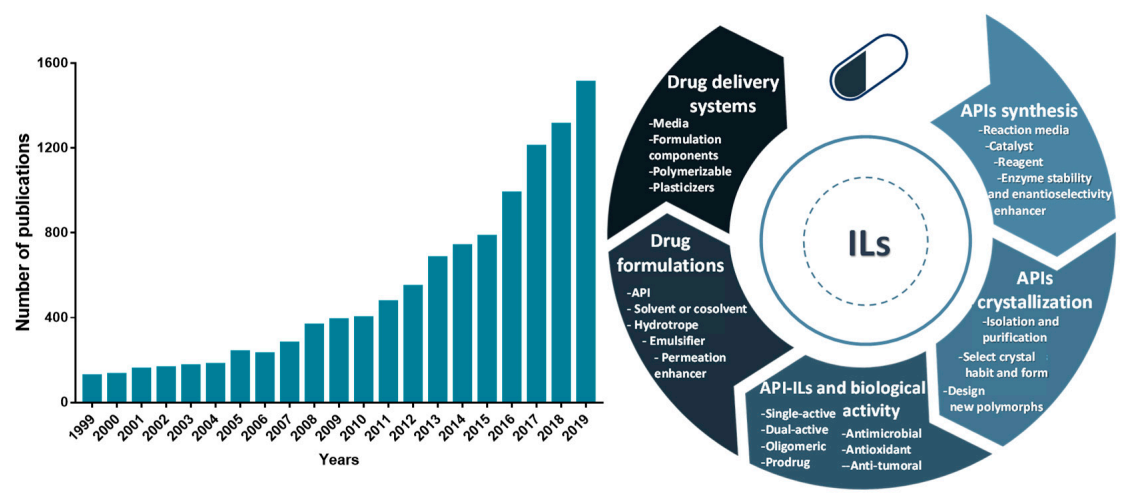

Figure 1. Number of publications per year in a twenty years perspective related to ILs and active pharmaceutical ingredients (APIs) (number of articles, reviews and book chapters according to a ScienceDirect database search using as keywords "ionic liquids", "active pharmaceutical ingredients", and "drug delivery") (left). Overview of the ILs' applications in the pharmaceutical field reported hitherto (right). 


\section{ILs in the Synthesis of Pharmaceutical Compounds}

The increase in environmental awareness led to the proposal of the so-called Environmental factor (E-factor), which assesses the environmental impact of manufacturing processes, being defined by the ratio of the mass of waste per mass of product [35]. The pharmaceutical E-factor is one of the highest in the industry context (25-100) [35]. The waste production that is generated by the pharmaceutical industry is mainly attributed to solvent losses. In order to reduce these losses and minimize the environmental impact, it is essential to consider alternative solvents, i.e., to develop more sustainable processes. To this purpose, ILs have been studied as (i) solvents; (ii) catalysts; (iii) reagents; and, (iv) enantioselectivity enhancers in the synthesis of different APIs [36-38]. Reactions in these solvents may be faster and involve fewer steps than those that were carried out in conventional organic solvents, and additionally be easier to implement [39]. However, an initial assessment of conditions must be performed, since the kinetic of reactions that were carried out in ILs differ from those performed in conventional organic solvents [40]. The following described examples intend to illustrate the multifunction role displayed by ILs in APIs' synthesis, in which some have been even combined. Figure 2 provides an illustrative summary of the applications of ILs in the synthesis of APIs and their precursors, giving one example of each application discussed in this section, with the goal of replacing the use of volatile organic solvents.

\begin{tabular}{|c|c|c|c|c|}
\hline \multicolumn{2}{|c|}{ Reaction media } & Catalyst & Reagent & Enzyme stability and \\
\hline Anti-inflammatory & Antiviral & APIs precursors & Antifungal & Anti-inflammatory \\
\hline Pravadoline & Trifluridine & 2,3-dihydroquinazolin-4(1H)-one core & Clioquinol & Ibuprofen \\
\hline $\begin{array}{l}{\left[\mathrm{C}_{4} \mathrm{C}_{1} \text { im] }\left[\mathrm{PF}_{6}\right]\right.} \\
90-94 \% \text { yield }\end{array}$ & $\begin{array}{c}{\left[\left(\mathrm{C}_{1} \mathrm{OC}_{2}\right) \mathrm{C}_{1} \text { im] }\right.} \\
91 \% \text { yield }\end{array}$ & $\begin{array}{c}{[\mathrm{Nbmd}][\mathrm{OH}]} \\
98 \% \text { yield }\end{array}$ & $\begin{array}{l}{\left[\mathrm{C}_{4} \mathrm{C}_{1} \text { py] }[\mathrm{DCl}]\right.} \\
93 \% \text { yield }\end{array}$ & $\begin{array}{l}\left.\left[\mathrm{C}_{4} \mathrm{C}_{1} \text { im] }\right] \mathrm{PF}_{6}\right] \\
\text { 3-fold increase }\end{array}$ \\
\hline
\end{tabular}

Figure 2. Multiple roles of ILs in the synthesis of different APIs and their respective efficiency (adequate references are given along the current section).

Given the high ILs' applicability in different chemical processes, they have been applied in the production of pharmaceutical precursors, such as lactam [41], pyrazolone [42], thiazole [43], imidazole [44], and thiazolidine [43,45] cores, which are APIs' precursors with vast biological activities. Due to their charged nature, ILs can provide fast microwave heating, resulting in faster and more effective reactions. For example, this approach has been successfully applied to the direct lactamization of lactones in a one-pot reaction with high yields $(>80 \%)$, obtained in short reaction times $(\leq 35 \mathrm{~min}$.) (Figure 3) [41]. The combination of ILs with ultrasound irradiation can be also useful to accelerate organic reactions, allowing for synthetizing APIs' precursors at room temperature with high yields (95\%) [46]. 


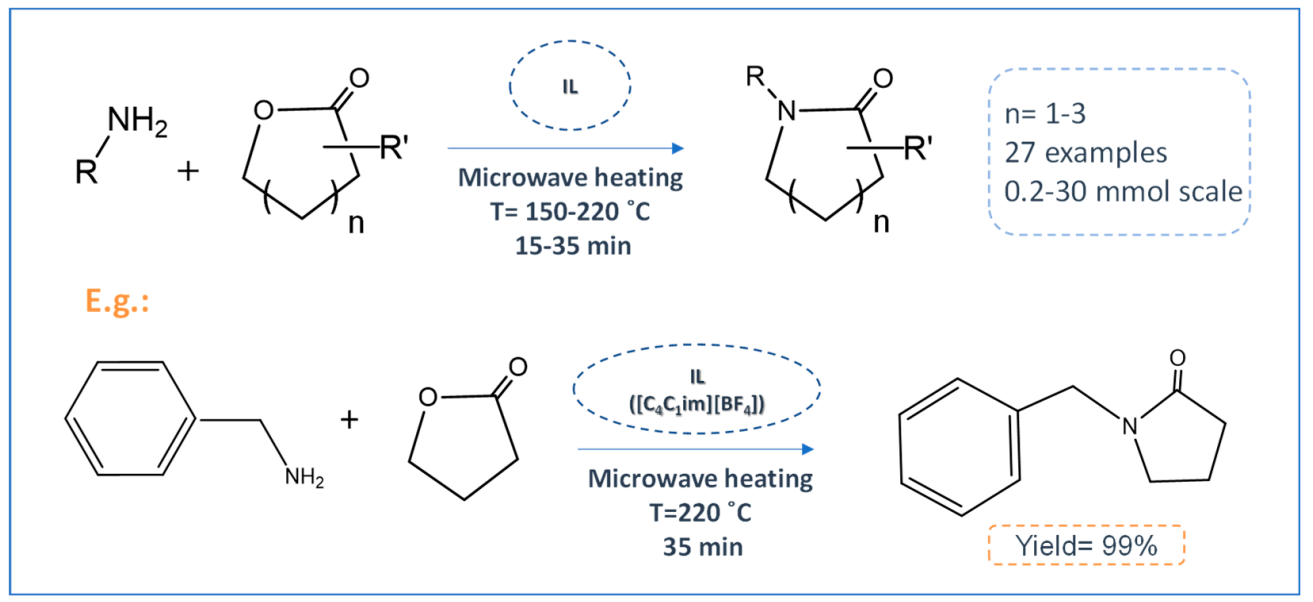

Figure 3. Fast and acid-free one-pot IL-based microwave methodology for direct synthesis of lactams from lactones and primary amines proposed in [41].

The versatile nature of ILs allows for reducing the volume of solvents and the use of metal catalysts in APIs synthesis [47]. Despite the variety of cations and anions, imidazolium-based salts have been the most studied as solvents for the synthesis of APIs and their precursors [45,48-51]. In 2000, Seldon and coworkers reported the first high yield (90-94\%) IL-based route to produce a non-steroidal anti-inflammatory (NSAID) drug, pravadoline, using an imidazolium-based IL as solvent, namely 1-butyl-3-methylimidazolium hexafluorophosphate $\left(\left[\mathrm{C}_{4} \mathrm{C}_{1} \mathrm{im}\right]\left[\mathrm{PF}_{6}\right]\right)($ Figure 4) [51]. Conventionally, the reaction to produce pravadoline is carried out in volatile organic solvents, such as dimethylformamide (DMF), while using sodium hydride as a base that additionally presents health and environmental concerns [52,53]. The proposed reaction using the IL as solvent and potassium hydroxide as base allowed for improving the conventional reaction yield (70-91\%) up to $95 \%$, simply by heating the IL at $150{ }^{\circ} \mathrm{C}$ for $2 \mathrm{~min}$. With this strategy, it is possible to easily separate the API product, recycle and reuse the solvent, and the only chemical waste generated in the process is an aqueous solution of potassium chloride.

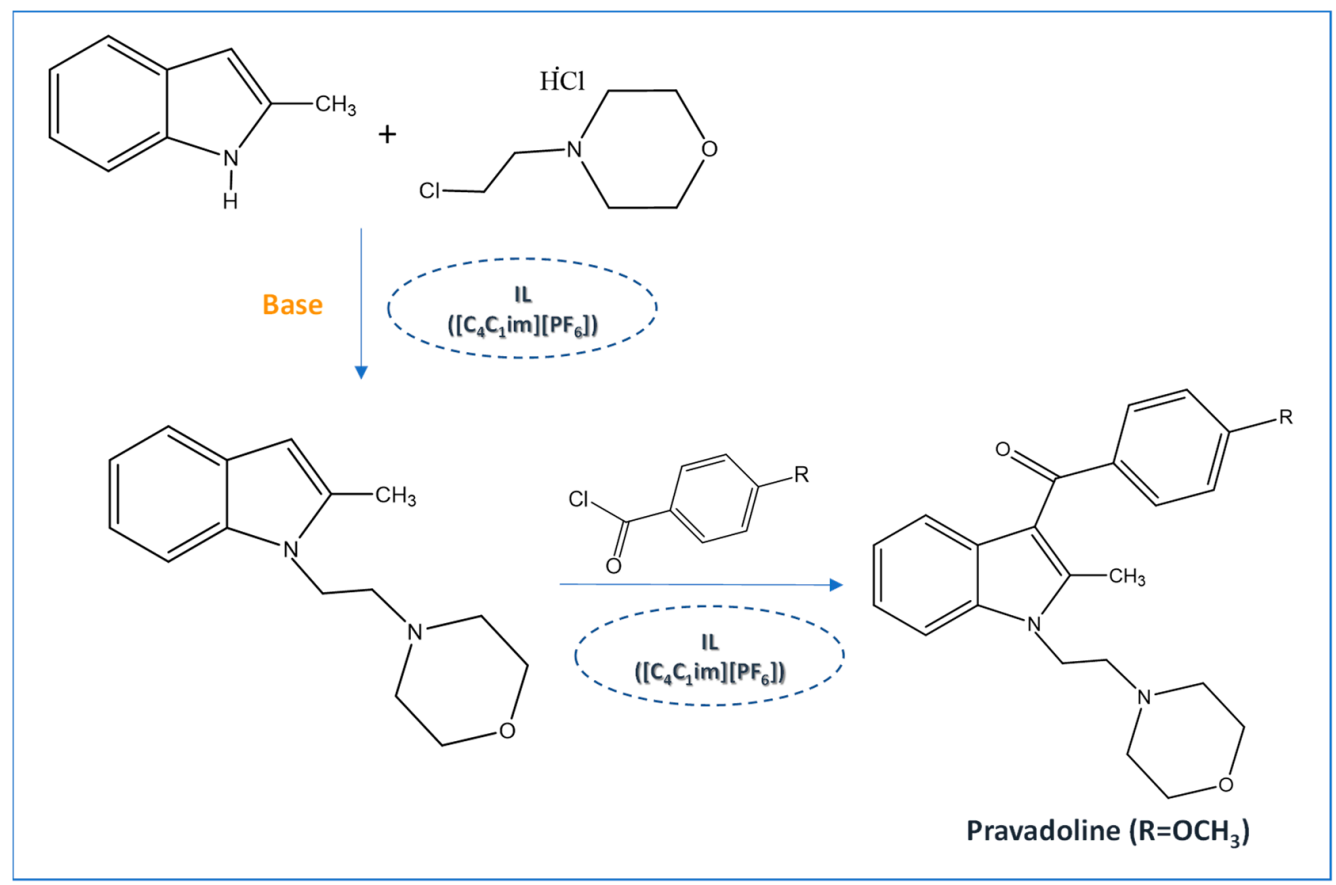

Figure 4. Pravadoline synthesis in an IL media proposed in [51]. 
A variety of pharmaceutical agents (e.g., antibiotics, antifungals, alkaloids, or cardiac glycosides) have an heterocyclic structure to mimic the structure and, thus, the biological action of natural compounds [54]. Reactions that were carried out in IL solvent media have high regioselectivity and, for this reason, have been successfully applied in the synthesis of different heterocyclic APIs [55,56]. Imidazolium-based ILs have been used as solvents in the synthesis of antiviral drugs as brivudine, stavudine and trifluridine [56]. Figure 5 provides a summary on the synthesis time and yield of nucleoside-based antiviral drugs in IL media. Trifluridine, for example, was produced as a single product in IL media. Among others, the best results were obtained with 1-methoxyethyl-3-methylimidazolium methanesulfonate $\left(\left[\left(\mathrm{C}_{1} \mathrm{OC}_{2}\right) \mathrm{C}_{1} \mathrm{im}\right][\mathrm{MsO}]\right)$, using 4-dimethylaminopyridine (DMAP) as catalyst and acetic anhydride as acylating agent. Trifluridine was obtained with $91 \%$ yield in $20-25 \mathrm{~min}$. without the need of extra-purification steps. The IL was recycled and reused up to four times.

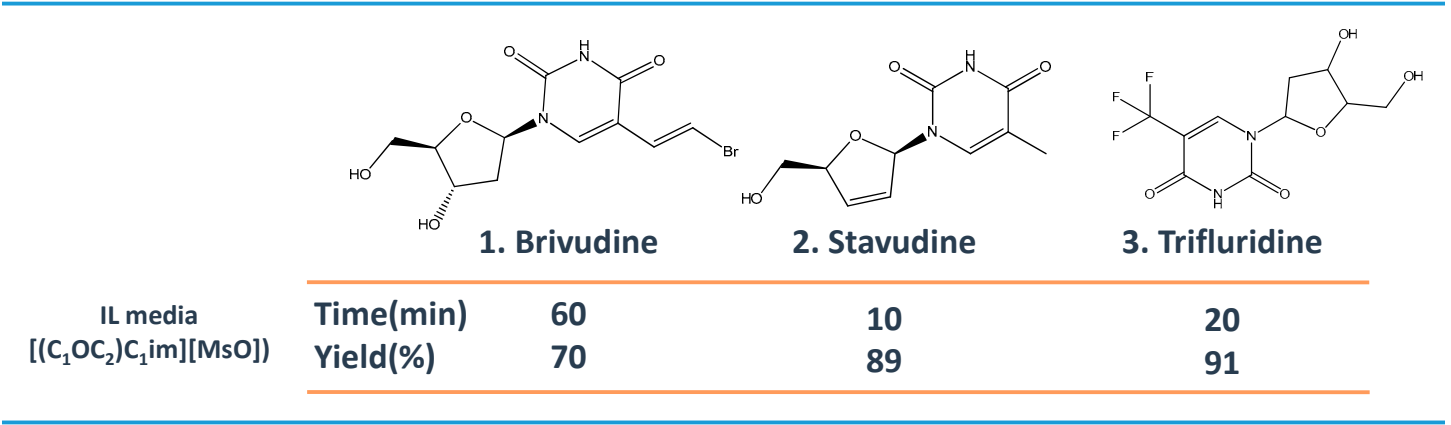

Figure 5. Synthesis of nucleoside-based antiviral drugs in IL media proposed in [56].

Antifungal and antiprotozoal drugs, such as iodoquinol and clioquinol, respectively, have been prepared by a simple and efficient iodination method, while taking advantage of the ILs' multiple roles in synthesis, as summarized in Figure 6 [57]. The IL 1-butyl-3-methylpyridinium dichloroiodate $\left(\left[\mathrm{C}_{4} \mathrm{C}_{1}\right.\right.$ py $\left.][\mathrm{DCI}]\right)$ was used both as solvent and iodinating agent in the absence of any oxidant, catalyst, or base. It was possible to regenerate the IL for up to five runs by addition of $\mathrm{ICl}$ (1.2 eq.), with $>90 \%$ yield, without losing its iodinating activity.

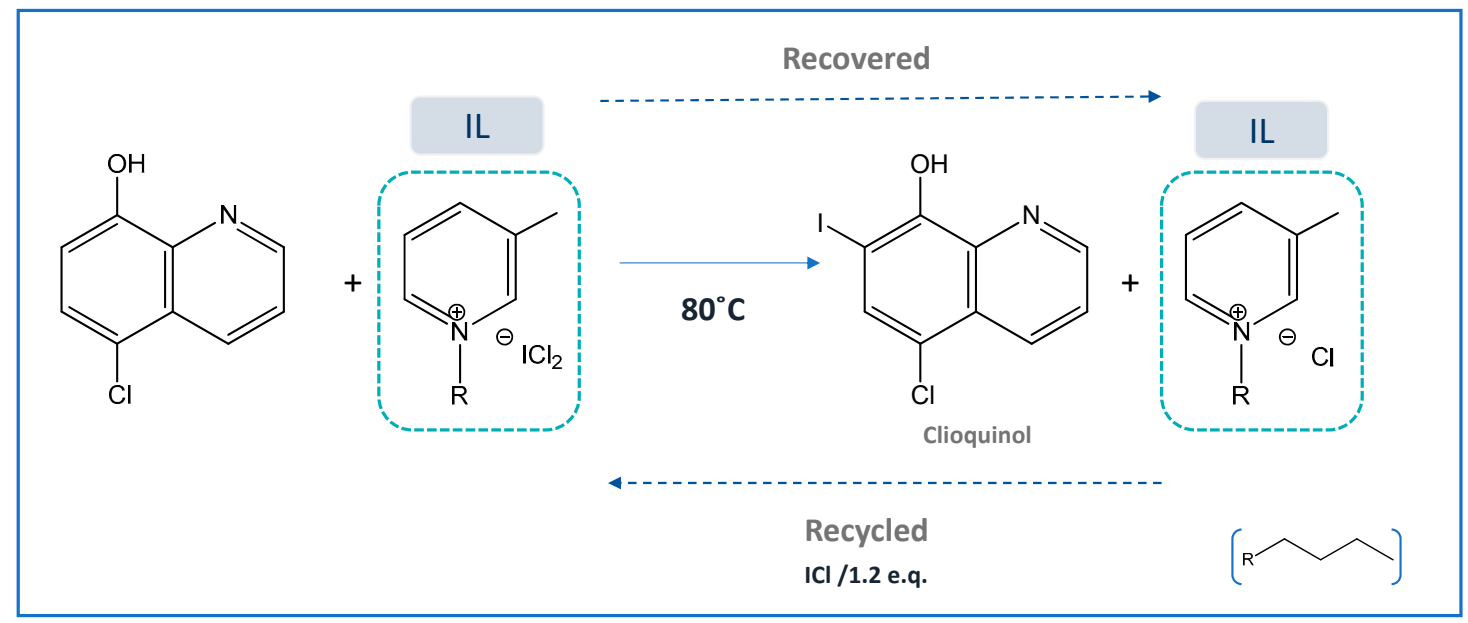

Figure 6. IL application as solvent and iodinating agent in the synthesis of clioquinol proposed in [57].

Naproxen was initially synthesized and commercialized by Syntex while using b-naphthol as precursor for its synthesis [58]. However, this process uses several undesirable reagents, such as nitroaromatic compounds, ammonium sulfide sodium hydride, and methyl iodide. In order to overcome these drawbacks, new procedures were considered, increasing the yields from less 
than $50 \%$ to $90 \%$, but the formation of undesired side products and use of metal catalysts in these processes remained [59]. Recently, 1-butyl-3-methylimidazolium tetrafluoroborate $\left(\left[\mathrm{C}_{4} \mathrm{C}_{1} \mathrm{im}\right]\left[\mathrm{BF}_{4}\right]\right)$ was applied as a reaction medium in the electrosynthesis of naproxen through the electrocarboxylation of 2-(1-chloroethyl)-6-methoxynaphthalene using $\mathrm{CO}_{2}$ [60], as summarized in Figure 7. This process allowed for achieving high yields ( $89 \%$ ) and conversion rates $(90 \%)$, with $65 \%$ of atom economy when considering the recovery of the solvent. Despite the new adapted synthesis routes mentioned above also allowing for obtaining similar high yields, the process in IL media uses cheaper and more available catalysts (electrons) and $\mathrm{CO}_{2}$ instead of $\mathrm{CO}$, a well-known pollutant, contributing for the development of "greener" routes in the synthesis of APIs.

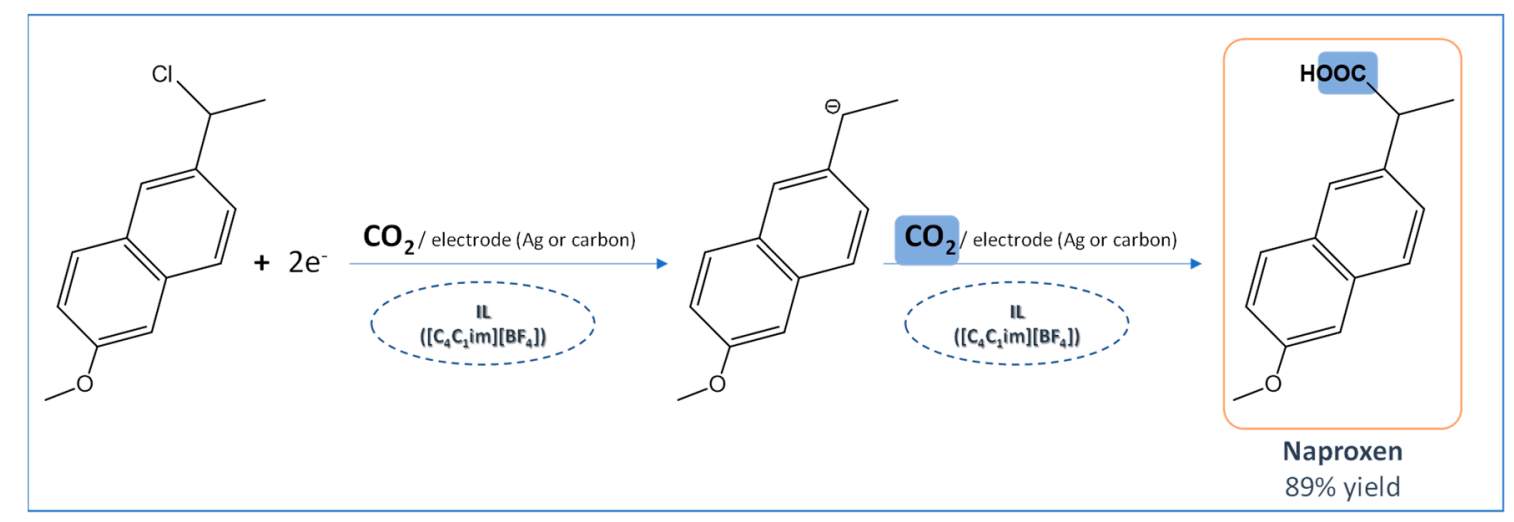

Figure 7. Schematic representation of naproxen's electrosynthesis under CO2 atmosphere proposed in [60].

Biologically active compounds, with antidiuretic, anti-inflammatory, and antihypertensive activities, usually possess 2,3-dihydroquinazolin-4(1H)-one (DHQ) cores. Due to their importance for the production of such compounds, the synthesis of substituted DHQ derivatives has attracted significant attention, and different synthetic strategies have been developed. In alternative to the conventional harsh reaction conditions, gemini basic ILs (such as (4,4'-(butane-1,4-diyl)bis(4-dodecyl-morpholin-4-ium)hydroxide ([Nbmd][OH])), have been proposed as catalysts and reaction media for their synthesis [61]. In addition to the high reported yields (98\%), it was shown the possibility to reuse the ILs up to five times without significant losses in catalytic activity.

Several industrial processes apply enzyme-catalyzed reactions in organic media for the production of APIs. An example of the advantageous use of ILs in biocatalysis was demonstrated in the transesterification of ribavirin, a nucleoside antiviral drug, using C. antarctica lipase [55]. The use of the IL $\left[\mathrm{C}_{4} \mathrm{C}_{1} \mathrm{im}\right]\left[\mathrm{BF}_{4}\right]$ as adjuvant allowed to improve the regioselectivity, the reaction yield and reaction rate about 3.5 times. The enantioselectivity and enzyme activity in IL media was comparable or even improved when compared to the results that were obtained in traditional organic solvents. Furthermore, lipase catalyzed transterification reactions can be 25 times more effective in IL media than in conventional solvents [62].

Stereoselectivity and enantioselectivity are major concerns regarding the bioavailability and safety of pharmaceutics. In this context, ILs have been studied in order to improve the kinetic resolution of APIs and API precursors. Enantiopure chiral alcohols have been shown to be versatile chiral building blocks for the synthesis of chiral pharmaceuticals [63]. For instance, (S)-3-chloro-1-phenyl-1-propanol ((S)-CPPO) is a useful chiral building block for the synthesis of anti-depressant drugs [64]. Aiming to produce (S)-CPPO with high yields and selectivity, a variety of ILs were tested as media, where $\left[\mathrm{C}_{4} \mathrm{C}_{1} \mathrm{im}\right]\left[\mathrm{NTf}_{2}\right]$ was ultimately selected for increasing the solubility of the (S)-CPPO's precursor, 3-chloro-1-phenyl-1-propanone (3-CPP), in a IL/water mixture [65]. The use of the IL, allowed to dramatically increase the concentration of 3-CPP and the yield of the target compound, where the 
yeast reductase YOL151W was able to convert the 3-CPP enantioselectively into (S)-CPPO exclusively, with an enantiomeric excess of $>99 \%$.

The selected examples provide evidences where the use of ILs leads to comparable or superior reaction conditions and yields, and they may also simplify the separation and purification steps of some target products. The possibility to recycle and reuse ILs, without compromising the synthesis yield and lack of toxic by-products production, as shown in some examples, further reinforces the advantageous properties of ILs from the environmental and pharmaceutical perspectives. However, as happens with organic solvents, the amount of residual IL in the final product must be limited in order to guarantee the safety of the drug in the final dosage form. Following this, it is essential for a more careful monitorization of these contaminants in the final product and to study their impact in the drug's therapeutic performance and toxicity.

\section{ILs as Solvents, Co-Solvents or Emulsifiers for APIs Solubilization}

The therapeutic efficacy of APIs is mostly defined by their solubility/bioavailability, since higher solubilities in aqueous solutions may allow for better achieving the desired concentration of a drug in systemic circulation [66]. An API is considered highly soluble when its highest dose strength is soluble in $250 \mathrm{~mL}$ or less of aqueous medium over a pH range 1-6.8 at human body's temperature [67]. Nevertheless, many APIs from different pharmacological classes do not fulfill these requirements and they are only sparingly soluble in water. Although water is the preferable medium when considering human consumption, occasionally the use of non-aqueous solvents is considered since their presence may positively influence the API absorption [68]. Organic solvents like ethanol, methanol or dimethyl sulfoxide (DMSO) are generally used as solvents or co-solvents in pharmaceutical formulations to improve solubility [30]. To address this solubility challenge, ILs have been investigated as alternative neat solvents [69]. The good solvation ability of ILs also allowed for increasing the aqueous solubility of APIs by cosolvency, hydrotropy and micellization phenomena, as summarized in Table 1. ILs represent a novel class of hydrotropes with superior performance to enhance the solubility of poorly water-soluble compounds in aqueous solution, driven by the formation of API-IL aggregates [21]. Cosolvency, unlike the hydrotropic mechanism, is not based on the formation of aggregates, but on the solvation of the solute by a mixed solvent (water + IL), acting by disrupting the water self-association and by reducing the interfacial tension between the API and the solvent medium [70]. The use of surface-active agents, on the other hand, acts by taking advantage of their amphiphilic nature and by incorporating hydrophobic APIs into the micelles core [71]. It has been demonstrated that the selection of IL anion/cation combinations has a significant impact on the solubilization mechanism of poorly water-soluble APIs and solvation ability, as shown by solubility enhancements for antifungal, analgesic, and nonsteroidal anti-inflammatory drugs that are listed in Table 1. In particular, it has been demonstrated that the solubility of drugs like amphotericin B, albendazole, itraconazole, paclitaxel, or etodolac, which are very low-water soluble, can be enhanced by several orders of magnitude (from $700-5.6 \times 10^{6}$-fold) by adding ILs. 
Table 1. Solubility of different APIs in selected ILs and comparison with their water solubility.

\begin{tabular}{|c|c|c|c|c|c|}
\hline API & Structure & Water Solubility & IL & Solubility & Reference \\
\hline 4-Hydroxycoumarin & & - & $\begin{array}{c}{\left[\mathrm{P}_{666(14)}\right]\left[\mathrm{NTf}_{2}\right]} \\
{\left[\mathrm{C}_{2} \mathrm{C}_{1} \mathrm{im}\right]\left[\mathrm{CF}_{3} \mathrm{O}_{3} \mathrm{~S}\right]} \\
{\left[\mathrm{C}_{4} \mathrm{C}_{1} \mathrm{im}\right]\left[\mathrm{CF}_{3} \mathrm{O}_{3} \mathrm{~S}\right]}\end{array}$ & $\begin{array}{l}0.0524^{a *} \\
0.1107^{a *} \\
0.0907^{a *}\end{array}$ & $\begin{array}{l}{[72]} \\
{[73]} \\
\end{array}$ \\
\hline 5-Fluorouracil & & $12.21^{b} *$ & {$\left[\mathrm{C}_{4} \mathrm{C}_{1} \mathrm{im}\right] \mathrm{Br}$} & $31.19^{b} *$ & [74] \\
\hline Acetaminophen & & $98.8^{\mathrm{c}} 19.16^{\mathrm{b}}$ & $\begin{array}{l}{\left[\mathrm{C}_{4} \mathrm{C}_{1} \mathrm{im}\right]\left[\mathrm{BF}_{4}\right]} \\
{\left[\mathrm{C}_{8} \mathrm{C}_{1} \mathrm{im}\right]\left[\mathrm{BF}_{4}\right]} \\
{\left[\mathrm{C}_{4} \mathrm{C}_{1} \mathrm{im}\right]\left[\mathrm{PF}_{6}\right]} \\
{\left[\mathrm{C}_{8} \mathrm{C}_{1} \mathrm{im}\right]\left[\mathrm{PF}_{6}\right]} \\
{\left[\mathrm{C}_{6} \mathrm{C}_{1} \mathrm{im}\right]\left[\mathrm{PF}_{6}\right]}\end{array}$ & $\begin{array}{c}>132^{\mathrm{c}} \\
126^{\mathrm{c}} \\
52^{\mathrm{c}} \\
10^{\mathrm{c}} \\
13.21^{\mathrm{b}} \\
\end{array}$ & [69] \\
\hline Acetylcysteine & & - & $\begin{array}{c}{\left[\mathrm{C}_{2} \mathrm{C}_{1} \mathrm{im}\right]\left[\mathrm{CF}_{3} \mathrm{O}_{3} \mathrm{~S}\right]} \\
{\left[\mathrm{C}_{4} \mathrm{C}_{1} \mathrm{im}\right]\left[\mathrm{CF}_{3} \mathrm{O}_{3} \mathrm{~S}\right]} \\
{\left[\mathrm{C}_{4} \mathrm{C}_{1} \mathrm{im}\right]\left[\mathrm{NTf}_{2}\right]} \\
{\left[\mathrm{C}_{6} \mathrm{C}_{1} \mathrm{im}\right]\left[\mathrm{NTf}_{2}\right]} \\
{\left[\mathrm{C}_{10} \mathrm{C}_{1} \mathrm{im}\right]\left[\mathrm{NTf}_{2}\right]}\end{array}$ & $\begin{array}{c}0.1711^{a *} \\
0.1088^{a *} \\
0.0866^{a *} \\
0.0635^{a} \\
0.0102^{a *}\end{array}$ & [73] \\
\hline Albendazole & & $0.0020^{\mathrm{c}}$ & $\begin{array}{l}{\left[\mathrm{C}_{4} \mathrm{C}_{1} \mathrm{im}\right]\left[\mathrm{BF}_{4}\right]} \\
{\left[\mathrm{C}_{6} \mathrm{C}_{1} \mathrm{im}\right]\left[\mathrm{BF}_{4}\right]} \\
{\left[\mathrm{C}_{8} \mathrm{C}_{1} \mathrm{im}\right]\left[\mathrm{BF}_{4}\right]} \\
{\left[\mathrm{C}_{4} \mathrm{C}_{1} \mathrm{im}\right]\left[\mathrm{PF}_{6}\right]} \\
{\left[\mathrm{C}_{6} \mathrm{C}_{1} \mathrm{im}\right]\left[\mathrm{PF}_{6}\right]} \\
{\left[\mathrm{C}_{8} \mathrm{C}_{1} \mathrm{im}\right]\left[\mathrm{PF}_{6}\right]}\end{array}$ & $\begin{array}{l}1.49^{c} \\
2.97^{c} \\
7.2^{c} \\
29^{c} \\
53^{c} \\
>75^{c} \\
\end{array}$ & [69] \\
\hline Amphotericin B & & $2.0 \times 10^{-4 b}$ & $\begin{array}{c}{\left[\mathrm{C}_{2} \mathrm{C}_{1} \mathrm{im}\right]\left[\mathrm{CH}_{3} \mathrm{COO}\right]} \\
{\left[\mathrm{C}_{4} \mathrm{NH}_{3}\right]\left[\mathrm{CH}_{3} \mathrm{COO}\right]} \\
{\left[\mathrm{C}_{6} \mathrm{NH}_{3}\right]\left[\mathrm{CH}_{3} \mathrm{COO}\right]} \\
{\left[\mathrm{C}_{8} \mathrm{NH}_{3}\right]\left[\mathrm{CH}_{3} \mathrm{COO}\right]} \\
{\left[\mathrm{C}_{4} \mathrm{NH}_{3}\right][\text { Oleate }]} \\
{\left[\mathrm{C}_{6} \mathrm{NH}_{3}\right][\text { Oleate }]} \\
{\left[\mathrm{C}_{8} \mathrm{NH}_{3}\right][\text { Oleate }]}\end{array}$ & $\begin{array}{l}85^{\mathrm{b}} \\
30^{\mathrm{b}} \\
30^{\mathrm{b}} \\
20^{\mathrm{b}} \\
<5^{\mathrm{b}} \\
<5^{\mathrm{b}} \\
<5^{\mathrm{b}}\end{array}$ & [76] \\
\hline
\end{tabular}


Table 1. Cont.

\begin{tabular}{|c|c|c|c|c|c|}
\hline API & Structure & Water Solubility & IL & Solubility & Reference \\
\hline Danazol & & $0.00030^{c}$ & $\begin{array}{c}{\left[\mathrm{C}_{4} \mathrm{C}_{1} \mathrm{im}\right]\left[\mathrm{BF}_{4}\right]} \\
{\left[\mathrm{C}_{8} \mathrm{C}_{1} \mathrm{im}\right]\left[\mathrm{BF}_{4}\right]} \\
{\left[\mathrm{C}_{4} \mathrm{C}_{1} \mathrm{im}\right]\left[\mathrm{PF}_{6}\right]} \\
{\left[\mathrm{C}_{8} \mathrm{C}_{1} \mathrm{im}\right]\left[\mathrm{PF}_{6}\right]} \\
{\left[\mathrm{C}_{6} \mathrm{C}_{6} \mathrm{OCOpy}\right]\left[\mathrm{N}(\mathrm{CN})_{2}\right.} \\
{\left[\mathrm{C}_{6} \mathrm{C}_{6} \mathrm{OCOpy}\right]\left[\mathrm{NTf}_{2}\right]}\end{array}$ & $\begin{array}{c}18.9^{\mathrm{c}} \\
>59^{\mathrm{c}} \\
11.9^{\mathrm{c}} \\
35^{\mathrm{c}} \\
>90^{\mathrm{d}} \\
25^{\mathrm{d}}\end{array}$ & [69] \\
\hline Erythromycin & & - & $\begin{array}{c}{\left[\mathrm{C}_{4} \mathrm{C}_{1} \mathrm{im}\right]\left[\mathrm{NTf}_{2}\right]} \\
{\left[\mathrm{C}_{10} \mathrm{C}_{1} \mathrm{im}\right]\left[\mathrm{NTf}_{2}\right]} \\
{\left[\mathrm{P}_{666(14)}\right] \mathrm{Cl}} \\
{\left[\mathrm{N}_{4,1,1,1}\right]\left[\mathrm{NTf}_{2}\right]} \\
{\left[\mathrm{Pyrr}_{4,1}\right]\left[\mathrm{NTf}_{2}\right]}\end{array}$ & $\begin{array}{l}0.037^{\mathrm{a} *} \\
0.072^{\mathrm{a}} \\
0.085^{\mathrm{a}} \\
0.053^{\mathrm{a}} \\
0.017^{\mathrm{a}}\end{array}$ & [78] \\
\hline Etodolac & & Insoluble & {$\left[\mathrm{C}_{4} \mathrm{C}_{1} \mathrm{im}\right]\left[\mathrm{PF}_{6}\right]$} & $374.33^{b *}$ & [79] \\
\hline & & & $\begin{array}{c}{\left[\mathrm{C}_{6} \mathrm{C}_{6} \mathrm{OCOpy}\right]\left[\mathrm{N}(\mathrm{CN})_{2}\right]} \\
{\left[\mathrm{C}_{6} \mathrm{C}_{6} \mathrm{OCOpy}\right]\left[\mathrm{NTf}_{2}\right]}\end{array}$ & $\begin{array}{l}>125^{d} \\
>130^{d}\end{array}$ & \\
\hline Fenofibrate & & - & & & [77] \\
\hline
\end{tabular}


Table 1. Cont.

\begin{tabular}{|c|c|c|c|c|c|}
\hline API & Structure & Water Solubility & IL & Solubility & Reference \\
\hline Glibenclamide & & $2.4 \times 10^{-6 b *}$ & {$[\mathrm{Ch}][$ Try $]$} & $9.89^{b} *$ & [80] \\
\hline Ibuprofen & & 0.124 & $\begin{array}{l}{\left[\mathrm{C}_{4} \mathrm{C}_{1} \mathrm{im}\right]\left[\mathrm{PF}_{6}\right]} \\
{\left[\mathrm{C}_{6} \mathrm{C}_{1} \mathrm{im}\right]\left[\mathrm{PF}_{6}\right]} \\
{\left[\mathrm{P}_{666(14)}\right]\left[\mathrm{NTf}_{2}\right]}\end{array}$ & $\begin{array}{c}6.95^{b} \\
26.38^{b} \\
0.0528^{a}\end{array}$ & $\begin{array}{l}{[75]} \\
{[72]}\end{array}$ \\
\hline Isoniazid & & - & $\begin{array}{c}{[\mathrm{DDA}]\left[\mathrm{NO}_{3}\right]} \\
{\left[\mathrm{C}_{2}\right]\left[\mathrm{NTf}_{2}\right]} \\
{\left[\mathrm{C}_{4} \mathrm{C}_{1} \mathrm{im}^{2}\right][\mathrm{NTf} 2]} \\
{\left[\mathrm{C}_{6} \mathrm{C}_{1} \text { im] }\right][\mathrm{NTf} 2]} \\
{\left[\mathrm{P}_{666(14)}\right]\left[\mathrm{NTf}_{2}\right]}\end{array}$ & $\begin{array}{c}0.0452^{\mathrm{a} *} \\
0.0235^{\mathrm{a}} \\
0.004^{\mathrm{c}} \\
0.003^{\mathrm{c}} \\
0.0651^{\mathrm{c}}\end{array}$ & $\begin{array}{l}\text { [81] } \\
{[82]}\end{array}$ \\
\hline Itraconazole & & $1.0 \times 10^{-6 b}$ & $\begin{array}{c}\left.\mathrm{C}_{2} \mathrm{C}_{1} \mathrm{im}\right]\left[\mathrm{CH}_{3} \mathrm{COO}\right] \\
{\left[\mathrm{C}_{4} \mathrm{NH}_{3}\right]\left[\mathrm{CH}_{3} \mathrm{COO}\right]} \\
{\left[\mathrm{C}_{6} \mathrm{NH}_{3}\right]\left[\mathrm{CH}_{3} \mathrm{COO}\right]} \\
{\left[\mathrm{C}_{8} \mathrm{NH}_{3}\right]\left[\mathrm{CH}_{3} \mathrm{COO}\right]} \\
{\left[\mathrm{C}_{4} \mathrm{NH}_{3}\right][\mathrm{Oleate}]} \\
{\left[\mathrm{C}_{6} \mathrm{NH}_{3}\right][\text { Oleate }]} \\
{\left[\mathrm{C}_{8} \mathrm{NH}_{3}\right][\text { Oleate }]} \\
{\left[\mathrm{C}_{6} \mathrm{C}_{6} \mathrm{OCOpy}\right]\left[\mathrm{N}(\mathrm{CN})_{2}\right]} \\
{\left[\mathrm{C}_{6} \mathrm{C}_{6} \mathrm{OCOpy}\right]\left[\mathrm{NTf}_{2}\right]}\end{array}$ & $\begin{array}{l}<5^{b} \\
<5^{b} \\
<5^{b} \\
<5^{b} \\
<5^{b} \\
<5^{b} \\
<5^{b} \\
40^{d} \\
8^{d}\end{array}$ & [76] \\
\hline
\end{tabular}


Table 1. Cont.

\begin{tabular}{|c|c|c|c|c|c|}
\hline API & Structure & Water Solubility & IL & Solubility & Reference \\
\hline Paclitaxel & & $<4.0 \times 10^{-6 b}$ & $\begin{array}{c}\text { [Ch][Gly] } \\
{[\text { Ch][Ala] }} \\
{[\text { Ch][Pro] }} \\
{[\text { Ch][Phe] }} \\
{[\text { Ch][Ile] }} \\
{[\text { Ch][Ser] }} \\
\text { [Ch][Leu] }\end{array}$ & $\begin{array}{c}22.34^{\mathrm{b}} \\
18.52^{\mathrm{b}} \\
16.16^{\mathrm{b}} \\
14.15^{\mathrm{b}} \\
9.39^{\mathrm{b}} \\
7.32^{\mathrm{b}} \\
6.61^{\mathrm{b}}\end{array}$ & [83] \\
\hline Pyrazinecarboxamide & & - & $\begin{array}{c}{\left[\mathrm{C}_{2} \mathrm{C}_{1} \mathrm{im}\right]\left[\mathrm{NTf}_{2}\right]} \\
{\left[\mathrm{C}_{4} \mathrm{C}_{1} \mathrm{im}\right]\left[\mathrm{NTf}_{2}\right]} \\
{\left[\mathrm{C}_{6} \mathrm{C}_{1} \mathrm{im}\right]\left[\mathrm{NTf}_{2}\right]} \\
{\left[\mathrm{C}_{8} \mathrm{C}_{1} \mathrm{im}\right]\left[\mathrm{NTf}_{2}\right]} \\
{\left[\mathrm{C}_{10} \mathrm{C}_{1} \mathrm{im}\right]\left[\mathrm{NTf}_{2}\right]} \\
{\left[\mathrm{C}_{10} \mathrm{C}_{1} \mathrm{im}\right]\left[\mathrm{CF}_{3} \mathrm{O}_{3} \mathrm{~S}\right]} \\
{\left[\mathrm{C}_{2}\right]\left[\mathrm{NTf}_{2}\right]} \\
{\left[\mathrm{P}_{666(14)}\right]\left[\mathrm{NTf}_{2}\right]}\end{array}$ & $\begin{array}{c}0.0048^{\mathrm{a}} \\
0.0054^{\mathrm{a} *} \\
0.0050^{\mathrm{a} *} \\
0.0052^{\mathrm{a}} \\
0.0046^{\mathrm{a}} \\
0.0116^{\mathrm{a}} \\
0.0165^{\mathrm{a}} \\
0.0125^{\mathrm{a}}\end{array}$ & $\begin{array}{l}{[81]} \\
{[72]}\end{array}$ \\
\hline Thymoquinone & & - & {$\left[\mathrm{P}_{666(14)}\right]\left[\mathrm{NTf}_{2}\right]$} & $0.1105^{a}$ & [72] \\
\hline
\end{tabular}

a: molar fraction; b: $\mathrm{mg} \mathrm{mL}^{-1} ; \mathrm{c}: \mathrm{mmol} \mathrm{L}^{-1} ; \mathrm{d}: \mathrm{mg} \mathrm{g}^{-1} .{ }^{*}$ Solubility determined at body's temperature $\left(34-38^{\circ} \mathrm{C}\right)$. If not specified, the reported solubilities were assessed at a temperature range from 21 to $30^{\circ} \mathrm{C}$. Relevant solubilities determined at $>38^{\circ} \mathrm{C}$ are further addressed in this chapter. 
The application of pure ILs for APIs solubilization was first reported in 2008 by Jaitely et al. [85], who investigated the ILs $\left[\mathrm{C}_{4-8} \mathrm{C}_{1} \mathrm{im}\right]\left[\mathrm{PF}_{6}\right]$ on the solubilization of potassium penicillin $\mathrm{V}$, dexamethasone dehydroepiandrosterone, and progesterone. Although these ILs are immiscible in water, it is possible to use these formulations to enhance the release of some solutes into an aqueous medium. The studied ILs were submitted to a current flow (over the range 1-5 mA) allowing to increase the release rate of the APIs from the IL to the aqueous medium. The release of these APIs slowly increased with the increase of the alkyl chain length of the IL cation (up to three-fold). The partition of APIs in the studied ILs/water systems was further correlated with the APIs octanol-water partition coefficient. To infer the safety of these solvents for pharmaceutical applications, their cytotoxicity was evaluated in Caco-2 cell lines, which suggests that, with the exception of 1-octyl-3-methylimidazolium hexafluorophosphate $\left(\left[\mathrm{C}_{8} \mathrm{C}_{1} \mathrm{im}\right]\left[\mathrm{PF}_{6}\right]\right)$, these compounds are non-toxic $(90 \%$ cell viability) at the conditions and concentrations studied, and might be considered as excipients in pharmaceutical formulations.

The same trend was observed by Mizuuchi et al. [69], who studied similar ILs in order to solubilize albendazole, danazol, acetaminophen, and caffeine. The increase in the hydrophobicity of the imidazolium cation $\left(\left[\mathrm{C}_{4-8} \mathrm{C}_{1} \mathrm{im}\right]^{+}\right)$resulted in a higher solvation ability for hydrophobic drugs. However, this trend resulted in a decrease in the solubility of hydrophilic drugs. The authors demonstrated that it is possible to increase albendazole's solubility more than 37,000 -fold while using $\left[\mathrm{C}_{8} \mathrm{C}_{1} \mathrm{im}\right]\left[\mathrm{PF}_{6}\right]$ as solvent. In a different study by Forte et al. [82], the variation of the anion in 1-decyl-3-methylimidazolium-based ILs and the alkyl chain length of the cation $\left(\left[\mathrm{C}_{2-10} \mathrm{C}_{1} \mathrm{im}\right]^{+}\right)$were studied to infer their effect on isoniazid's (antibiotic) solubility. The results showed that the presence of an acidic proton at the 2-position of $\left[\mathrm{C}_{2} \mathrm{C}_{1} \mathrm{im}\right]^{+}$increases the ILs ability to hydrogen-bond with isoniazid, leading to higher solubility values. Among the ILs studied, 1-decyl-3-methylimidazolium trifluoromethanesulfonate $\left(\left[\mathrm{C}_{10} \mathrm{C}_{1} \mathrm{im}\right]\left[\mathrm{CF}_{3} \mathrm{O}_{3} \mathrm{~S}\right]\right)$ was found to be the best solvent for isoniazid (at $\mathrm{T}$ $>38^{\circ} \mathrm{C}$ ). Furthermore, the increase of the alkyl chain length at the imidazolium cation decreases the acidity of the proton at the 2-position, thus increasing the API's solubility in the IL. Overall, the trends that were obtained in the described studies demonstrate that the influence of the cation's alkyl chain length differs according to the IL and the APIs nature, and accordingly with the molecular-level mechanisms involved. These differences make difficult the establishment of heuristic rules and development of predictive models that could be used in a widespread manner.

Although interactions between the IL anion and the API have been reported as relevant, mainly via hydrogen-bonding, the influence of the IL anion in which the IL hydrogen-bond basicity can be strongly tuned is less studied and still not completely understood. Although promising results have been reported in terms of APIs solubility, comparisons between the results obtained in IL media with the ones that were obtained with other common solvents, such as water or ethanol, are shortly explored along with the bioavailability profiles. These assays should be considered in order to support the advantageous use of IL-based solvents alternatives.

In addition to the study of pure ILs as solvents for APIs, the application of ILs as co-solvents has been investigated. For instance, cholinium-based ILs have been successfully applied as co-solvents in paclitaxel formulations for chemotherapeutic treatment [83]. Paclitaxel is a low-water soluble API $\left(<4 \mu \mathrm{g} \mathrm{mL}^{-1}\right)$ that is used in the treatment of different types of cancer; however, its parenteral formulation requires the use of ethoxylated castor oil (CrEL) and ethanol as solubilizing agents. The use of these agents can be associated with major hypersensitivity reactions and side effects. By using cholinium-amino-acid-based ILs as co-solvents, it was possible to remarkably enhance the APIs solubility in aqueous media ( $>5500$-fold) and decrease the formulation toxicity and hypersensitivity, while maintaining the antitumor therapeutic action of the API. In a different study, also using amino-acid-based ILs, and in particular cholinium tryptophan, it increased the glibenclamide's (an antidiabetic drug) solubility in aqueous solutions with $6.5 \mathrm{wt} \%$ of IL from 400 to 2000-fold [80]. The establishment of hydrogen bonds and $\pi-\pi$ interactions between the API and the IL anion were described as playing a major role in the obtained solubility improvements in both studies. 
In a more fundamental study, tetrabutylammonium-, phosphonium-, imidazolium-, pyridinium-, piperidinium- and pyrrolidinium, and cholinium-based ILs were investigated in aqueous solution regarding their ability to act as hydrotropes and improve the solubility of ibuprofen [86]. It was found that the IL cation and anion synergistically contribute to the hydrotropic mechanism of solubilization. Among the cations that were investigated in a chloride-based IL series, imidazoliumand phosphonium-based ILs lead to a higher increase in the drug solubility. In order to evaluate the influence of the IL anion on ibuprofen's solubility, $\left[\mathrm{C}_{4} \mathrm{C}_{1} \mathrm{im}\right]$ - and sodium-based hydrotropes were investigated, where a higher hydrotropic activity was disclosed with 1-butyl-3-methylimidazolium thiocyanate $\left(\left[\mathrm{C}_{4} \mathrm{C}_{1} \mathrm{im}\right][\mathrm{SCN}]\right)$ and 1-butyl-3-methylimidazolium dicyanamide $\left(\left[\mathrm{C}_{4} \mathrm{C}_{1} \mathrm{im}\right]\left[\mathrm{N}(\mathrm{CN})_{2}\right]\right)$. These ILs increase the aqueous solubility of ibuprofen by 60 - and 120-fold, respectively, in comparison to the API in pure water. The formation of IL-drug aggregates was proved based on dynamic light scattering and molecular dynamics simulations. In particular, ILs have been reported as powerful catanionic hydrotropes [23,86].

The use of surfactants above the critical micelle concentration (CMC) can be also an appealing alternative to increase API's solubility. By varying the cation type and alkyl chain length and the nature and size of the counterion it is possible to change the ILs' hydrophilic-hydrophobic balance. ILs with surfactant behavior are usually referred to as surface-active ionic liquids (SAILs), displaying high potential to increase the solubility of pharmaceutical agents in aqueous media. Sanan et al. [87] studied 1-dodecyl-3-methylimidazolium chloride $\left(\left[\mathrm{C}_{12} \mathrm{C}_{1} \mathrm{im}\right] \mathrm{Cl}\right)$-ibuprofen mixtures in aqueous solution, ranging from monomeric to micellar regions. Aggregate assemblies in aqueous media (mixed micelles) were observed, depending on the mixture composition. The formation of these complexes was mainly attributed to the establishment of hydrophobic, electrostatic and hydrogen-bonding interactions. Faria et al. [88] investigated surface-active ILs, both cationic and anionic, as well as composed of different cations and anions, for the solubilization of the nutraceutic ursolic acid in aqueous media. For this, different ILs constituted by long alkyl side chains with known surface-active characteristics $\left(\left[\mathrm{C}_{8-18} \mathrm{C}_{1} \mathrm{im}\right] \mathrm{X}\right.$ with $\mathrm{X}=\mathrm{Cl}$ and $\left.\left[\mathrm{C}_{8} \mathrm{H}_{17} \mathrm{SO}_{4}\right]\right)$ and tributyltetradecylphosphonium chloride $\left(\left[\mathrm{P}_{444(14)}\right] \mathrm{Cl}\right)$ were considered. The use of the best SAIL aqueous solutions allows for solubility enhancements of ursolic acid in 8 orders of magnitude when compared to pure water. More recently, aqueous solutions of $\left[\mathrm{C}_{12} \mathrm{C}_{1} \mathrm{im}\right] \mathrm{Cl}$ were used to increase the solubility of the nutraceutical oleanolic acid [89]. An increase in the IL concentration up to $1000 \mathrm{mM}$ improved the solubility of oleanolic acid to $21.10 \mathrm{mg} \mathrm{mL}^{-1}$, indicating that aqueous solutions of SAILs leads to a remarkable increase (up to $10^{6}$-fold) on the solubility of the target compound in water.

Although significant results have been disclosed on the use of ILs as solvents, co-solvents, or surfactants to improve the APIs solubility, most studies reported so far focus on imidazolium-based ILs. This trend is probably associated with the fact that these ILs are commercially available, and well studied and characterized in literature. Although few other IL combinations were investigated, the results reported hitherto on drug solubility enhancements promote the evolution of ILs further from their solvent applications to the study of novel drug delivery approaches, where stability, absorption, and bioavailability can be improved. Furthermore, special care must be taken for the mutual administration of ILs and APIs, since these can also induce multixenobiotic/multidrug cell resistance and/or reduce the effectiveness of therapies, an issue that is usually not addressed in the reported studies. More biocompatible combinations are expected to be studied and more complete studies are still required to boost IL research and enable their use in pharmaceutical formulations.

\section{ILs in APIs Crystallization}

The properties of crystalline APIs, such as their solubility, structural stability, and dissolution rates, are mainly dependent on the respective polymorphs $[8,90]$. Thus, designing the correct polymorph represents a critical requirement in drug development and production as it impacts the APIs bioavailability and shelf life. Crystallization from organic or aqueous-based reaction media is often a key step in pharmaceuticals isolation and purification [91]. APIs polymorphs can be originated 
from the variety of intermolecular interactions between the molecules, which are dependent on the crystallization conditions (solvent, temperature, additives, and supersaturation) [92]. It is possible to fine-tune the polymorphic form by adjusting the crystallization conditions, introducing guest molecules or promoting a preferred crystal nucleation while using additives [93]. Several studies have reported the application of ILs as adjuvants in APIs crystallization [94-96], allowing for not only the design of new polymorphic forms, but also to manipulate the crystal form and habit to present enhanced properties, and ultimately, to separate and isolate specific polymorphic forms that are not achievable with conventional solvents (Figure 8). IL-based crystallization techniques, which include solvent-antisolvent [97], cooling crystallization [98], or drowning-out [92] techniques, were proposed in order to promote the correct habit and polymorphic forms of several drugs.

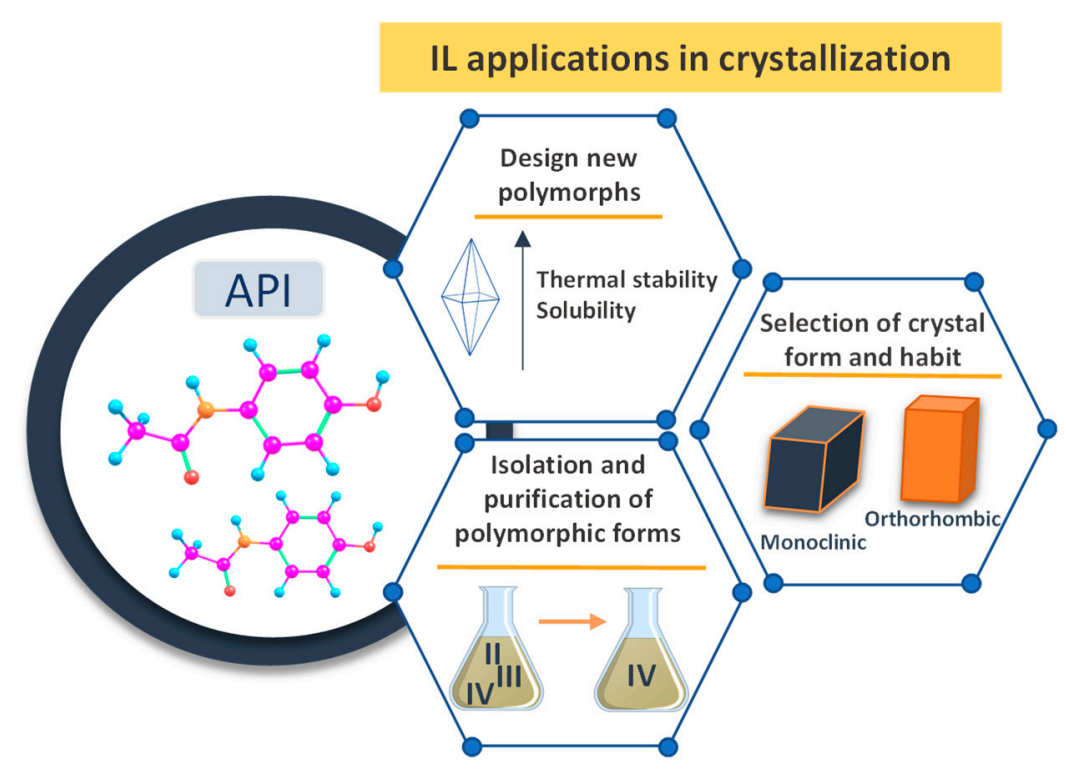

Figure 8. Applications of ILs in APIs' crystallization processes (adequate references are given along the current section).

The use of ILs has shown the possibility to design new APIs' polymorphs with enhanced thermal stability [92]. The IL 1-allyl-3-ethylimidazolium tetrafluoroborate $\left(\left[\left(\mathrm{CH}_{2} \mathrm{CH}=\mathrm{C}_{2}\right) \mathrm{C}_{2} \mathrm{im}\right]\left[\mathrm{BF}_{4}\right]\right)$ has been applied to design polymorphs of adefovir dipivoxil, through drowning-out crystallization. This process can be considered to be one of the most important techniques to be applied when the separation of solutes from multicomponent solutions is envisaged [99]. This method relies on the supersaturation of the solution by adding specific substances, drowning-out agents to the initial solution in order to reduce the solubility of the solute. The use of the IL in the crystallization process allowed for obtaining the form-II of the API, and upon an increase of the crystallization temperature two new polymorphic structures and hydrated crystals form. A significant increase in the thermostability in aqueous solutions was verified when using the IL.

By the application of the IL $\left[\left(\mathrm{CH}_{2} \mathrm{CH}=\mathrm{C}_{2}\right) \mathrm{C}_{2} \mathrm{~m}\right]\left[\mathrm{BF}_{4}\right]$ as solvent and 1-butyl-2,3 -dimethylimidazolium tetrafluoroborate $\left(\left[\left(\mathrm{C}_{4} \mathrm{C}_{1} \mathrm{C}_{1} \mathrm{~m}\right]\left[\mathrm{BF}_{4}\right]\right)\right.$ as antisolvent, a new form of adefovir dipivoxil crystal was obtained at a crystallization temperature below $50^{\circ} \mathrm{C}$ [97]. This new polymorphic form was achieved due to unique intermolecular interactions between API molecules that were promoted by the IL, resulting in different molecular packing during crystallization. However, when considering the use of the ILs $\left[\left(\mathrm{CH}_{2} \mathrm{CH}=\mathrm{C}_{2}\right) \mathrm{C}_{2} \mathrm{~m}\right]\left[\mathrm{BF}_{4}\right]$, 1,3-diallylimidazolium tetrafluoroborate $\left(\left[\left(\mathrm{CH}_{2} \mathrm{CH}=\mathrm{C}_{2}\right)_{2} \mathrm{im}\right]\left[\mathrm{BF}_{4}\right]\right)$ and 1-ethyl-3-methylimidazolium ethylsulfate $\left(\left[\mathrm{C}_{2} \mathrm{C}_{1} \mathrm{im}\right]\left[\mathrm{EtSO}_{4}\right]\right)$, the conventional form-I polymorph was obtained. The possibility to use high crystallization temperatures enabled the formation of a stable polymorph, with enhanced solubility and thermal stability over $100{ }^{\circ} \mathrm{C}$ (two-fold increase in the decomposition temperature). Using a similar approach, rifampicin 
nanosized particles were prepared to improve the solubility and dissolution kinetics of poorly-water soluble APIs [100]. To this purpose, the use of the IL 1-ethyl-3-methylimidazolium methylphosphonate $\left(\left[\mathrm{C}_{2} \mathrm{C}_{1} \mathrm{im}\right]\left[\mathrm{CH}_{3} \mathrm{OHPO}_{2}\right]\right)$ as alternative solvent and phosphate buffer as an antisolvent was considered, allowing for obtaining API crystals with $<1 \mu \mathrm{m}$. Reducing the particle size down to the submicron range allowed not only a faster dissolution ability, but also to increase the APIs' solubility by $30 \%$.

Imidazolium-based ILs have been studied to control the crystallization of gabapentin, a neuroleptic drug used to treat epilepsy [101]. This API presents three polymorphic forms (forms II, III, and IV) and a hydrated form (form I) [102]. The commercialized polymorph is the form II due to its highest thermodynamic stability [103]. However, forms III and IV are commonly obtained through crystallization in ethanol at room or high temperature, where the form IV cannot be completely isolated [102]. Distinct IL cation/anion combinations were studied in order to access their ability in directing the crystallization process towards the isolation and stabilization of less stable polymorphs [101]. Using 1-hexyl-3-methylimidazolium tetrafluoroborate $\left(\left[\mathrm{C}_{6} \mathrm{C}_{1} \mathrm{im}\right]\left[\mathrm{BF}_{4}\right]\right)$, the API form IV was isolated, which is a highly unstable polymorph.

ILs have been investigated as well for the isolation of specific polymorphic forms of paracetamol [94]. Imidazolium-based ILs were studied regarding their impact on the API's solubility, mainly by tailoring their hydrogen-bond ability with the API. Because the solubility of the API was shown to be governed by the basicity of the IL anion, 1-ethyl-3-methylimidazolium acetate $\left(\left[\mathrm{C}_{2} \mathrm{C}_{1} \mathrm{im}\right]\left[\mathrm{CH}_{3} \mathrm{COO}\right]\right)$ was then selected for the crystallization process. The strong interactions between the IL and the studied antisolvents (ethanol, acetic acid, and 1,1,1,3,3,3-hexafluoroisopropanol) allowed for engineering the crystallization in the form of polymorph I (the most stable) and manipulating the system's interactions to obtain crystallization yields greater than $88 \%$ at room temperature.

Attempting to control the crystallization of paracetamol, Smith et al. [104] studied the ILs $\left[\mathrm{C}_{4} \mathrm{C}_{1} \mathrm{im}\right]\left[\mathrm{PF}_{6}\right]$ and 1-hexyl-3-methylimidazolium hexafluorophosphate $\left(\left[\mathrm{C}_{6} \mathrm{C}_{1} \mathrm{im}\right]\left[\mathrm{PF}_{6}\right]\right)$. The selected ILs, the respective concentration, and the method of crystal growth considered (cooling crystallization) have shown impact on the crystal habit and size. When $\left[\mathrm{C}_{6} \mathrm{C}_{1} \mathrm{im}\right]\left[\mathrm{PF}_{6}\right]$ was used at the lowest concentration $\left(16 \mathrm{mg} \mathrm{mL}^{-1}\right)$, tetragonal bypyramids were formed; by increasing the concentration of the IL, it was possible to move from plate particles to more tubular structures $\left(30-69 \mathrm{mg} \mathrm{mL}^{-1}\right.$ ) as a consequence of growth post spontaneous nucleation. At higher concentrations, $\approx 69 \mathrm{mg} \mathrm{mL}-1$, particles with 23 to $206 \mu \mathrm{m}$ were obtained.

To avoid the use of an antisolvent, Weber et al. [98] proposed the cooling crystallization in IL media, with 1-ethyl-3-methylimidazolium bis(trifluoromethanesulfonyl)imide $\left(\left[\mathrm{C}_{2} \mathrm{C}_{1} \mathrm{im}\right]\left[\mathrm{NTf} \mathrm{f}_{2}\right]\right)$, also acting as a purification methodology for twelve APIs with anti-inflammatory, antifungal and antipyretic properties. From those, ten of the APIs proved to be highly soluble in the IL at their melting temperature. Among the studied systems, similar or higher purities with improved yields to those that were obtained with antisolvent crystallization were achieved, enabling the possibility to use this method for APIs purification.

Despite the promising results reported so far and the growing interest on the use of ILs to tailor the APIs polymorphs, there is still a gap in a systematic and comprehensive research on this topic, particularly to better understand the IL cation and anion effects. The use of computational methods can be an advantageous alternative to understanding the IL-API interactions driving the formation of specific polymorphic forms and habits, as it is already performed for other conventional solvents [105]. Furthermore, the development of effective separation methods and research on techniques to avoid the IL contamination in the final product are highly demanding.

\section{ILs with Biological Activity}

Because of the myriad of anion-cation combinations in ILs, these solvents may display specific biological activities [106]. Although the application of ILs in this area is emerging, promising results were already disclosed. Figure 9 provides an overview on the biological activities of ILs, namely 
antioxidant, anti-tumoral, and antimicrobial activity, covering some of the main types of cation-based ILs studied so far.

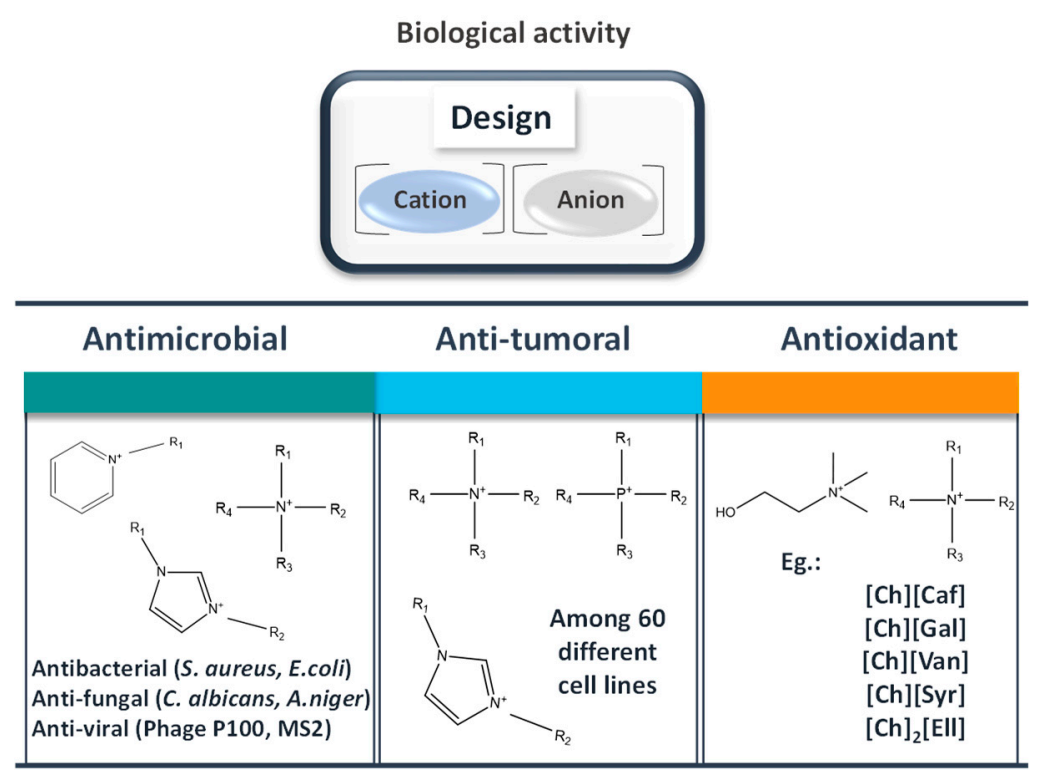

Figure 9. Biological activities reported for ILs and the respective studied cations (adequate references are given along the current section).

Imidazolium- and pyridinium-based ILs have been largely investigated in what regards their antibacterial activity [107-110]. Although some exceptions may appear and have been reported, in general, an increase in the alkyl chain length of the IL cation (1-alkyl-3-methylimidazolium based ILs $\left(\left[\mathrm{C}_{4-8} \mathrm{C}_{1} \mathrm{im}\right]^{+}\right)$and 1-alkyl-N-methylpyrrolidinium based ILs $\left.\left(\left[\mathrm{C}_{4-8} \mathrm{C}_{1} \mathrm{pyr}\right]^{+}\right)\right)$leads to higher antibacterial activity. Furthermore, ILs cations with longer aliphatic chains and more alkyl group substituents on the cation ring exhibit higher antibacterial activity against Gram-positive bacteria (e.g.,: Staphylococcus aureus, Bacillus subtilis) and Gram-negative bacteria (e.g.; Escherichia coli, Pseudomonas fluorescens) and Saccharomyces cerevisiae [110]. From these, B. subtilis demonstrated the higher susceptibility to the tested ILs. Later studies with ILs with longer alkyl chain lengths (1-alkyl-3-methylimidazolium based ILs $\left(\left[\mathrm{C}_{8-14} \mathrm{C}_{1} \mathrm{im}\right]^{+}\right)$and 1-alkyl-N-methylpyrrolidinium based ILs $\left.\left.\left[\mathrm{C}_{8-14} \mathrm{C}_{1} \mathrm{pyr}\right]^{+}\right)\right)$provided further insights on the antimicrobial activity of ILs [111]. Overall, the effect of the tested ILs against Gram-positive microorganisms was similar or even higher than that displayed by a common antimicrobial agent, cetyltrimethylammonium chloride. Based on the exposed, the ILs antibacterial efficiency can be tuned by varying both the alkyl chain length and modifying the head group at the cation. The increase in the susceptibility of these pathogens can be assigned to the ability of ILs to interact or disturb biological membranes, which leads to cell death [112]. In all of these cases, varying the anion identity did not reveal a significant effect on the ILs' antimicrobial activity.

Doria et al. [113] synthesized a series of $N$-cinnamylimidazolium salts with different alkyl chain lenghts $(1,6,8$, and 10 carbons), and evaluated their antibacterial activity against skin and soft tissue infections. These ILs were synthesized while employing microwave radiation under solvent-free conditions, attempting to minimize the environmental concerns that were related to conventional IL synthesis. Based on antimicrobial activity studies, it was possible to verify that as the alkyl chain is increased, the antibacterial activity increased with a dose-dependent effect. Molecular dynamics simulation studies allowed for explaining this antimicrobial behavior, as the result of the ILs' insertion in the lipidic double layer, facilitating the subsequent diffusion to the intracellular space. While higher aliphatic chain lenght ILs extend to the interior of the membrane, the lack of hydrophobicity of lower alkyl chain lenght ILs reduces this phenomenon [113]. 
More recently, predictive models for the antimicrobial and antifungal activities of ILs started to be developed, aiming at a rational design of ILs to be included in pharmaceutical applications. Cho et al. [114] reported six quantitative structure-activity relationship (QSAR) models, which were developed while using linear free energy relationship (LFER) descriptors calculated by density functional theory and a conductor screening model, to predict the minimal inhibitory concentration (MIC) and minimal biocidal concentration (MBC) of ILs against E. coli and S. aureus. Later, QSAR and molecular docking were applied in order to address the antibacterial activity of 131 imidazolium-based ILs against S. aureus ATCC 25923 and its clinical isolate [115]. The developed models presented robustness, predictive power and reliability, with $80-82 \%$ of accuracy. The obtained results reveal that ILs with $C_{12}$ alkyl chains or with two identical $C_{8}$ and $C_{9}$ alkyl chains seem to have higher activity against the pathogen, and they can be foreseen to design novel strategies against this microorganism. Attempting to investigate IL candidates as antibacterial agents, Zheng et al. [116] studied a series of ILs by molecular dynamics. The cations of ILs were found to insert into the lipid bilayer spontaneously, regardless of the cation types. Furthermore, imidazolium-based ILs with different alkyl chain lengths not always keep the preferential orientation, presenting the alkyl side chain of the cations close to the tail groups of the bilayer and the imidazolium ring close to the head groups of the lipid bilayer. This spontaneous insertion and reorientation inside the lipidic bilayers might be the cause of disorder and disruption of membranes and, thus, influence antibacterial activity [116].

In addition to antibacterial properties, ILs were disclosed as presenting antiviral activity. A systematic analysis investigated the effects of defined structural elements of 55 ILs (by changing the cation core, anion, and the length of the cation alkyl side chains) on virus activity, namely on the human norovirus surrogate phage MS2 and phage P100, representing non-enveloped DNA viruses [117]. Imidazolium-based ILs $\left(\left[\mathrm{C}_{1-10} \mathrm{C}_{1} \mathrm{im}\right] \mathrm{Cl}\right)$ did not show particular effectiveness against the phages, except for the IL with a higher alkyl chain cation that exhibited a reduction in the phages number. The antiviral activity shown to be IL concentration-dependent. Because the phages used in the previous study are nonenveloped, the observed inactivation by long alkyl chain ILs could be mainly attributed to protein denaturation (as the capsid of the phages consists of proteins), rather than membrane disturbance typically caused by surfactant-like behavior. However, the effect of the IL anion on the antiviral activity remains unclear.

Despite their antibacterial and antiviral properties, some ILs can present antifungal activity, even at low concentrations $\left(0.28 \mu \mathrm{g} \mathrm{mL} \mathrm{m}^{-1}\right)$. Bergamo et al. [118] reported an in vitro antifungal activity of 1-hexadecyl-3-methylimidazolium chloride $\left(\left[\mathrm{C}_{16} \mathrm{C}_{1} \mathrm{im}\right] \mathrm{Cl}\right)$ against multidrug-resistant Candida tropicalis isolates, whereas other authors [107] have shown the potential of $\left[\mathrm{C}_{6-14} \mathrm{C}_{1} \mathrm{~m}\right] \mathrm{Cl}$ ILs to control planktonic bacteria and biofilm formation. ILs with tetraalkylammonium and pyridinium cations were combined with anions that were derived from artificial sweeteners (saccharinate and acesulfamate) attempting to pair the biological activity inherent in the cation with the anion's biological function [119]. These ILs were tested for their antifungal activity against $C$. albicans. However, these ILs present equal or decreased antifungal activity towards the microorganism than the starting compounds. Previous findings have shown that the IL effect on fungal metabolism is more intricated than the attribution of their activity to the ILs' toxicity [120]. In this regard, Suchodolski et al. [121] synthesized novel menthol-based ammonium ILs ([ $\left.\left.\mathrm{C}_{10-12}-\mathrm{Am}-\mathrm{Men}\right] \mathrm{Cl}\right)$ attempting to understand the mechanisms underlying their antifungal activity on C. albicans. As it happens for the previous mentioned works, the antimicrobial activity increased with the increase of the alkyl chain length of the cation, being the most effective ILs the ones that present more than 11 carbon atoms. When used at $50 \mu \mathrm{M}$, these ILs cause partial decomposition of the cell wall and promote the detachment of fungal cells. These novel ILs can be considered as disinfectants due to their antifungal activity and low hemolytic activity.

Antioxidant properties have gained interest in the pharmacological context due to the possibility to reduce the free radicals' concentration at skin, and thereby preventing and repairing damages caused by oxidative stress. Some phenolic compounds present high antioxidant and anti-inflammatory activities; however, their limited aqueous solubility represents a disadvantage towards their incorporation in 
water-rich pharmaceutical formulations and skin care products. To overcome these drawbacks, phenolic acids have been considered as IL anion sources to increase their solubility and antioxidant activity. However, it should be remarked that due to their action and when considered for therapeutic purposes, these may be also considered as new active principle ingredients in the form of ILs (API-ILs), which are discussed below. Overall, ILs have proven to possess high antioxidant activities, as summarized in Table 2. Sintra et al. [122] synthetized five cholinium-based ILs using gallate, caffeate, vanillate, syringate, and ellagate anions. The resulting ILs demonstrated a solubility in water $\approx 3$ orders of magnitude higher than the corresponding phenolic acids. These ILs presented not only similar, but even higher antioxidant activities, as well as comparable cytotoxicity and lower ecotoxicity profiles than their acidic precursors, being the most promising results obtained with the IL dicholinium ellagate. In another study, hydroxyl functionalized ammonium dicationic ILs containing natural derived ions and ether linkage between cationic head groups were synthesized and described as a novel form of antioxidants, where protocatechuic acid (also known as 3,4-dihydroxybenzoic acid), a natural compound with not only antioxidant properties but also chelation ability, was considered as anion [123]. All of the in vitro studies indicated that the antioxidant activity of dicationic ILs was significantly higher than that of free acids or commonly used antioxidants. More recently, attempting to understand the effect of the cation structure towards the antioxidant activity, Ahmad et al. [124] evaluated five ferulate-based ILs with ammonium cations comprising different alkyl chain lengths. The prediction of their antioxidant activity based on the $\sigma$-potential of the COSMO-RS model was in agreement with the experimental DPPH free radical scavenging results, revealing that tertiary alkanolamine-based ILs have higher antioxidant activities than secondary alkanolamine-based ILs. All of the synthesized ILs showed higher antioxidant activities than the ferulic acid precursor, even at low concentrations (up to $12.93 \mu \mathrm{M}$ ). In a different approach, novel ILs derived from natural sources were designed to enhance other biological properties in aqueous solutions, such as analogues of glycine-betaine (AGB-ILs) [125]. AGB-ILs, namely triethyl [2 -ethoxy-2-oxoethyl]ammonium bromide $\left(\left[\left(\mathrm{C}_{2}\right)_{3} \mathrm{NC}_{2}\right] \mathrm{Br}\right)$, have recently been studied regarding their potential to enhance anti-inflammatory and antioxidant activities. These ILs allowed for increasing the antioxidant/anti-inflammatory activities of nutraceutical extracts, being possible to use them in nutraceutical formulations.

Table 2. Antioxidant activity of ILs and comparison with reference compounds.

\begin{tabular}{|c|c|c|c|c|}
\hline IL & $\begin{array}{c}\text { DPPH Free } \\
\text { Radical } \\
\text { Scavenging }(\mu \mathrm{M})\end{array}$ & $\begin{array}{l}\text { Reference } \\
\text { Compound }\end{array}$ & $\begin{array}{c}\text { DPPH Free } \\
\text { Radical } \\
\text { Scavenging }(\mu \mathrm{M})\end{array}$ & Reference \\
\hline 2-(methylamino)ethanol ferulate & 17.40 & \multirow{5}{*}{ Ferulic acid } & \multirow{5}{*}{21.40} & \multirow{5}{*}{ [124] } \\
\hline 2-(propylamino)ethanol ferulate & 16.61 & & & \\
\hline 2-(butylamino)ethanol ferulate & 16.34 & & & \\
\hline 3-dimethylamino-1-propanol ferulate & 12.93 & & & \\
\hline 3-diethylamino-1-propanol ferulate & 14.09 & & & \\
\hline Bis(ammonium) protocatechuate & $5.06-5.98$ & Protocatechuic acid & 15.83 & [123] \\
\hline Cholinium caffeate & 2.55 & Caffeic acid & 1.99 & [122] \\
\hline Cholinium syringate & 2.44 & Syringic acid & 2.04 & [122] \\
\hline Cholinium vanillate & 16.03 & Vanillic acid & 80.46 & [122] \\
\hline Dicholinium ellagate & 1.22 & Ellagic acid & 0.79 & [122] \\
\hline
\end{tabular}

ILs have been largely tested in different cell lines in order to assess their antitumoral activity. From these, cancer cells lines have provided relevant results towards the understanding of the ILs potential as anticancer agents [126]. Phosphonium-, tetralkylammonium-, and, later, imidazolium-based ILs have been tested in vitro in 60 human tumor cell lines $[126,127]$. Phosphonium-based ILs were found to have higher anti-tumor activity than ammonium-based ones. Imidazolium-based ILs showed particularly high activity against leukemia cell lines, whereas an increase in the alkyl chain length leads to significant 
improvements in antitumor activity. Thus, multiple possibilities of IL cation-anion combinations can rule the resulting biological activity and associated cytotoxicity, playing a major role in therapeutic applications. The apoptotic mechanism that was caused by alkyl-methylimidazolium-based ILs was later unveiled using rat pheochromocytoma (PC12) cells [128].

As the analysis of the biological activity of ILs is strongly dependent on the organism considered, it is important to consider a broader study for each IL in order to obtain a complete profile of its activity. The proper cation/anion combination will allow for the synthesis of ILs with specific pharmacodynamic properties. These ILs with biological properties can be applied not only as novel active compounds, but ideally, and by taking advantage of their solubilization ability, be designed to enhance the solubility of a given API and supplement and/or potentiate their therapeutic action. Furthermore, a closer look is required towards the understanding of ILs' distinct mechanisms of membrane binding, insertion, and disruption.

\section{API-ILs as Liquid Forms of APIs}

The design of novel liquid forms of APIs where they are at least one the constituting ions in ILs (API-ILs) is an appealing strategy to overcome the solubility, bioavailability, and polymorphism drawbacks. Their charged and liquid state allow to overcome the melting enthalpy barrier and improve solubility/bioavailability. The large variety of IL cation-anion combinations allows for obtaining new drugs in the form of API-ILs with specific physicochemical and biological properties, and even to possess dual pharmacological action. These ILs can be also obtained using oligomeric ions or by applying the prodrug strategy to one of the ions of an API-IL. Figure 10 summarizes the options of design for API-ILs found in the literature. During this section, several alike summarizing images will be provided with the information collected from the works to be discussed.

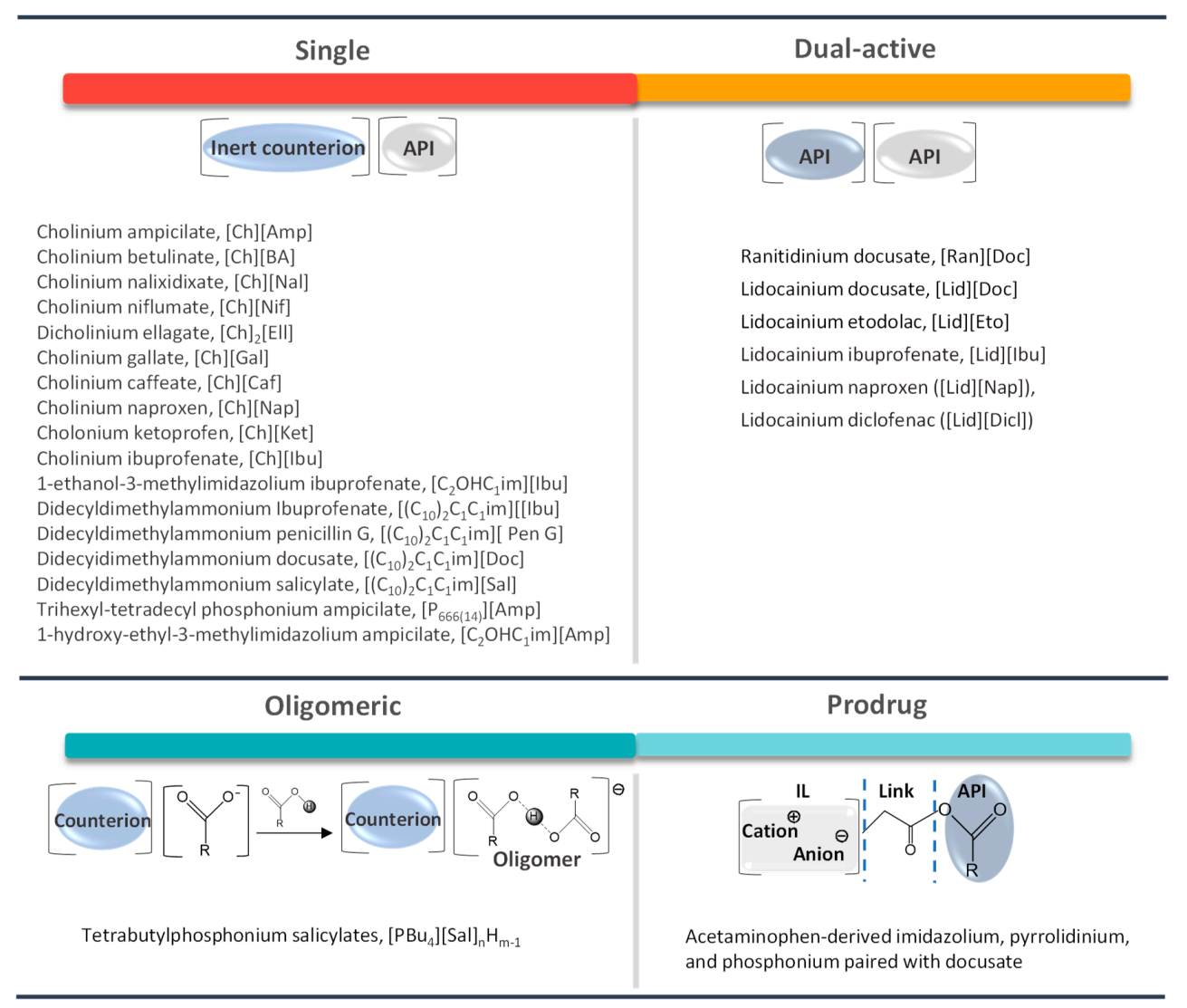

Figure 10. Schematic examples of API-ILs pharmaceutical formulations (adequate references are given along the current section). 
API-ILs were first reported by Rogers and coworkers [129] in 2007, with the synthesis of ranitidine docusate ([Ran][Doc]), liquid at room temperature. Ranitidine, which is a histamine $\mathrm{H}_{2}$-receptor antagonist, is well known for its polymorphic conversion that affects its pharmaceutical action. The authors demonstrated its conversion into an IL form by incorporating the docusate anion, which, in addition to overcoming the polymorphism concern, also improves the API absorption. After this pioneering work, an increasing number of reports on API-ILs emerged over the years, where the structural and chemical properties of the ions and a wise selection of counterions led to the formation of IL forms of the pristine drugs, with single or dual therapeutic action [130-134]. However, it should be taken into account that, upon dissolution, the combination of APIs with simple and inert counterions or other active agents will dissociate in the body fluids, and the cationic and anionic components will follow their independent pharmacokinetic and metabolic pathways [135].

API-ILs of different pharmacological classes have been reported, including the following APIs: lidocaine [106,136], sulfacetamide [129,137], ibuprofen [137,138], indomethacin [139], procaine [136], aspirin [131,136], salicylic acid [136], piperacillin [137], penicillin G [137], and docusate [138]. Most of the reported works comprise the API as the anion combined with an "inert" cation, as summarized in Figure 11, such as cholinium or phosphonium cations. These cations are mostly explored since they are widely characterized in the literature and, especially, in the case of cholinium, this is a safe and low-cost cation source. However, the possibility to predict if the selected ions will result in an API-IL and their resulting properties is still a challenge to be tackled.

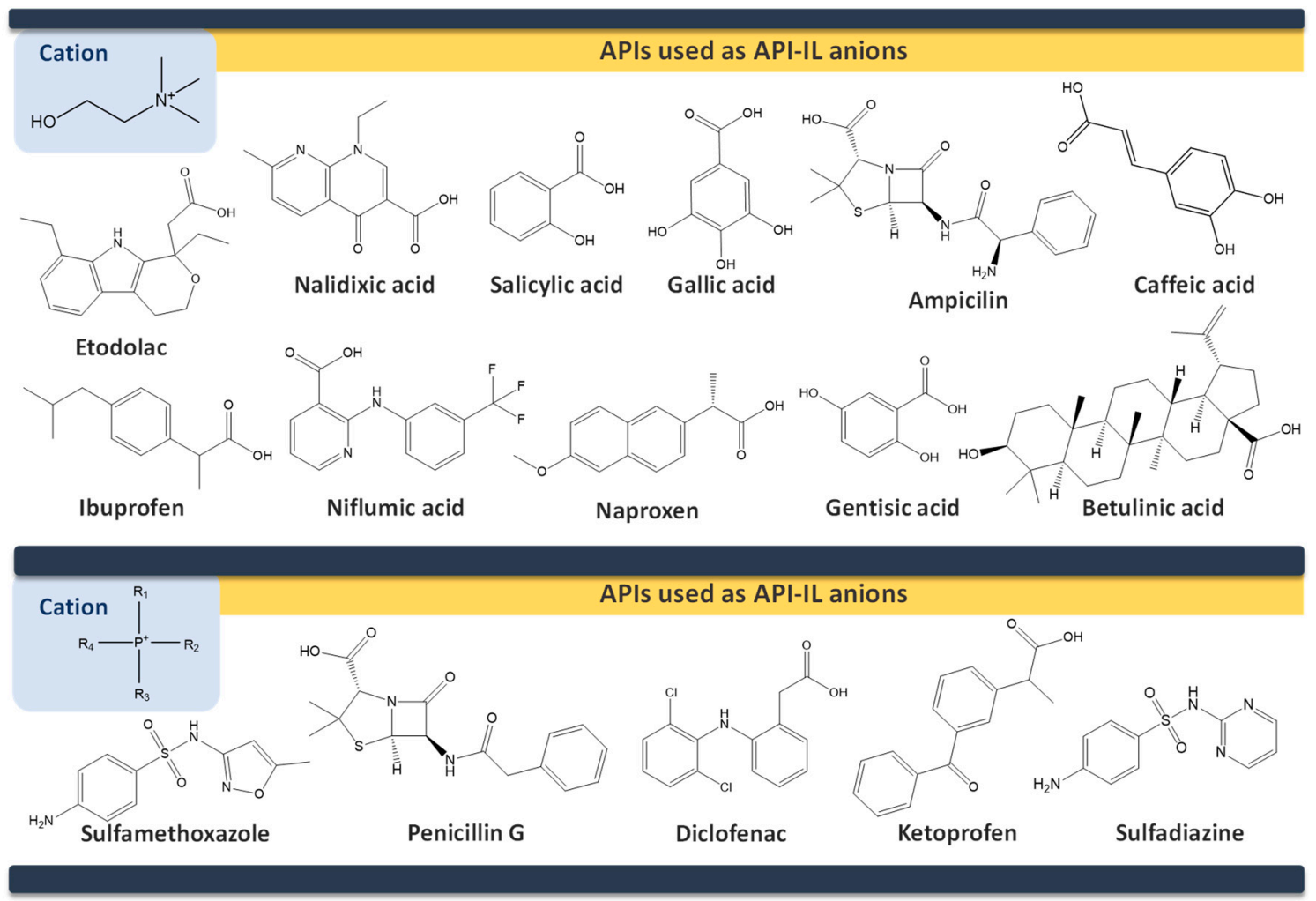

Figure 11. Selected examples of cations and anions used in API-ILs preparation (adequate references are given along the current section).

In general, API-ILs exhibit improved solubility in water and bioavailability when compared with the original and non-charged APIs. Figure 12 depicts examples of promising solubility enhancements that are achieved by this approach, which can be advantageous alternatives for different pharmacological classes. As an example, betulinic acid, a low-water soluble natural product with anti-cancer, anti-inflammatory, and anti-HIV properties, has been converted into an API-IL using cholinium 
as counterion [140]. The cholinium-based derivative has a significantly higher solubility in water than betulinic acid (by 100-fold) and its half maximal inhibitory concentration $\left(\mathrm{IC}_{50}\right.$ ) was considerably improved (from 60 to $22 \mu \mathrm{g} \mathrm{mL} \mathrm{m}^{-1}$ ), meaning that a higher ability of liberating its latent biological activity for inhibition of HIV-1 protease. The API-IL approach has been also applied to increase the solubility of nalidixic acid by its conversion into cholinium nalixidixate ([Ch][Nal]) and of niflumic acid by its conversion into cholinium niflumate ([Ch][Nif]), where an increase of 3300-fold and 53,0000-fold in solubility in aqueous media, respectively, was observed [141]. Furthermore, the in vitro study on two human cell lines, Caco-2 colon carcinoma cells and $\mathrm{HepG}_{2}$ hepatocellular carcinoma cells, revealed that the cytotoxicity of these APIs is preserved upon their conversion into ILs. Other poorly water-soluble APIs, such as diclofenac, ibuprofen, ketoprofen, naproxen, sulfadiazine, sulfamethoxazole, and tolbutamide, were converted into tetrabutylphosphonium-based ILs, and their solubility in water as compared to the free acids and sodium salts [142]. Tetrabutylphosphonium-based ILs improve the solubility of the corresponding API in aqueous media, where significantly higher maximum concentrations were reached with ibuprofen ( $\geq 80$-fold), ketoprofen ( $\geq 60$-fold), naproxen ( $\geq 70$-fold), sulfadiazine (130-fold), and sulfamethoxazole ( $\geq 50$ fold). In another study, the conversion of ibuprofen into the IL 1-ethanol-3-methylimidazolium ibuprofenate $\left(\left[\mathrm{C}_{2} \mathrm{OHC}_{1} \mathrm{im}\right][\mathrm{Ibu}]\right)$ allowed for increasing the API's solubility in water by 155,000-fold in comparison to the original API [143].

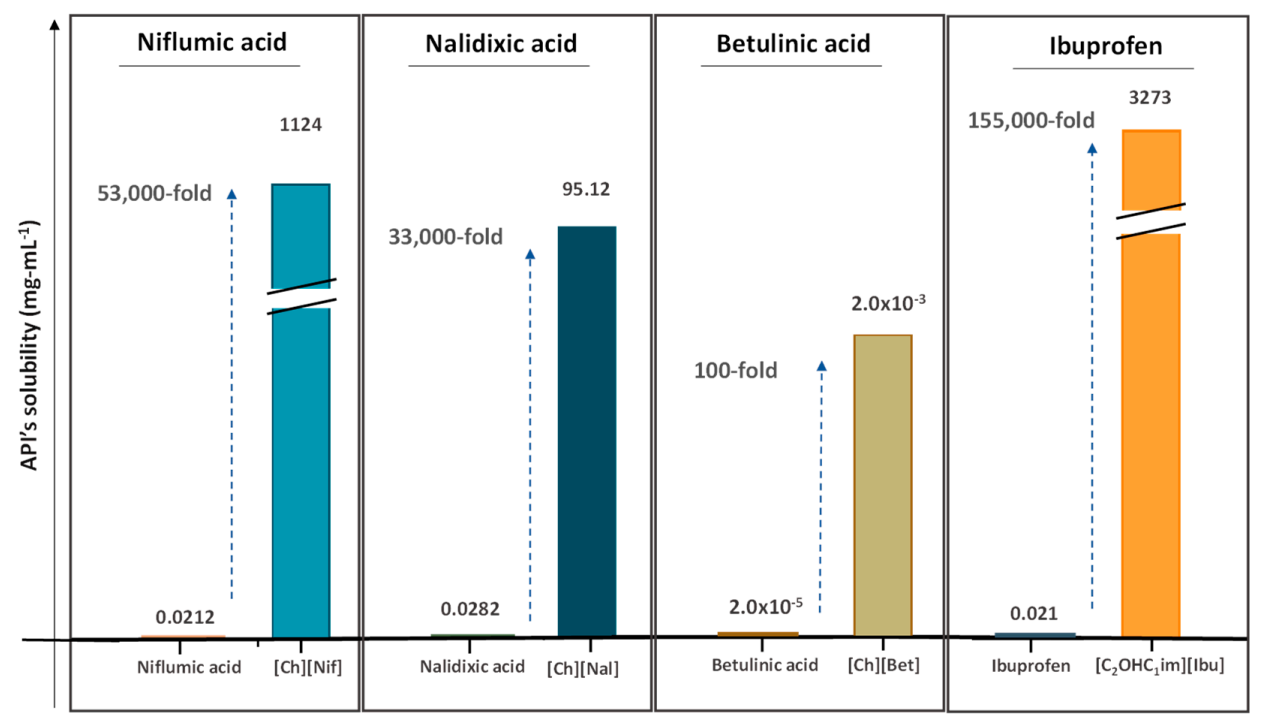

Figure 12. Example of solubility enhancements provided by API-ILs in aqueous media in comparison with the parent APIs and their dissolution in water $\left(\mathrm{mg} \mathrm{mL}^{-1}\right)$ (adequate references are given along the current section).

Ferraz et al. [144] reported the conversion of ampicillin into ampicillin salts/ILs, including API-ILs liquid below body's temperature, namely trihexyltetradecylphosphonium ampicillin ([ $\left.\left.\mathrm{P}_{666(14)}\right][\mathrm{Amp}]\right)$ and 1-hydroxy-ethyl-3-methylimidazolium ampicillin ( $\left.\left[\mathrm{C}_{2} \mathrm{OHC}_{1} \mathrm{im}\right][\mathrm{Amp}]\right)$, as well as a water-soluble alternative with low melting temperature $\left(\mathrm{T}_{\mathrm{m}}=58^{\circ} \mathrm{C}\right)$, cholinium ampicillin $([\mathrm{Ch}][\mathrm{Amp}])$. Later, the water solubility (at room and body's temperature) and the respective hydrophilic/lipophilic balance of these API-ILs was evaluated [145]. The solubility for [Ch][Amp] and [ $\left.\mathrm{C}_{2} \mathrm{OHC}_{1} \mathrm{im}\right][\mathrm{Amp}]$ was found to be comparable to the water solubility of the respective ampicillin sodium salts and it increased by nine-fold at body's temperature in comparison with the pure salt, thus standing as a competitive alternative to the marketed drug. For both ILs, an enhancement in the octanol-water partition coefficient by 11- and 7-fold was relatively verified to the starting ampicillin. The authors also evaluated the antibacterial activity of the prepared ampicillin-based ILs [146]. The studied ILs showed increased growth inhibition for some Gram-negative resistant bacteria, achieving MIC values 10-1000 higher than the ampicillin salt, including the action against resistant bacterial strains. More recently, 
the anti-tumoral activity of these ampicillin-based-ILs was assessed in human cancer cell lines in order to evaluate the possibility to have multiple and enhanced biological activity in the liquid form. To this purpose, the anti-tumoral activity was assessed in T47D (breast), PC3 (prostate), HepG2 (liver), MG63 (osteosarcoma), and RKO (colon) cell lines [147]. [ $\left.\mathrm{C}_{2} \mathrm{OHC}_{1} \mathrm{im}\right][\mathrm{Amp}]$ shown to be the most relevant ampicillin-based IL, with a higher antiproliferative activity and lower cytotoxicity being associated towards healthy cells.

Following the previous reports with ampicillin [144-147], primaquine-based ILs were synthesized aiming to treat malaria infection [148]. Primaquine blocks disease transmission due to its gametocytocidal action; however, its action is overshadowed by toxicity issues and by the drug's poor activity against blood-stage parasites. Aiming to tackle these drawbacks, the API was combined with different cinnamates as counterions and screened against blood-stage chloroquine-sensitive and chloroquine-resistant Plasmodium falciparum parasites. The novel API-ILs showed an increased in vitro blood-stage activity when compared to the pure API. Later, it was discovered that primaquine-derived ILs may contribute to increasing the API's permeation into malaria-infected erythrocytes, behavior that considerably diverges from that of the parent drug [149]. This trend was explained based on more pronounced electrostatic interactions of the charged anti-malarial drugs with the polar head groups of the phospholipids in the erythrocyte membranes, thus potentiating treatment efficacy [149].

The possibility of replacing the "inert" counterion of an API-IL by a second API may lead to dual therapeutic function ILs. However, the physicochemical and pharmaceutical properties of both APIs in the API-IL form, i.e., the resulting melting temperature, solubility, bioavailability, and stability will most likely be different for the two APIs in comparison to the precursors, and their adequate characterization is mandatory. Both lidocaine and etodolac, in the form of lidocainium etodolac ([Lid][Eto]), can exhibit superior water solubility than both APIs alone, with an increase of $>90$-fold for etodolac and two-fold for lidocaine [150]. Rogers and co-workers reported the enhancement of aqueous solubility, thermal stability and topical analgesic effect of lidocainium docusate ([Lid][Doc]) in comparison with the parent API (lidocaine hydrochloride)[129]. Lidocaine is known for its anesthetic effect, where docusate was selected due to its action as dispersing agent in formulations. Studies of anti-nociception in mice suggested that [Lid][Doc] produces a longer duration of antinociceptive effect than the original APIs. The longer pain relief afforded by this API-IL is provided by the synergistic effect of both APIs that impact pharmacokinetic, resulting in a different mechanism of action with higher therapeutic efficacy. The bioavailability of [Lid][Doc] was later addressed in vivo through its transdermal application on Sprague-Dawley rats [151]. The concentration of lidocaine in blood plasma was evaluated over time after the topical application of creams containing $5.0 \mathrm{wt} \%$ of [Lid][Doc]. However, the total systemic lidocaine absorption was almost undetectable even after $240 \mathrm{~min}$. of the transdermal application. Despite the fact that many APIs display higher solubility in water and higher therapeutic efficacy when solubilized in ILs or when converted into ionic liquid salts, addressing the in vivo bioavailability of the developed formulations is a crucial requirement.

The conversion of APIs into liquid forms as API-ILs may not always require a stochiometric approach. Oligomeric ion formation can be a possible alternative [152]. The preparation of oligomeric API-ILs, which are hydrogen-bonded moieties that include both the ions and the neutral non-ionized material, may contribute to the expansion of liquid drug formulations by simply changing the stoichiometry and/or complexity of the ions, i.e., by introducing the free acid/base of the conjugate base/acid within the salt formulation, thus lowering the API's melting point [22]. This concept was first introduced in 2010, by Bica and coworkers [153], with tetrabutylphosphonium salicylates, $\left(\left[\mathrm{PBu}_{4}\right][\mathrm{Sal}]_{\mathrm{nHm}-1}\right)$. The combination of tetrabutylphosphonium hydroxide and salicylic acid beyond one equivalent originated several liquid compositions in a range of $\left[\mathrm{PBu}_{4}\right]\left[\mathrm{Sal}_{1.3-3} \mathrm{H}_{0.7-2}\right.$, where the proton transfer is stronger. This behavior can be explained by the formation of hydrogen-bonded dimer complexes between salicylic acid and the salicylate anion, which can reach the composition of $\left[\mathrm{PBu}_{4}\right]\left[\mathrm{Sal}_{3} \mathrm{H}_{2}\right.$ (Figure 13). MacFarlane et al. [154] presented a library of nine compounds and also four oligomeric API-ILs were synthesized and prepared. Benzoic, salicylic, and gentisic acids were 
chosen for this study, as these are frequently found in pharmaceutical formulations. These oligomers may modulate membrane transport properties in vivo, enabling a higher permeability of APIs in this form than the starting materials.

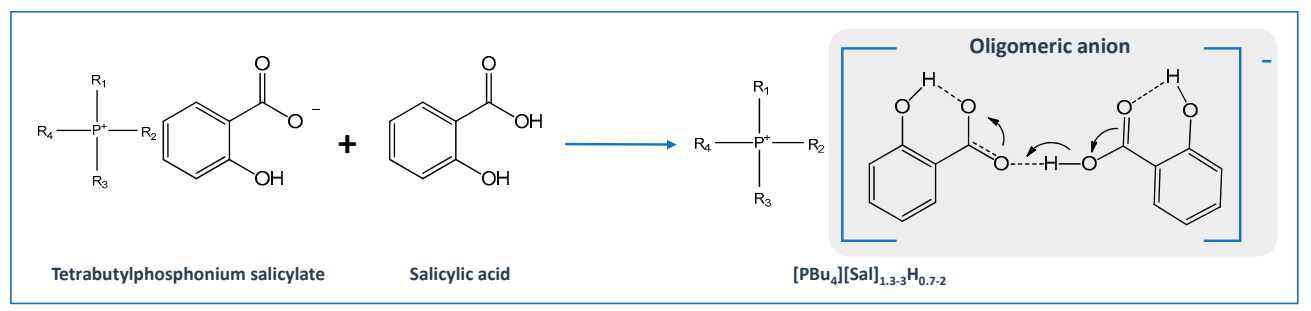

Figure 13. Schematic representation of the formation of oligomeric ions based on salicylate/salicylic acid proposed in [153].

Another way of enhancing the APIs therapeutic action and their delivery is by the prodrug approach. The prodrug concept has been refined over the years, and, nowadays, is defined by IUPAC as any compound that undergoes biotransformation before exhibiting pharmacological effect [155]. A prodrug only has activity after enzymatic and/or chemical transformation in vivo in order to release the active parent drug into the therapeutic target [156]. The prodrug strategy may enable the optimization of several drug properties, i.e., achieve higher stability, improved solubility and/or increased permeability. Yet, solid prodrugs can suffer from the same problems as any solid API and notably polymorphism [157]. Therefore, the combination of API-IL advantages with a prodrug strategy can be an appealing alternative to enhancing the APIs efficacy. The functionalization of APIs with easily biochemically cleavable (e.g., by hydrolysis) ionic functional moieties, which can be combined with selected counterions, is the basis of prodrug API-IL development. Similar to other IL strategies, it is possible to design the prodrug API-IL for a specific therapeutic purpose by the proper selection of the counterion, which may also include a second API (dual-function prodrug) or even a permeation enhancer [22,158]. A reported example of this approach encompasses liquid paracetamol-based drugs combined with imidazolium, pyrrolidinium, pyridinium, and phosphonium paired with docusate (Figure 14) [158]. The resulting prodrugs present lower water solubilities than the neutral paracetamol and slower release profiles in aqueous media. These differences in the paracetamol derivative properties may be advantageous for the development of controlled release systems. The promising results that were obtained with paracetamol may boost the study of this strategy for other APIs.

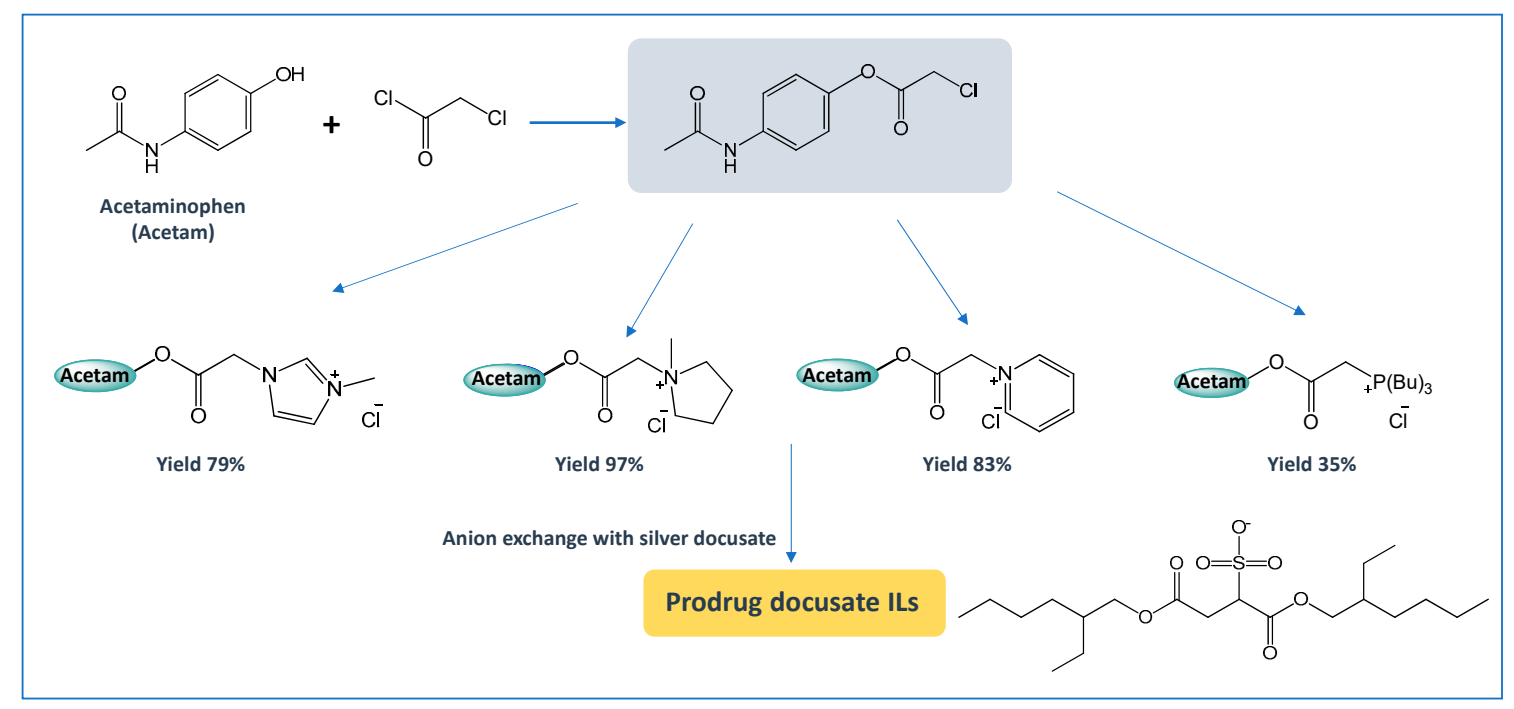

Figure 14. Synthesis of cationic acetaminophen prodrug ILs paired with the docusate anion proposed in [158]. 
Despite being shortly explored, prodrug API-ILs can be designed to target specific tissues. Following this notion, a promising protecting-group-free synthesis for the modification of tertiaryand heteroaryl-amine containing complex small molecules with quaternary-ammonium linkers has recently been proposed as a chemoselective approach for targeted delivery [159].

The diversity in the API-IL toolbox stands as a unique possibility to provide new biologically active combinations that must be properly investigated. The largest fraction of published works focus on enhancing the APIs solubility; however, the assessment of in vitro and especially in vivo studies of API-ILs are still less reported. Furthermore, the lack of pharmacokinetic and pharmacodynamic studies with new API-ILs hinders the understanding of the changes on the therapeutic action, the metabolic pathways that are involved in their uptake and the alterations in toxicity in comparison with the precursor API. This gap might be partially attributed to the lack of guidelines from the pharmaceutical entities for API-ILs, which makes difficult their formulation and correct testing as new drugs. Establishing these lines will allow for overcoming these drawbacks and also considering other challenges, such as the scale-up, purification, stability, and delivery of liquid forms of therapeutics.

\section{IL-Based Drug Delivery Systems}

In the field of drug delivery, ILs have been applied as novel pharmaceutical forms (API-ILs) and the respective drug delivery appraised, and as solvents or as polymerizable monomers for the development of polymer drug delivery systems $[75,79,80,160-166]$. ILs are excellent solvents for a wide range of biopolymers, such as proteins [167,168], DNA [169,170], and polysaccharides [171-173], being used in their processing into films and micro and nanoparticles with potential for drug delivery. Additionally, ILs have shown promising ability to functionalize ionogels, opening new routes for designing advanced materials, including their use as drug release systems [174,175]. Figure 15 depicts the versatility of ILs in the development of novel drug delivery systems. Adding up to existing reviews on this area $[30,161,176]$, our discussion focuses on the advances made for each type of administration route. The selection of the administration route is mostly dependent on the physicochemical properties of the API (e.g., melting temperature, molecular weight, polarity, solubility, etc.), its pharmacokinetic profile and ultimately the intended target site of action $[6,177]$. This selection is also dependent on other factors, such as invasiveness, where non-invasive routes of administration are preferable.

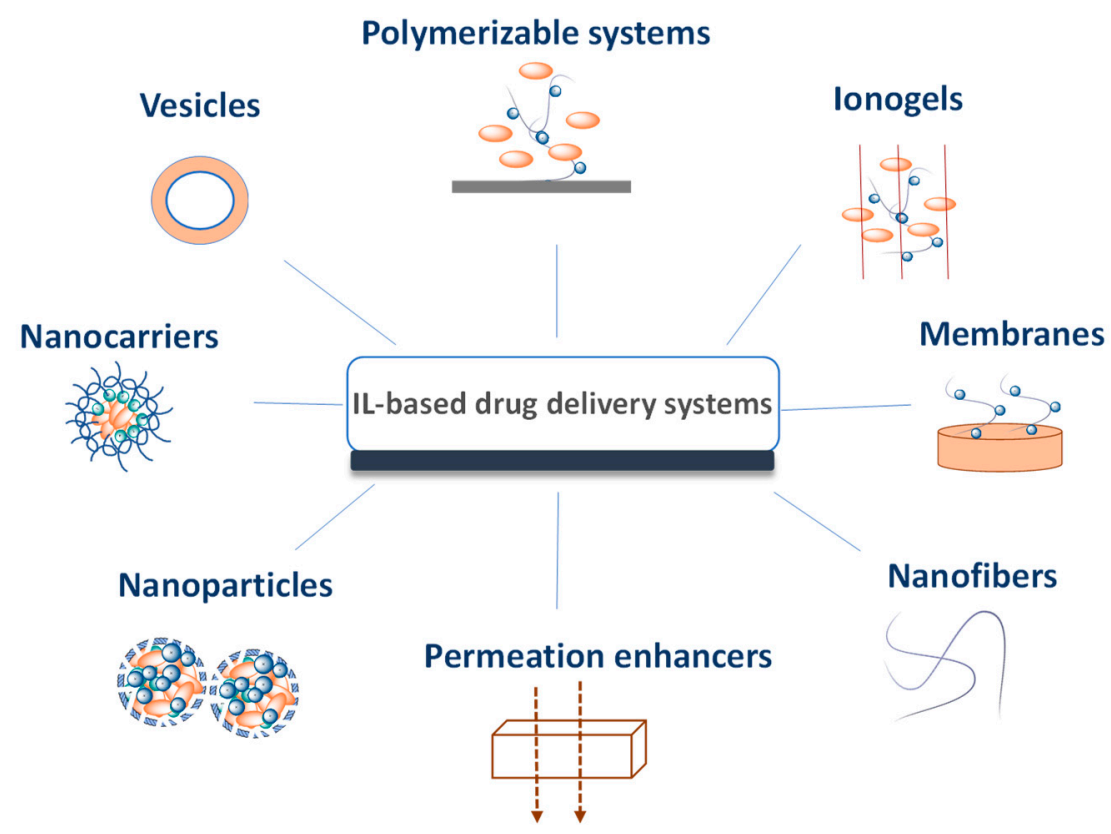

Figure 15. Schematic representation on the use of ILs in drug delivery systems (adequate references are given along the current section). 


\subsection{Intravenous Drug Delivery}

Intravenous drug administration is a preferable choice when aiming to bypass biological absorption barriers [178]. The selection of this route offers several advantages, since it provides the most complete drug bioavailability with a minimal delay. Foreseeing intravenous drug delivery applications, ILs have recently been explored for the development of polymer nanocomplexes. In this field, the conjugation of SAILs with chitosan was studied [179]. The SAILs 1-butyl-3-methylimidazolium octylsulfate $\left(\left[\mathrm{C}_{4} \mathrm{C}_{1} \mathrm{im}\right]\left[\mathrm{C}_{8} \mathrm{OSO}_{3}\right]\right)$ and 3-methyl-1-octylimidazolium chloride $\left(\left[\mathrm{C}_{8} \mathrm{C}_{1} \mathrm{im}\right] \mathrm{Cl}\right)$ induced the formation of chitosan nanoparticles at low concentrations. While the negative charge of the counter ion $\mathrm{Cl}^{-}$of $\left[\mathrm{C}_{8} \mathrm{C}_{1} \mathrm{im}\right] \mathrm{Cl}$ could promote the IL-chitosan agglomeration (particles size of $450 \mathrm{~nm}$ ), $\left[\mathrm{C}_{4} \mathrm{C}_{1} \mathrm{im}\right]\left[\mathrm{C}_{8} \mathrm{OSO}_{3}\right]$ allowed for the formation of particles with smaller size due to stronger electrostatic interactions between the positively charged chitosan chain and $\left[\mathrm{C}_{8} \mathrm{OSO}_{3}\right]^{-}$ions (particles with $300 \mathrm{~nm}$ ). Thus, work focused on the preparation and characterization of these particles; however, further studies regarding the encapsulation and release profile of a selected drug from these particles, as well as the knowledge of their cytotoxicity profile, are required issues to better appraise their potential in drug delivery. More recently, the IL 1-butyl-3-methylimidazolium acetate, $\left(\left[\mathrm{C}_{4} \mathrm{C}_{1} \mathrm{im}\right]\left[\mathrm{CH}_{3} \mathrm{COO}\right]\right)$, was applied as solvent media for the synthesis of an amphiphilic derivative of a chitosan oligosaccharide grafted with linoleic acid-(LCOS), followed by self-assembly in aqueous media [180]. The use of the IL allowed for a higher degree of grafting when compared to the values obtained with a conventional procedure using DMSO. It was then possible to obtain ibuprofen-loaded LCOS micelles in aqueous solution with an average size lower than $200 \mathrm{~nm}$, suitable for intravenous administration. Despite the possibility to recover and reuse the IL from the reaction media, the cytotoxicity of the loaded LCOS micelles was not assessed.

In a different approach, polydopamine nanoparticles that were loaded with doxorubicin and the IL $\left[\mathrm{C}_{4} \mathrm{C}_{1} \mathrm{im}\right]\left[\mathrm{PF}_{6}\right]$ were recently developed for cancer treatment (Figure 16) [181]. The IL was employed as a microwave sensitizer to prepare these novel nanoplatforms for combined chemotherapy and microwave thermal therapy by intravenous administration. The antitumor efficacy of doxorubicin-loaded IL-polydopamine nanoparticles was demonstrated in in vitro and in vivo experiments in the treatment of tumors in mice, after intravenous injection via tail vein. The referred nanoparticles exhibited high inhibition effect when combined with the microwave thermal irradiation, acting in the tumor ablation without inducing significant tissue toxicity.

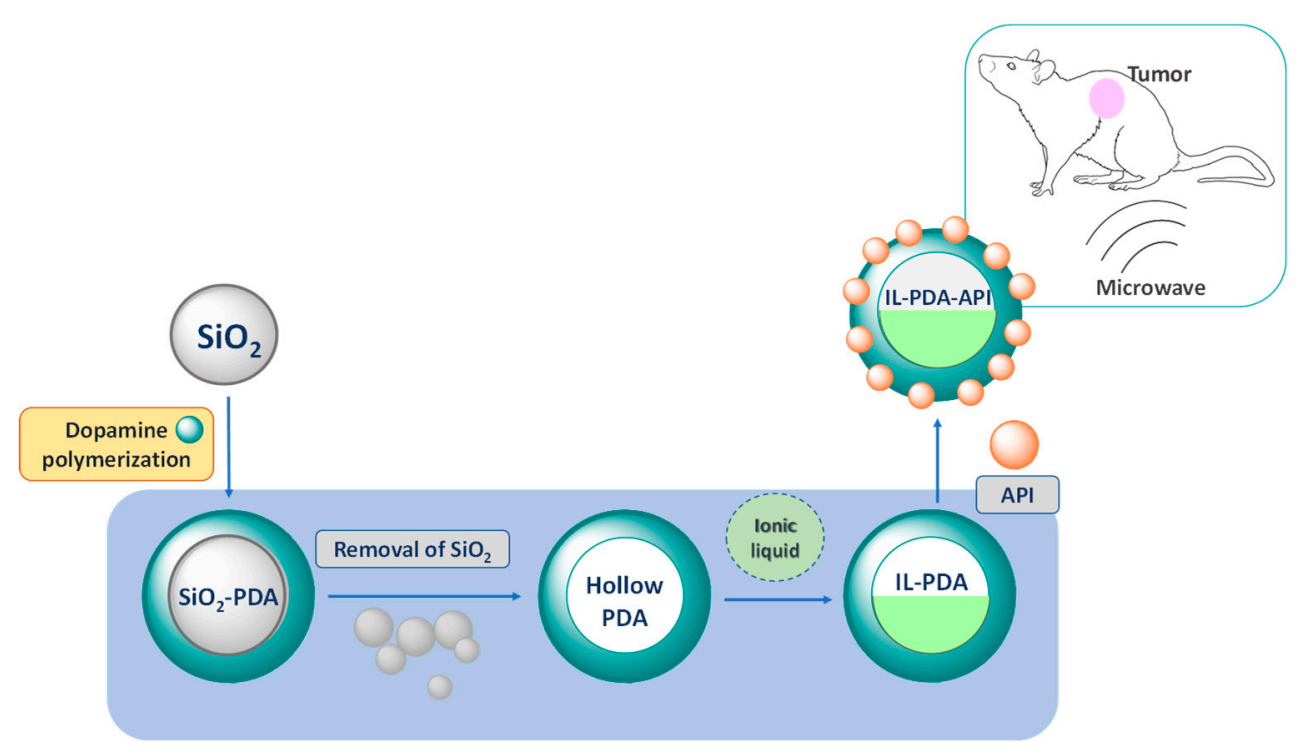

Figure 16. Schematic illustration of the preparation of IL-polydopamine (PDA) nanoparticles loaded with doxorrubucin for combined chemotherapy and microwave thermal therapy proposed in [181]. 
Micelles self-assembled from amphiphilic block copolymers were proposed for the administration of prednisone, a glucocorticoid that was mostly used to suppress the immune system [182]. To this end, the IL 1-allyl-3-methylimidazolium chloride $\left(\left[\left(\mathrm{CH}_{2} \mathrm{CH}=\mathrm{C}_{2}\right) \mathrm{C}_{1} \mathrm{im}\right] \mathrm{Cl}\right)$ was used as solvent in order to prepare cellulose grafted with polylactic acid by ring opening graft polymerization of 1-lactide. Colloidal solutions comprising micelles of cellulose-g-PLLA were prepared in aqueous media by a membrane-dialysis method. The resulting micelles exhibited spheric morphology within a size range of 30-80 nm, and allowed for sustained drug release. The IL removal and the cytotoxicity evaluation in 3T3 mouse fibroblasts cell line showed low toxicity towards cells, reinforcing their potential applicability as drug carriers.

ILs can be used to form IL-in-oil (IL/O) [183], IL-in-water (IL/W) [79,184], oil-in-IL (O/IL), and water-in-IL (W/IL) [185] emulsions. The possibility to manipulate and design the IL structure allows for the use of IL-based vesicles and micelles as novel carriers of low-water soluble APIs. Accordingly, hydrophobic nontoxic ILs were used to prepare novel IL/W nanoemulsions for intravenous administration of amphotericin B [186]. Amphotericin B is an antifungal agent that, due to its low-water solubility $\left(<1.0 \mu \mathrm{g} \mathrm{mL}^{-1}\right)$ and self-aggregation in aqueous media, presents undesired side-effects, thus being its intravenous drug delivery a challenge. In a preliminary study, high contents $\left(>5.0 \mathrm{mg} \mathrm{mL}^{-1}\right)$ of the API were solubilized in a new hydrophobic dicholinium-based IL with the bis(trifluoromethanesulfonyl)imide $\left(\left[\mathrm{NTf}_{2}\right]^{-}\right)$anion. The mixture of this hydrophobic IL with a hydrophilic cholinium-based IL resulted in the solubilization of the drug, preventing the concentration-dependent aggregation with controlled release of the API. Despite the maintenance of the antifungal activity of the API, and the low toxicity towards embryo-larval zebrafish models, further studies are required in order consider this formulation adequate for intravenous administration.

\subsection{Oral Drug Delivery}

The challenges that are faced in oral drug delivery are primarily related with the API's poor bioavailability, i.e., related with the API's dissolution, permeability, and solubility. An example of using ILs in the development of oral drug delivery systems comprises their application as monomers in the synthesis of positively charged polymers loaded with naproxen, in the form of an anionic API [187]. The drug delivery systems were prepared by free radical polymerization while using two IL monomers, 1-(4-vinylbenzyl)-3-methyl imidazolium hexafluorophosphate and 1-(4-vinylbenzyl)-4-(dimethylamino)-pyridinium hexafluorophosphate, and methyl styrene. The resulting positively charged polymers were loaded with naproxen and provided a controlled release of the API, avoiding the delivery in acidic and neutral media ( $\mathrm{pH} 2-6.5)$. Given their $\mathrm{pH}$-dependent behavior, these systems can be envisaged to target the intestine delivery. Similarly, ILs with a $\mathrm{pH}$-sensitive character have been used in order to modify positively charged silica nanoparticles for oral delivery of methotrexate, a chemotherapeutic drug [188]. Imidazolium-based ILs were grafted to silica nanoparticles that were also grafted with polymethacrylic acid to form stimuli-responsive nanoparticles. These systems allowed for high drug encapsulation efficiencies $(76 \%)$ due to the strong electrostatic interactions established between the nanoparticles and the API. Recently, cholinium geranate ([Ch][geranate $\left.{ }_{2}(\mathrm{H})\right]$ ) has been used for insulin solubilization as a novel formulation for the administration of this API [189]. The IL-based insulin formulation was coated with Eudragit L-100 and orally administrated, exhibiting a promising, in vivo, pharmacokinetic and pharmacodynamic outcome. The respective oral bioavailability of the IL-insulin formulation was found to be $51 \%$ relative to subcutaneous injection of insulin. When orally administrated, this formulation significantly enhanced the paracellular transport of insulin, protecting it from enzymatic degradation, which resulted in a sustained decrease in blood glucose down to $45 \%$ in $2.5 \mathrm{~h}$. This delivery system was also investigated for its cytotoxicity and stability, showing no relevant toxicity and a constant stability over two months at room temperature and for at least four months under refrigeration. Despite tolerability tests still being required to establish a direct comparison between this system and the injection administration of insulin, the possibility to develop alternative and less invasive routes of administration must 
be highlighted as an advantage of the use of ILs for delivery purposes. Additionally, this type of formulations preserves the API structure, avoiding immunological reactions or loss of the API in a multistep system development.

In a different approach, API-ILs have been incorporated in carrier materials for the development of IL-based oral drug delivery systems. For instance, tetrabutylphosphonium ibuprofenate $\left(\left[\mathrm{P}_{4444}\right][\mathrm{Ibu}]\right)$ and lidocainium ibuprofenate ([Lid][Ibu]) were successfully immobilized into mesoporous silica particles for a fast and complete API release when placed into an aqueous environment, where approximately within $5 \mathrm{~min}$. all IL was released from the solid support [190]. Zhang et al. [191] proposed an all-in-one concept for the application of API-ILs as drug delivery systems. The pharmaceutically active IL itself works as both the carrier and the active drug. The API-IL self-assemble into vesicles in aqueous solution due to the combination of an anionic surfactant (sodium dodecylsulfate) with a cationic drug with anti-depressive properties (amitriptyline hydrochloride) (Figure 17). Furthermore, the referred IL-based vesicles have high drug loading contents, an advantage over conventional drug delivery systems. Also, it was possible to control the release profile of the API, moving from a total release of $74 \%$ and $82 \%$ to $28 \%$ and $32 \%$ in just $2 \mathrm{~h}$, using the correspondent API-IL, at pH 7.4 and $\mathrm{pH} 1.2$, respectively.

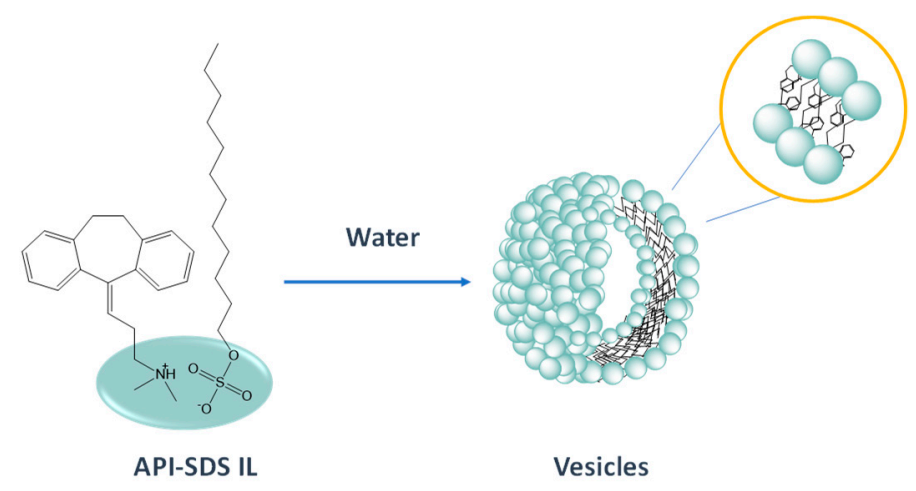

Figure 17. Illustration of the API-IL self-assembling into vesicles in aqueous media proposed in [191].

Itraconazole and cinnarizine were converted into lipophilic ILs (cinnarizine decylsulfate, itraconazole dioctyl sulfosuccinate) aiming to facilitate their incorporation into lipid-based formulations [192]. The resulting API-ILs were completely miscible or highly soluble in lipid-based self-emulsifying drug delivery systems (SEDDs). These systems, composed of long or medium chain glycerides, surfactants, such as Kolliphor-EL, and cosolvents, like ethanol, were easily incorporated into lipid-based formulations for in vivo oral drug delivery. The pharmacokinetic evaluation upon the administration of SEDDs revealed higher drug plasma exposure for the API-IL formulations (2-fold for cinnarizine and 20-fold for itraconazole) in comparison with the SEDDs with the respective parent APIs. The use of API-ILs for the development of these formulations enabled obtaining liquid SEDDs, increasing the oral exposure to the API. The increase in the drug absorption is enabled by the increase in the APIs' solubility and by promoting the gastrointestinal lipid absorption pathways. The design of the IL structure was also employed for optimization of the solubility of danazol, an API used in the treatment of endometriosis and fibrocystic breast disease, and itraconazole, an antifungal drug [77]. Like many other low-water soluble APIs, itraconazole and danazol present low-water and lipidic solubilities. Such conditions hinder the selection of formulation excipients that can enhance these drugs' bioavailability. The solubility of danazol and itraconazole was increased 20-fold and $>500$-fold using 1-hexyl-3-hexyloxycarbonylpyridinium dicyanamide $\left(\left[\mathrm{C}_{6} \mathrm{C}_{6} \mathrm{OCOpy}\right]\left[\mathrm{N}(\mathrm{CN})_{2}\right]\right)$, when compared to its solubility in soybean oil (a common lipid excipient). These solubility enhancements surpass those that were provided by using co-solvents like PEG and ethanol. The oral administration of the danazol-containing self-emulsifying IL formulation rises up to 4.3-fold the API's bioavailability when compared to the respective crystalline drug. Not only the absorption of the API was improved, but also 
its release sustained, as the formulation prolonged the plasma exposure to the API when compared with the respective lipid formulation.

\subsection{Topical and Transdermal Drug Delivery}

When considering the topical application of APIs, the drug delivery system must target one or more different skin layers and underlying tissues, or skin associated structures (sebaceous or sweat glands, etc.) [193]. Transdermal drug delivery, in particular, aims to reach systemic circulation, representing an alternative to parenteral and oral routes, while avoiding pre-systemic metabolism [194]. Despite being just recently explored, ILs have been studied as promising pharmaceutical agents or formulation components in order to tackle the challenges in topical and transdermal delivery systems, presenting a wide range of applications, as illustrated in Figure 18 [195]. ILs have been investigated in microemulsions, nanoparticles, (bio)polymer-based drug delivery systems (e.g., patches and membranes), and as permeation enhancers aiming to deliver poorly water-soluble drugs at topical and transdermal level, as summarized in Table 3.

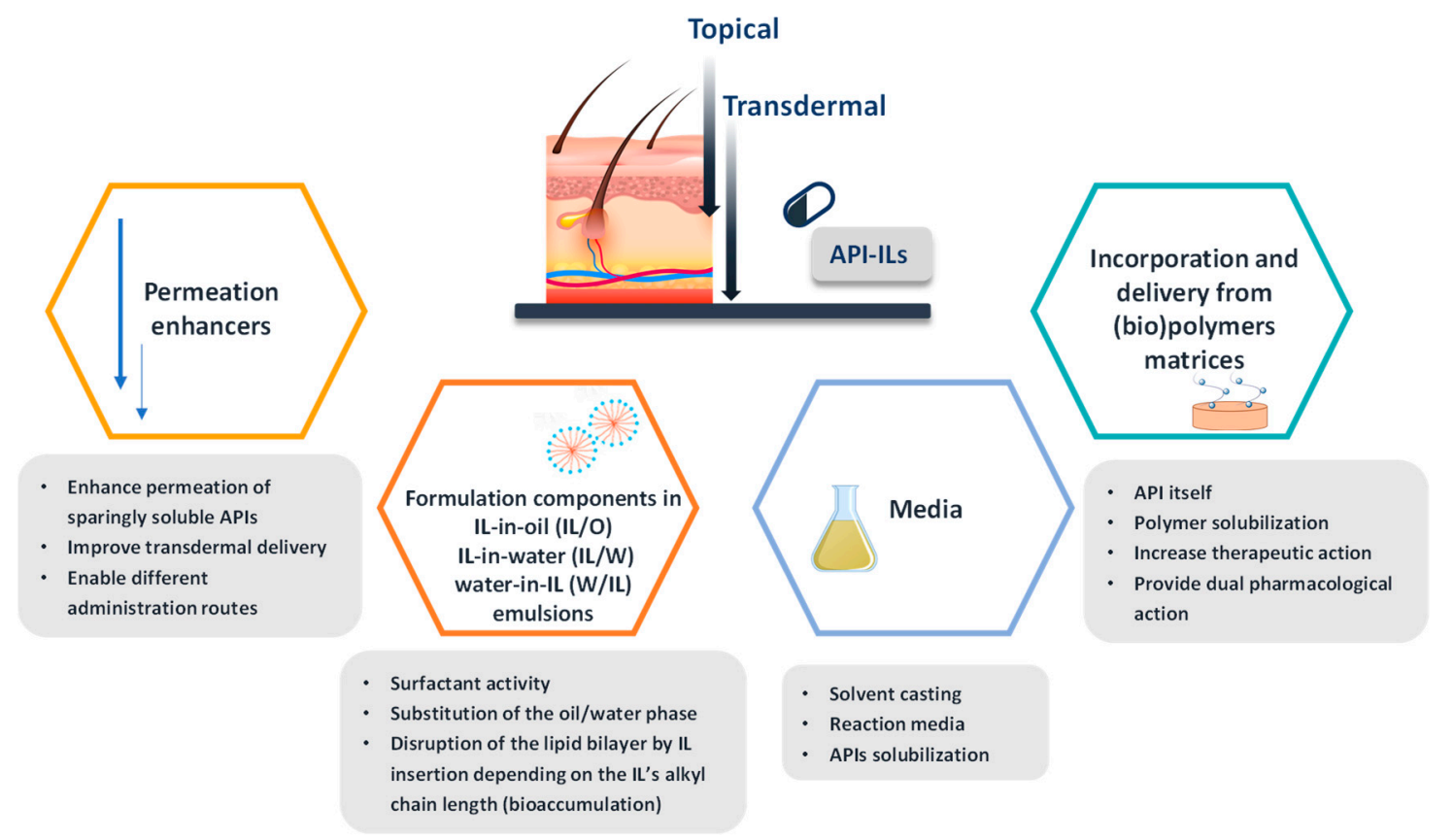

Figure 18. IL applications in the development of drug delivery systems for topical and transdermal administration (adequate references are given along the current section).

Microemulsions have been proposed in order to improve transdermal delivery, especially when comprising ILs. A single IL can replace different components in a given drug formulation, by substituting the oil, water or surfactant phase in microemulsions, acting as the permeation enhancer and/or being the API itself, as aforementioned. Furthermore, the fine-tuning of SAILs allows for manipulating the structure and dynamics of their micellar aggregates, making these ILs promising vehicles for APIs delivery due to their ability to enhance the solubility and specially the permeability of the drug across biological membranes. 
Table 3. IL application in topical and transdermal strategies.

\begin{tabular}{|c|c|c|c|c|}
\hline Strategy & IL & IL Role & API & Reference \\
\hline Micellar system & {$\left[\mathrm{C}_{14} \mathrm{C}_{1} \mathrm{im}\right] \mathrm{Br}$} & Surfactant & $\begin{array}{l}\text { Dopamine } \\
\text { hydrochloride } \\
\text { Acetylcholine } \\
\text { chloride }\end{array}$ & [196] \\
\hline Micellar system & {$\left[\mathrm{C}_{12} \mathrm{C}_{1} \mathrm{im}\right] \mathrm{Cl}$} & Surfactant & Ibuprofen & [87] \\
\hline Micellar system & $\begin{array}{l}{\left[\mathrm{C}_{12} \mathrm{C}_{1} \mathrm{im}\right] \mathrm{Cl}} \\
{\left[\mathrm{C}_{14} \mathrm{C}_{1} \mathrm{im}\right] \mathrm{Cl}}\end{array}$ & Surfactant & $\begin{array}{c}\text { Lidocaine } \\
\text { hydrochloride }\end{array}$ & [197] \\
\hline Microemulsion & $\begin{array}{c}{\left[\mathrm{C}_{6} \mathrm{C}_{1} \mathrm{im}\right] \mathrm{Cl}} \\
{\left[\mathrm{C}_{4} \mathrm{C}_{1} \text { im }\right]\left[\mathrm{PF}_{6}\right]}\end{array}$ & Aqueous/Oil phase & $\begin{array}{l}\text { Reichardt's dye } \\
\text { (drug model) }\end{array}$ & [29] \\
\hline Microemulsion & {$\left[\mathrm{C}_{4} \mathrm{C}_{1} \mathrm{im}\right]\left[\mathrm{PF}_{6}\right]$} & Oil phase & Etodolac & [79] \\
\hline Microemulsion & {$\left[\mathrm{C}_{1} \mathrm{C}_{1} \mathrm{im}\right]\left[\left(\mathrm{CH}_{3} \mathrm{O}\right)_{2} \mathrm{PO}_{2}\right]$} & Aqueous phase & Acyclovir & [198] \\
\hline Microemulsion & $\begin{array}{c}\text { [Ch][formate] } \\
{[\text { Ch][lactate] }} \\
{[\text { Ch][propionate }]} \\
{[\text { Ch][oleate] }}\end{array}$ & $\begin{array}{c}\text { Non-aqueous } \\
\text { phase; Surfactant in } \\
\text { oil phase }\end{array}$ & Acyclovir & [199] \\
\hline Microemulsion & {$\left[\mathrm{C}_{1} \mathrm{C}_{1} \mathrm{im}\right]\left[\left(\mathrm{CH}_{3} \mathrm{O}\right)_{2} \mathrm{PO}_{2}\right]$} & Aqueous phase & Methotrexate & [200] \\
\hline Microemulsion & $\begin{array}{c}{\left[\mathrm{C}_{2} \mathrm{OHC}_{1}\right] \mathrm{Cl}} \\
{\left[\mathrm{C}_{1} \mathrm{C}_{1} \mathrm{im}\right]\left[\mathrm{C}_{12} \mathrm{SO}_{3}\right]}\end{array}$ & $\begin{array}{l}\text { Aqueous phase; } \\
\text { Surfactant phase }\end{array}$ & Dencichine & [201] \\
\hline $\begin{array}{l}\text { Bacterial } \\
\text { nanocellulose } \\
\text { membranes }\end{array}$ & $\begin{array}{l}{[\mathrm{Ch}][\mathrm{Caf}]} \\
{[\mathrm{Ch}][\mathrm{Gal}]}\end{array}$ & API & $\begin{array}{l}\text { Caffeic acid } \\
\text { Gallic acid }\end{array}$ & [202] \\
\hline $\begin{array}{c}\text { Bacterial } \\
\text { nanocellulose } \\
\text { membranes }\end{array}$ & $\begin{array}{c}{[\mathrm{Ch}][\mathrm{Ibu}]} \\
{[\mathrm{Ch}][\mathrm{Nap}]} \\
{[\mathrm{Ch}][\text { Ket }]}\end{array}$ & API & $\begin{array}{l}\text { Ibuprofen } \\
\text { Naproxen } \\
\text { Ketoprofen }\end{array}$ & [203] \\
\hline $\begin{array}{c}\text { Bacterial } \\
\text { nanocellulose } \\
\text { membranes }\end{array}$ & $\begin{array}{l}{[\mathrm{Ch}]\left[\mathrm{B}_{3}\right]} \\
{[\mathrm{Ch}]\left[\mathrm{B}_{5}\right]} \\
{[\mathrm{Ch}]\left[\mathrm{B}_{6}\right]}\end{array}$ & API & $\begin{array}{c}\text { Niacin } \\
\text { Pantothenic acid } \\
\text { Pyridoxine }\end{array}$ & [204] \\
\hline Patch & [Lid][Eto] & Dual API & $\begin{array}{l}\text { Lidocaine } \\
\text { Etodolac }\end{array}$ & [205] \\
\hline $\begin{array}{l}\text { Polyvinvylidene } \\
\text { fluoride membrane }\end{array}$ & $\begin{array}{c}\text { [Lid][Nap] } \\
{[\mathrm{Lid}][\mathrm{Ibu}]} \\
{[\text { Lid][Dicl] }}\end{array}$ & Dual API & $\begin{array}{l}\text { Naproxen } \\
\text { Ibuprofen } \\
\text { Diclofenac }\end{array}$ & [206] \\
\hline $\begin{array}{c}\text { PLGA } \\
\text { nanoparticles }\end{array}$ & $\begin{array}{l}{[\mathrm{Ch}][\mathrm{Phe}]} \\
{[\mathrm{Ch}][\mathrm{Glu}]}\end{array}$ & API solubilization & Rutin & [207] \\
\hline $\begin{array}{l}\text { Permeation } \\
\text { enhancers }\end{array}$ & $\begin{array}{c}{\left[\mathrm{C}_{8} \mathrm{im}\right] \mathrm{Cl}} \\
{\left[\mathrm{C}_{1} \mathrm{C}_{8} \mathrm{im}\right] \mathrm{Cl}} \\
{\left[\mathrm{C}_{1} \mathrm{C}_{1} \mathrm{C}_{8} \mathrm{im}\right] \mathrm{Cl}}\end{array}$ & $\begin{array}{l}\text { Membrane } \\
\text { disruption }\end{array}$ & Testosterone & [208] \\
\hline $\begin{array}{l}\text { Permeation } \\
\text { enhancers }\end{array}$ & {$[$ ProOEt] $][\mathrm{Ibu}]$} & API & Ibuprofen & [209] \\
\hline $\begin{array}{c}\text { Permeation } \\
\text { enhancers }\end{array}$ & $\begin{array}{c}{\left[\mathrm{mPEG}_{3} \mathrm{~N}_{444}\right][\mathrm{Sal}]} \\
{\left[\mathrm{HN}_{444}\right][\mathrm{Sal}]} \\
{[\mathrm{Ch}][\mathrm{Sal}]} \\
{\left[\mathrm{C}_{1} \text { Pyrr }\right][\mathrm{Sal}]}\end{array}$ & API & Salicylic acid & [210] \\
\hline $\begin{array}{l}\text { Permeation } \\
\text { enhancers }\end{array}$ & {$[\mathrm{Ch}]\left[\right.$ geranate $\left._{2}(\mathrm{H})\right]$} & API & Geranic acid & [211] \\
\hline
\end{tabular}

The design of IL-excipient with tunable lipophilicity/hydrophilicity character is advantageous, especially when used as a solubility-enhancing agent for complex amphiphilic APIs, like amphotericin 
B and itraconazole, which are antifungal drugs [76]. Mahajan et al. [196] studied the performance of the SAIL 1-methyl-3-tetradecylimidazolium bromide $\left(\left[\mathrm{C}_{14} \mathrm{C}_{1} \mathrm{im}\right] \mathrm{Br}\right)$ as a drug carrier, and then compared it to a conventional cationic surfactant tetradecyltrimethylammonium bromide (TTAB). $\left[\mathrm{C}_{14} \mathrm{C}_{1} \mathrm{im}\right] \mathrm{Br}$ revealed not only superior surface activity, but also acts as better drug carrier of APIs, namely dopamine hydrochloride and acetylcholine chloride, than the traditional TTAB. Further, Sanan et al. [87] established the effect of the aggregate morphology and dilution on the micellar transition of $\left[\mathrm{C}_{12} \mathrm{C}_{1} \mathrm{im}\right] \mathrm{Cl}$ and ibuprofen mixtures. The transition is driven by the release of the API from the mixed micelles due to the solubility disparity between both components. Similar SAILs, $\left[\mathrm{C}_{12} \mathrm{C}_{1} \mathrm{im}\right] \mathrm{Cl}$ and 1-methyl-3-tetradecylimidazolium chloride $\left(\left[\mathrm{C}_{14} \mathrm{C}_{1} \mathrm{im}\right] \mathrm{Cl}\right)$ have shown capability to form aggregates with lidocaine hydrochloride, improving the drug's dissolution into aqueous media [197]. Furthermore, the reported thermal stability of nonaqueous IL microemulsions (up to $150{ }^{\circ} \mathrm{C}$ ) was shown to be compatible with sterilization processes, an advantage over conventional formulations [212]. All of the described works envisioned the application of the studied emulsions in transdermal and topical drug delivery; however, permeation studies on skin models were not conducted for evaluating the ability of these systems to improve dermal delivery.

The influence of imidazolium-based ILs on the properties and stability of oil-in-water (W/O) and water-in-oil (O/W) emulsions was investigated by Dobler et al. [29] using a fluorescent probe, namely Reichardt's dye, as a drug model. A hydrophilic IL, 1-hexyl-3-methylimidazolium chloride $\left(\left[\mathrm{C}_{6} \mathrm{C}_{1} \mathrm{im}\right] \mathrm{Cl}\right)$, and a hydrophobic $\mathrm{IL},\left[\mathrm{C}_{4} \mathrm{C}_{1} \mathrm{im}\right]\left[\mathrm{PF}_{6}\right]$, were incorporated as water and oil phase components, respectively, resulting in stable formulations. Skin permeation across pig's ear skin was studied in vitro on Franz glass diffusion cells. A permeation enhancement was observed when using these formulations due to the disruption of the lipidic bilayer packing by the ILs used. These ILs present antimicrobial activity and preservative efficacy within these formulations, being possible to fulfil the requirements as novel preservatives. Similar ILs where studied for an IL/W microemulsion designed for etodolac's topical delivery [79], which is used in the treatment of inflammation and pain that are associated with rheumatoid arthritis and osteoarthritis [213]. The prepared microemulsion was based on $\left[\mathrm{C}_{4} \mathrm{C}_{1} \mathrm{im}\right]\left[\mathrm{PF}_{6}\right]$, Tween 80 as surfactant, and ethanol as co-surfactant. The IL/W-based formulation was able to efficiently enhance the solubility and ex-vivo permeability of the API for its transdermal delivery [79]. Skin penetration was evaluated while using the fluorescent dyes sodium fluorescein (a hydrophilic fluorescence marker) and Nile red (lipophilic), which in the presence of ILs revealed a more efficient penetration into the deeper skin layers. Likewise, in-vivo pharmacodynamic evaluation showed improved anti-arthritic and anti-inflammatory activities in comparison to $\mathrm{O} / \mathrm{W}$ microemulsions and marketed etodolac's formulations, exhibiting the high capability of these formulationsin order to enhance the API's performance.

The first IL-based microemulsion reported for transdermal delivery aimed to improve membrane transport of a sparingly soluble API, namely the antiviral drug acyclovir [198]. In this work, a blend of two nontoxic surfactants, Tween-80 and Span-20, was used in combination with imidazolium-based ILs to form stabilized IL droplets. In the referred microemulsion, the external phase (oil phase) is constituted by isopropyl myristate (Figure 19). Among the investigated ILs, dimethylimidazolium dimethylphosphate $\left(\left[\mathrm{C}_{1} \mathrm{C}_{1} \mathrm{im}\right]\left[\left(\mathrm{CH}_{3} \mathrm{O}\right)_{2} \mathrm{PO}_{2}\right]\right)$ presented superior ability to dissolve the selected API and form more stable droplets in the formulation. This improvement was justified by the hydrogen bonding interactions between the polar groups of acyclovir and the IL anions. The in vitro study across Yucatan micropig porcine skin (performed on Franz diffusion cells), allowed for verifying an increase in acyclovir's skin permeability of several orders of magnitude, as well as the API's transdermal permeation when using the IL/O system as drug carrier. 


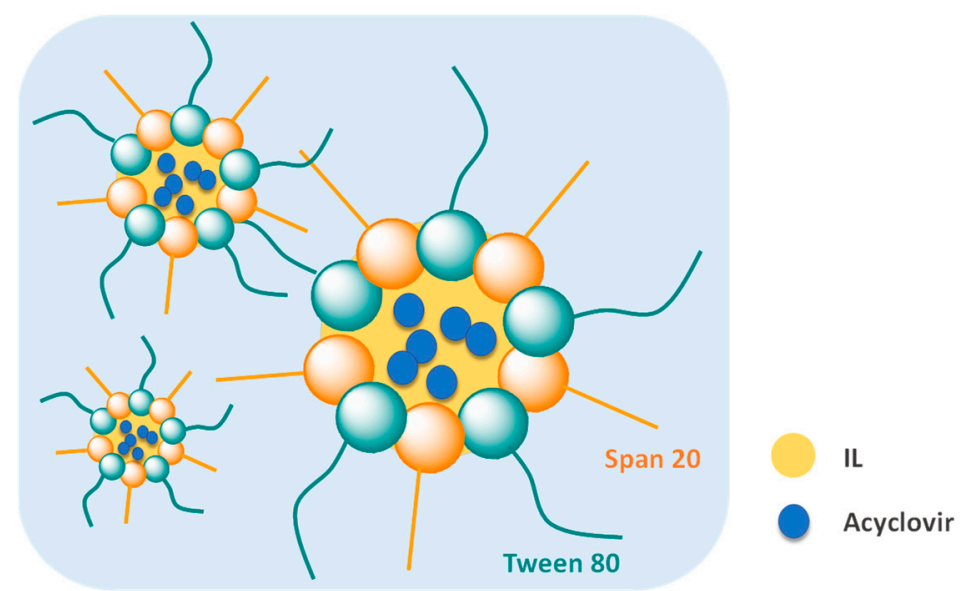

Figure 19. IL-in-oil microemulsions based on $\left[\mathrm{C}_{1} \mathrm{C}_{1} \mathrm{im}\right]\left[(\mathrm{MeO})_{2} \mathrm{PO}_{2}\right]$ as drug carriers of acyclovir proposed in [198].

Cholinium-based ILs comprising anions that were derived from carboxylic acids were also used in IL/O microemulsions to increase the transdermal delivery of acyclovir, as non-toxic and non-irritating alternatives [199]. Hydrophilic ILs (cholinium formate, cholinium lactate and cholinium propionate) were used as the non-aqueous polar phase and a surface-active IL (cholinium oleate) as the surfactant in combination with a co-surfactant, Span 20, in a continuous oil phase. An enhancement in skin permeation due to the modification and disruption of the regular arrangement of the corneocytes of the stratum corneum was observed, and related to the ionic character of the IL. Cytotoxicity tests revealed a high cell survival rate $(>90 \%)$ in comparison with Dulbecco's phosphate-buffered saline solution, highlighting the potential of these formulations as low toxic drug carriers. Similarly, the IL $\left[\mathrm{C}_{1} \mathrm{C}_{1} \mathrm{im}\right]\left[\left(\mathrm{CH}_{3} \mathrm{O}\right)_{2} \mathrm{PO}_{2}\right]$ was used in an IL/O microemulsion in order to improve the transdermal delivery of the sparingly soluble chemotherapeutic methotrexate [200]. In this work, drug permeation across a similar skin model to the previous enounced was evaluated, revealing a significant transdermal permeation of the API in comparison to the application of other typical $\mathrm{O} / \mathrm{W}$ and $\mathrm{O} / \mathrm{W}$ formulations. IL-based microemulsions were also developed for enhancing the skin permeation of dencichine, a haemostatic agent [201]. An initial screening with fourteen imidazolium-based ILs was performed, from which 1-(2-hydroxyethyl)-3-methylimidazolium chloride $\left(\left[\mathrm{C}_{2} \mathrm{OHC} \mathrm{C}_{1} \mathrm{im}\right] \mathrm{Cl}\right)$ and dimethylimidazolium dodecanesulfate $\left(\left[\mathrm{C}_{1} \mathrm{C}_{1} \mathrm{im}\right]\left[\mathrm{C}_{12} \mathrm{SO}_{3}\right]\right)$ were selected and incorporated into the aqueous and surfactant phases, respectively, with an enhancement on skin permeation of approximately 10-fold. However, despite that the in vivo pharmacodynamic activity was found to be in good correlation with the in vitro permeability, hemostatic activity studies revealed no statistic difference between these formulations and dencichine aqueous solution.

The application of API-ILs represents an advantage in the design of topical delivery systems due not only to the possibility of providing new biologically active combinations and enhancing the therapeutic action, but also due to the possibility to enhance the transdermal delivery of pharmaceuticals. The use of API-ILs might allow significant developments in delivery systems, since these can be designed to self-aggregate, trapping the drug in a micelle, or to display tunable hydrophilic-lipophilic balance to potentiate the drugs permeation. In addition to the incorporation of ILs into microemulsions as transdermal drug delivery systems, the combination of API-ILs with polymers and biopolymers has been recently investigated. Morais et al. [202] synthesized cholinium-based ILs paired with anions that are derived from phenolic acids, namely gallic, caffeic, and ellagic acids. These ILs were incorporated into bacterial nanocellulose membranes (BC). The developed drug delivery systems showed superior antioxidant activity to the starting materials, and with controlled diffusion of the active compounds from the wet membranes. The obtained results demonstrated that the dissolution profiles were essentially governed by the solubility of the ILs rather by their interactions with the BC nanofibrils. For both $\mathrm{BC}-[\mathrm{Ch}][\mathrm{Caf}]$ and $\mathrm{BC}-[\mathrm{Ch}][\mathrm{Gal}]$ wet membranes, approximately $70 \%$ dissolution of the IL content in 
membranes was reached after $6 \mathrm{~h}$. Regarding the cytotoxicity of these delivery systems, it was shown that they do not cause any decrease in cell viability at the concentrations investigated. Additionally, the exposure of cells to BC-ILs membranes significantly decreases the LPS-induced NO production, indicating a relevant anti-inflammatory and antioxidant potential (Figure 20). The permeation flux of both API-ILs from the BC membranes was assessed in vitro in human epidermal skin, at body's temperature, on Franz diffusion cells. The skin permeation assay showed the possibility to obtain a slow and sustained release profile while using these drug delivery systems over $5 \mathrm{~h}$ of administration.

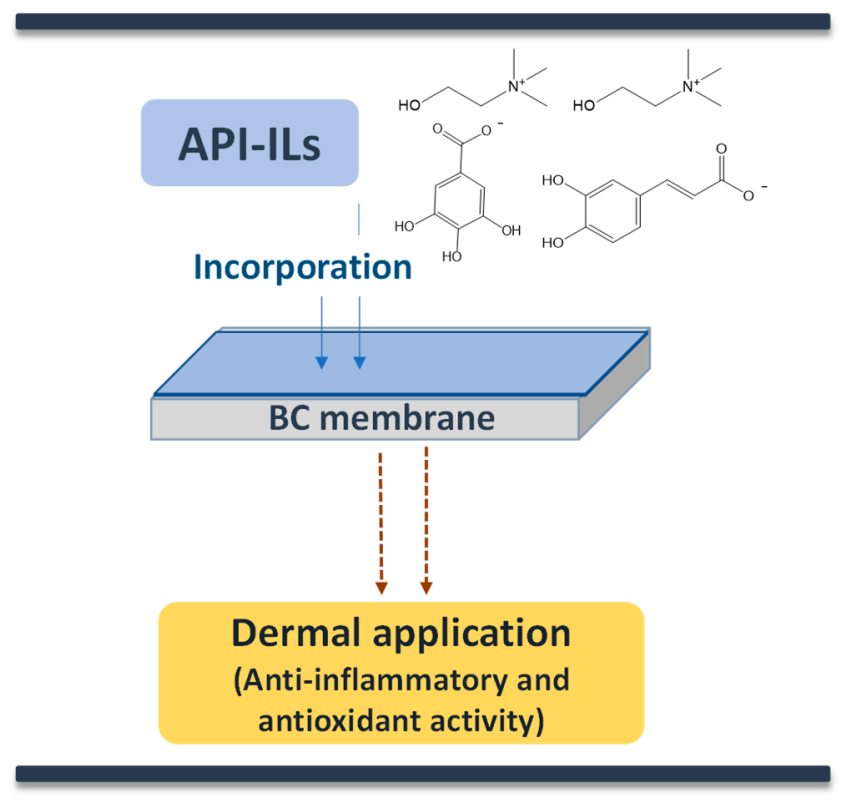

Figure 20. Illustration of BC-IL membranes' with antioxidant and anti-inflammatory action for dermal application proposed in [202].

Chantereau et al. [203] later incorporated NSAID-based ILs also into BC membranes envisaging their use in transdermal drug delivery systems. These [Ch][NSAID] ILs allowed for increasing up to 100 -fold the solubility of the respective NSAID precursors (ibuprofen, naproxen and ketoprofen) in aqueous media. The impregnation of BC membranes with these ILs also increased, by 18 to 26 -fold, the rehydration ability of the membranes, allowing their potential application on the absorption of exudates. Giving the obtained results, the developed systems are promising alternatives for the design of transdermal patches for anti-inflammatory drugs delivery. More recently, the same researchers investigated the possibility to develop membranes that were loaded with vitamin B-based ILs for dermal applications [204]. Three ILs, namely cholinium nicotinate ([Ch][B3]), cholinium pantothenate ([Ch][B5]), and cholinium pyridoxylate ([Ch][B6]), were also synthesized and incorporated in BC, resulting in more thermally stable forms for the vitamins without toxicity associated for skin cells. The solubility of these ILs in aqueous media was higher than their vitamin precursors, with solubility enhancements up to 30.6-fold. The increase on the re-hydration ability of BC-IL membranes, allowed for obtaining a complete and faster release profile of ILs in aqueous media than the release of the precursor vitamins. These ILs also displayed a plasticizing effect on the BC membranes, favoring the application of these systems on irregular skin regions.

The IL [Lid][Eto] has been incorporated into a topical delivery system [205]. The patch (Etoreat), studied by IL Pharma Inc. (MEDRx, Kagawa, Japan), contains the only API-IL that has reached clinical trials. This API-IL based patch for alleviating pain caused by inflammation was tested for the treatment of ankle sprains and low back pain, due to its enhanced skin absorption. However, due to the lack of statistic significant results between Etoreat and placebo administration, its further stage of development was suspended. In addition to this example, other dual-active API-ILs have been considered for improving transdermal delivery of analgesic and anti-inflammatory APIs in wound 
healing [206]. Lidocainium naproxen ([Lid][Nap]), [Lid][Ibu], and lidocainium diclofenac ([Lid][Dicl]) were synthesized, which resulted in liquid mixtures at room temperature. These API-ILs displayed significantly higher solubility in aqueous media than the parent APIs, except for [Lid][Dicl]. These ILs were then incorporated into a bilayer wound dressing, which was composed of a hydrophobic polyvinylidene fluoride membrane that acts as a drug reservoir and a biocompatible hyaluronic acid layer. The assessment of anti-inflammatory activity revealed similar therapeutic efficacy when compared with the original APIs, through the inhibition of LPS-induced production of nitric oxide and prostaglandin E2 by macrophages. These systems enable higher permeation of both APIs in API-IL form than the parent APIs without compromising the fibroblasts proliferation. Furthermore, the hyaluronic acid that was used in these systems played a protective effect on the cytotoxicity since it minimized the potential antiproliferative effects attributable to the APIs, allowing the simultaneous delivery of anti-inflammatory and analgesic drugs to the injured area without compromising skin regeneration.

ILs were also studied as solubility enhancers in conjugation with polymers as novel nanoparticle hybrid systems for the delivery of poorly water-soluble drugs [207]. Two amino-acid-based ILs, namely cholinium phenylalanine ([Ch][Phe]) and cholinium L-glutamine ([Ch][Glu]), were used in blends with poly-(lactic-co-glycolic acid) (PLGA) that was loaded with rutin, which shows antidiabetic, antihypertensive, and antilipidemic activities. These systems allowed for a drug loading capacity higher than $50 \%$ for both ILs, and up to $76 \%$ for [Ch][Phe] while using only $0.2 \%(\mathrm{v} / \mathrm{v})$ of IL. The systems provided a sustained release of rutin, with $85 \%$ released after $72 \mathrm{~h}$, without toxicity to associated skin cells.

Zhang et al. [208] used testosterone as a model drug to investigate the transdermal delivery enhancement provided by twenty imidazolium-based ILs. The conducted study revealed an interdependence between the API permeation enhancement and the structure and composition of the IL. ILs with longer alkyl side chains (N-octylimidazolium chloride $\left.\left(\left[\mathrm{C}_{8} \mathrm{im}\right] \mathrm{Cl}\right)\right)$, 1-octyl-3-methyl imidazolium chloride $\left(\left[\mathrm{C}_{1} \mathrm{C}_{8} \mathrm{im}\right] \mathrm{Cl}\right)$ and 1-octyl-2,3-dimethyl imidazolium chloride $\left.\left(\left[\mathrm{C}_{1} \mathrm{C}_{1} \mathrm{C}_{8} \mathrm{im}\right] \mathrm{Cl}\right)\right)$ led to higher transdermal delivery enhancements. Additionally, the number of alkyl groups at the cation, as well as the anionic constitution, was demonstrated to have an impact on the drug penetration through skin. However, this trend follows the cytotoxicity profile and disruptive character of ILs with longer alkyl chain lengths, in which the most cytotoxic compromise in a larger extent the structural integrity of biological membranes. The enhancement of API permeation was attributed to the change in skin permeability, rather than the change in drug concentration. Evaluations by ATR-FTIR and atomic force microscopy of skin membrane indicated that the ILs can disrupt the regular and compact arrangements of the corneocytes, altering the skin structure to a more permeable state. Although this mechanism was not observed for all ILs, further information must be gathered in order to properly understand the process of the interaction between these ILs and skin cells to better design IL-based permeation enhancers. This subject has been addressed by Jing and coworkers [214], which confirmed that amphiphilic ILs could disrupt the lipid bilayer by IL insertion, endcapping the hydrophobic edge of the lipid bilayer, and eventually disintegrating the membrane (Figure 21). This destabilization is directly related with the IL concentration, the length of the IL cation alkyl chain, and anion hydrophobicity, which are also correlated with the IL cytotoxicity. Hydrophilic and hydrophobic ILs seem to act on the APIs transportation through the stratum corneum by different mechanisms [215]. While hydrophilic ILs, particularly imidazolium-based ones, fluidize the cell membrane in order to create pathways for the diffusion of molecules (paracellular transport), hydrophobic ILs, on the contrary, modify the APIs partitioning by providing channels through biological membranes (transcellular transport) [211,216]. 


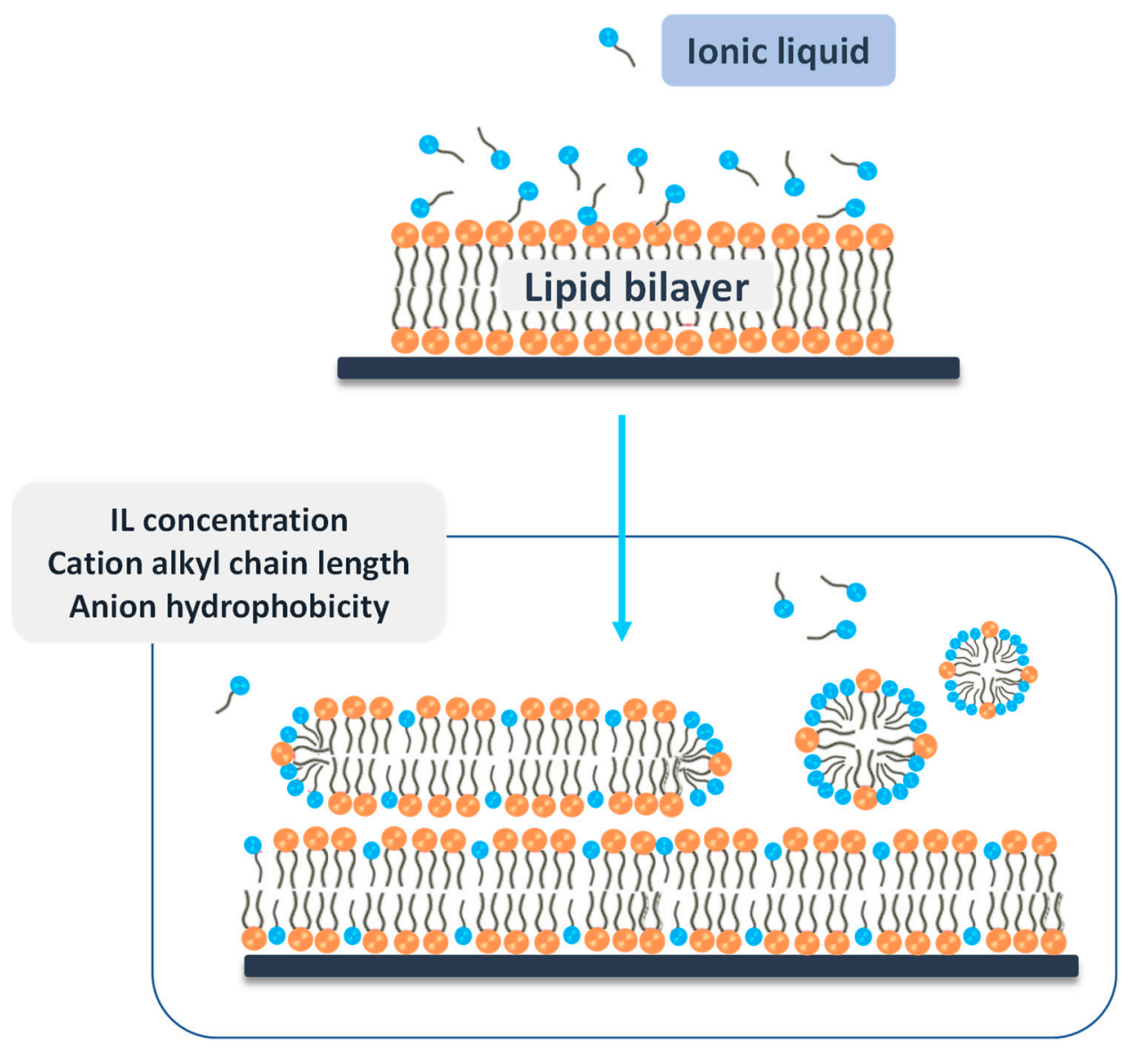

Figure 21. Schematic representation of IL effect and insertion into the lipid bilayer proposed in [214].

Different ILs that were based on carboxylic acids [217], aliphatic amines, amino acids [209,218] and polyethylene glycol derivatives [210] have been also studied as alternative permeation enhancers. An amino acid ester (proline ethylester) was used in combination with ibuprofen as a novel API-IL (proline ethylester ibuprofenate ([ProOEt][Ibu])) to improve transdermal delivery [209]. An approximately 10 -fold enhancement in the cumulative amount of API was achieved at $96 \mathrm{~h}$ when compared with the control sample while using [ProOEt][Ibu].

ILs generated by a neutralization reaction between aliphatic carboxylic acids (octanoic acid or isostearic acid) and aliphatic amines (diisopropanolamine or triisopropanolamine) were proposed in order to study the mechanism of permeability enhancement of model hydrophilic and hydrophobic APIs [217]. The model formulation containing these ILs exhibited a more pronounced permeation enhancement under acidic excess conditions than under neutral environments. Despite that these formulations displayed superior controlled release for the hydrophilic model API, the mechanism that was responsible for this behavior was not further explored. Later, the difference between API-ILs transport across membranes and the respective commercial sodium salts was studied for salicylic acid [210]. The membrane transport ability and rate of the ILs triethylene glycol monomethyl ether tributylammonium salicylate $\left(\left[\mathrm{mPEG}_{3} \mathrm{~N}_{444}\right][\mathrm{Sal}]\right)$, tributylammonium salicylate ([HN 444$\left.][\mathrm{Sal}]\right)$, cholinium salicylate ([Ch][Sal]), and 1-methylpyrrolidiniumsalicylate $\left(\left[\mathrm{C}_{1} \mathrm{Pyrr}\right][\mathrm{Sal}]\right)$, as well as the respective sodium salt ( $\mathrm{Na}[\mathrm{Sal}]$ ) and neutral form (HSal), was evaluated while using a Franz diffusion cell system. The cation influence in the efficiency of the membrane transport was also highlighted, as [mPEG $\left.\mathrm{N}_{444}\right][\mathrm{Sal}]$ showed a transport enhancement by $\sim 2.5$-fold in comparison to PEG-free cations.

Zakrewsky et al. [211] investigated the application of ILs in a multiple context for drug delivery, where the IL [Ch][geranate $\left.{ }_{2}(\mathrm{H})\right]$ was used not only to improve transdermal delivery, but also to tackle skin biofilm-protected microbial infections. This IL allowed to increase by 16 -fold the delivery 
of a model antibiotic, cefadroxil, into deeper skin layers when compared to its aqueous solution. The potential clinical efficacy of the IL formulation was accessed in vivo based on its antimicrobial activity against biofilm-infected wounds. [Ch][geranate $\left.{ }_{2}(\mathrm{H})\right]$ enabled reducing Pseudomonas aeruginosa and Salmonella enterica bacterial viability by $>95 \%$ after $2 \mathrm{~h}$. The IL ability to disrupt the bacterial biofilm allowed for delivering the antibiotic with increased efficacy, improving the pathogens susceptibility to the antibiotic.

For topical and transdermal, as it happens for intravenous and oral delivery systems, it is important to understand and better evaluate the activity, in vivo behavior, and safety to achieve more effective and less toxic options with a desired drug activity. Although an increase in in vivo results on the administration of IL-based formulations has been observed, the available information is still scarce. The evaluation of pharmacokinetic and pharmacodynamic parameters as well as the therapeutic efficacy must be encouraged to be pursued to provide missing insights on this strategy. In the future, other IL-(bio)polymer combinations are expected and the understanding of their mechanistic levels should be encouraged to be unveiled. The understanding of these therapeutic options and the increase in the research of ILs in the nanoparticle field will allow for developing targeted-specific drug delivery systems that will reduce drug side-effects and fluctuation in circulating drug levels, optimizing the treatment efficacy. For this, ILs use in drug delivery should be further explored from the use of imidazolium-based ILs to options with low toxicity and known cytotoxicity profiles. Additionally, it is expected an increase in the studies comprising IL-(bio)polymer-based systems with stimulus-responsiveness, and investigation on their ability to protect drugs from degradation while providing controlled drug release.

\section{Conclusions and Future Perspectives}

Organic volatile solvents have been a main choice in the pharmaceutical industry, particularly in the reaction and purification steps, but they still raise concerns on the contamination of the final product and on the related environmental and health impacts. To overcome some of these drawbacks, ILs have been investigated as solvents, reagents, or catalysts in the synthesis of APIs and applied in the crystallization process of drugs. Still, additional studies should focus on the development of more sustainable strategies to remove ILs after the APIs synthesis. A careful monitorization of these contaminants in the final product and study of their impact in the drug's performance and toxicity must be taking into consideration. Furthermore, the use of solvents and co-solvents, like ethanol, methanol or DMSO, hydrotropes, and surface-active agents, to improve the API's solubility in pharmaceutical formulations has been challenged by applying ILs to this purpose. ILs have been shown to allow the aqueous solubility improvement of APIs from distinct pharmacological classes in several orders of magnitude (to be best of our knowledge and up to date, up to $5.6 \times 10^{6}$-fold), standing as competitive alternatives to organic solvents. However, these formulations require a more comprehensive study in what concerns the stability, absorption and bioavailability of APIs. Furthermore, more recent studies employing aqueous solutions of ILs instead of pure ILs can be the key for their use and acceptance by the pharmaceutical field.

Because the APIs' solubility in aqueous solution and bioavailability can be limited by polymorphism, controlling this process is essential for obtaining a stable and high-quality drug product. The study of ILs in the crystallization process of APIs has enabled the possibility to design new polymorphs, with higher thermal stability, to select the crystal form and habit, and even isolate and purify the correct API polymorph through crystallization. To expand the research on this topic, it is still mandatory to comprehensively understand the IL-API interactions that drive the formation of specific polymorphic forms and habits. The use of computational tools can be helpful in designing ILs in such a way. Furthermore, as it happens with the APIs synthesis, the research on effective separation methods and the limitation of the IL contamination in the final product are highly demanding issues.

ILs can be designed to present biological activities due to the broad number of anion-cation combinations. In this sense, ILs have been successfully studied regarding their antimicrobial, 
antioxidant, and anti-tumoral activities. So far, IL activities have been mainly studied in vitro and have focused on imidazolium-based ILs. To expand this field of research, it is necessary to unveil the mechanisms of interaction between the IL and biological membranes and, consequently, establish a correlation with their biological activities, and in which computational tools may also play a crucial role. The possibility to manipulate the cation-anion combinations also allowed for obtaining new drugs with desired chemical and biological properties, while avoiding polymorphism concerns. API-ILs have provided double action in therapeutic formulations for topical and transdermal delivery, namely by providing the API facilitating its permeation through biological membranes. In this field, API-ILs stand as novel liquid forms that can be designed with a specific or dual pharmacological action, obtained by incorporating APIs as IL ions, using oligomeric ions or by applying a prodrug strategy. However, in this field, only few works conducted bioavailability assays, however allowing to demonstrate the increase in the API's bioavailability and the therapeutic efficacy of these novel drugs. Because API-ILs can present contrastive, enhanced or even dual effect when compared to the initial precursors, in vivo pharmacokinetic and pharmacodynamic tests are mandatory in understanding the pathways that are involved in their absorption, metabolism, and routes of elimination. These assays are required to enable the acceptance of these new drugs by the pharmaceutical industry, favoring the establishment of guidelines for their development and research. Until their implementation, additional obstacles are expected to be faced. The pharmaceutical industry is majorly prepared in order to produce solid APIs; thus, the scale-up implementation might be a lengthy process. Years of routinely working with solid forms of APIs might make the development of standardized procedures for the liquid drugs' purification difficult.

The flexibility of ILs allowed for the development of tailored (bio)polymer drug delivery systems as well, both due to their polymerizable character and polymer solvation ability. Because ILs can enhance the APIs solubility in aqueous media, they have successfully allowed the incorporation and delivery of several low-water soluble drugs, enabling the consideration of new administration routes. However, the lack of more complete studies on this topic that can assist the conscious development of more effective drug delivery options still confines their use and commercialization. Advances in this area should comprise integrated studies where the IL can be designed with a specific biological activity and/or therapeutic action. These designed ILs can simultaneously have a specific role in the development of the drug delivery systems. In this line, stimuli-responsive drug delivery systems, promoted by the IL and/or by the polymer, also are of particular relevance.

Overall, ILs have potential to overcome solubility, bioavailability, permeation, polymorphism, and stability concerns that are associated to solid-state pharmaceuticals. Furthermore, ILs are promising alternatives to volatile organic solvents when applied as solvents, reagents, and anti-solvents in the synthesis and crystallization of active pharmaceutical ingredients (APIs). More recent studies demonstrated their potential to improve the performance of drug-delivery-based systems. The results and advances herein revised support the multiple roles of ILs in the pharmaceutical field, encouraging new ways of taking advantage of their unique properties.

Author Contributions: S.N.P., Writing and Original Draft Preparation; M.G.F., Conceptualization and Review-Editing and Supervision; C.S.R.F. and A.J.D.S., Review-Editing and Supervision. All authors have read and agreed to the published version of the manuscript.

Funding: This work was developed within the scope of the project CICECO-Aveiro Institute of Materials, UIDB/50011/2020 \& UIDP/50011/2020, financed by national funds through the FCT/MEC and when appropriate co-financed by FEDER under the PT2020 Partnership Agreement. This work was financially supported by the project IonCytDevice (POCI-01-0145-FEDER-031106, PTCD/BTA-BTA/31106/2017) funded by FEDER, through COMPETE2020-Programa Operacional Competitividade e Internacionalização (POCI), and by national funds (OE), through FCT/MCTE). S. N. Pedro acknowledges the PhD grant SFRH/BD/132584/2017.

Conflicts of Interest: The authors declare no conflict of interests. 
Abbreviations

\begin{tabular}{|c|c|}
\hline \multicolumn{2}{|l|}{ General } \\
\hline 3-СРP & 3-chloro-1-phenyl-1-propanone \\
\hline AGB-ILs & Ionic liquids analogues of glycine-betaine \\
\hline APIs & Active pharmaceutical ingredients \\
\hline API-ILs & Ionic liquid comprising active pharmaceutical ingredients \\
\hline $\mathrm{BC}$ & Bacterial cellulose \\
\hline Cellulose-g-PLLA & Cellulose-graft-poly (L-lactide) \\
\hline CrEL & Ethoxylated castor oil \\
\hline DHQ & 2,3-Dihydroquinazolin-4(1H)-one \\
\hline DMAP & 4-Dimethylaminopyridine \\
\hline DMF & Dimethylformamide \\
\hline DMSO & Dimethyl sulfoxide \\
\hline $\mathrm{DPPH}$ & 2,2-diphenyl-1-picrylhydrazyl \\
\hline FTIR-ATR & Fourier transform infrared spectroscopy-attenuated total reflectance \\
\hline HSal & Salicylic acid (neutral form) \\
\hline $\mathrm{IC}_{50}$ & Half maximal inhibitory concentration \\
\hline IL & Ionic liquid \\
\hline $\mathrm{IL} / \mathrm{O}$ & IL-in-oil \\
\hline $\mathrm{IL} / \mathrm{w}$ & IL-in-water \\
\hline LCOS & Linoleic acid-grafted chitosan oligosaccharide \\
\hline LFER & Linear free energy relationship \\
\hline MIC & Minimal inhibitory concentration \\
\hline MBC & Minimal biocidal concentration \\
\hline NSAID & Non-steroidal anti-inflammatory \\
\hline$[\mathrm{Na}][\mathrm{Sal}]$ & Sodium salicylate \\
\hline $\mathrm{O} / \mathrm{IL}$ & Oil-in-IL \\
\hline PC12 & Pheochromocytoma cells \\
\hline PLGA & Poly (lactic-co-glycolic acid) \\
\hline QSAR & Quantitative structure-activity relationship \\
\hline SAIL & Surface-active ionic liquid \\
\hline (S)-CPPO & (S)-3-chloro-1-phenyl-1-propanol \\
\hline SEDDs & Self-emulsifying drug delivery systems \\
\hline TTAB & Tetradecyltrimethylammonium bromide \\
\hline $\mathrm{W} / \mathrm{IL}$ & Water-in-IL \\
\hline \multicolumn{2}{|l|}{ Ionic Liquids } \\
\hline \multicolumn{2}{|l|}{ Ammonium } \\
\hline$\left[\mathrm{C}_{4} \mathrm{C}_{1} \mathrm{im}\right]\left[\mathrm{BF}_{4}\right]$ & 1-butyl-3-methylimidazolium tetrafluoroborate \\
\hline$\left[\left(\mathrm{C}_{4} \mathrm{C}_{1} \mathrm{C}_{1} \mathrm{~m}\right]\left[\mathrm{BF}_{4}\right]\right.$ & 1-butyl-2,3dimethylimidazolium tetrafluoroborate \\
\hline$\left[\mathrm{C}_{6} \mathrm{C}_{1} \mathrm{im}\right]\left[\mathrm{BF}_{4}\right]$ & 1-hexyl-3-methylimidazolium tetrafluoroborate \\
\hline$\left[\mathrm{C}_{8} \mathrm{C}_{1} \mathrm{im}\right]\left[\mathrm{BF}_{4}\right]$ & 1-octyl-3-methylimidazolium tetrafluoroborate \\
\hline \multicolumn{2}{|c|}{$\left[\left(\mathrm{CH}_{2} \mathrm{CH}=\mathrm{C}_{2}\right) \mathrm{C}_{2} \mathrm{~m}\right]\left[\mathrm{BF}_{4}\right]$ 1-allyl-3-ethylimidazolium tetrafluoroborate } \\
\hline$\left[\mathrm{C}_{4} \mathrm{C}_{1} \mathrm{im}\right] \mathrm{Br}$ & 1-butyl-3-methylimidazolium bromide \\
\hline$\left[\mathrm{C}_{14} \mathrm{C}_{1} \mathrm{im}\right] \mathrm{Br}$ & 1-methyl-3-tetradecylimidazolium bromide \\
\hline$\left[\mathrm{C}_{8} \mathrm{im}\right] \mathrm{Cl}$ & N-octylimidazolium chloride \\
\hline$\left[\mathrm{C}_{1} \mathrm{C}_{8} \mathrm{im}\right] \mathrm{Cl}$ & 1-dodecyl-3-methylimidazolium chloride \\
\hline$\left[\mathrm{C}_{1} \mathrm{C}_{1} \mathrm{C}_{8} \mathrm{im}\right] \mathrm{Cl}$ & 1-methyl-3-tetradecylimidazolium chloride \\
\hline$\left[\mathrm{C}_{6} \mathrm{C}_{1} \mathrm{im}\right] \mathrm{Cl}$ & 1-hexyl-3-methylimidazolium chloride \\
\hline$\left[\mathrm{C}_{8} \mathrm{C}_{1} \mathrm{im}\right] \mathrm{Cl}$ & 3-methyl-1-octylimidazolium chloride \\
\hline$\left[\mathrm{C}_{12} \mathrm{C}_{1} \mathrm{im}\right] \mathrm{Cl}$ & 1-hexadecyl-3-methylimidazolium chloride \\
\hline$\left[\mathrm{C}_{14} \mathrm{C}_{1} \mathrm{im}\right] \mathrm{Cl}$ & 1-octyl-3-methyl imidazolium chloride \\
\hline$\left[\left(\mathrm{CH}_{2} \mathrm{CH}=\mathrm{C}_{2}\right)\right] \mathrm{Cl}$ & 1-allyl-3-methylimidazolium chloride \\
\hline$\left[\mathrm{C}_{2} \mathrm{C}_{1} \mathrm{im}\right]\left[\mathrm{CH}_{3} \mathrm{COO}\right]$ & 1-ethyl-3-methylimidazolium acetate \\
\hline
\end{tabular}


$\left[\mathrm{C}_{2} \mathrm{C}_{1}\right.$ im $]\left[\mathrm{CH}_{3} \mathrm{OHPO}_{2}\right]$ 1-ethyl-3-methylimidazolium methylphosphonate

$\left[\mathrm{C}_{1} \mathrm{C}_{1} \mathrm{im}\right]\left[\left(\mathrm{CH}_{3} \mathrm{O}\right)_{2} \mathrm{PO}_{2}\right]$ Dimethylimidazolium dimethylphosphate

$\left[\mathrm{C}_{4} \mathrm{C}_{1}\right.$ im $]\left[\mathrm{C}_{8} \mathrm{OSO}_{3}\right]$ 1-butyl-3-methylimidazolium octylsulfate

$\left[\mathrm{C}_{1} \mathrm{C}_{1} \mathrm{im}\right]\left[\mathrm{C}_{12} \mathrm{SO}_{3}\right] \quad$ Dimethylimidazolium dodecanesulfate

$\left[\mathrm{C}_{2} \mathrm{C}_{1} \mathrm{im}\right]\left[\mathrm{EtSO}_{4}\right]$ 1-ethyl-3-methylimidazolium ethylsulfate

$\left[\mathrm{C}_{4} \mathrm{C}_{1}\right.$ im $]\left[\mathrm{N}(\mathrm{CN})_{2}\right]$ 1-butyl-3-methylimidazolium dicyanamide

$\left[\mathrm{C}_{2}\right]\left[\mathrm{NTf}_{2}\right]$

$\left[\mathrm{C}_{2} \mathrm{C}_{1} \mathrm{im}\right]\left[\mathrm{NTf}_{2}\right]$

$\left[\mathrm{C}_{4} \mathrm{C}_{1} \mathrm{im}\right]\left[\mathrm{NTf}_{2}\right]$

$\left[\mathrm{C}_{6} \mathrm{C}_{1} \mathrm{im}\right]\left[\mathrm{NTf}_{2}\right]$

$\left[\mathrm{C}_{10} \mathrm{C}_{1}\right.$ im] $\left[\mathrm{NTf}_{2}\right]$

$\left[\mathrm{C}_{2} \mathrm{C}_{1} \mathrm{im}\right]\left[\mathrm{CF}_{3} \mathrm{O}_{3} \mathrm{~S}\right]$

N-ethyl-2-hydroxy-N,N-dimethylethanammonium

bis(trifluoromethylsulfonyl)amide)

1-ethyl-3-methylimidazolium bis(trifluoromethanesulfonyl)imide

1-butyl-3-methylimidazolium bis(trifluoromethylsulfonyl)imide

1-hexyl-3-methylimidazolium bis(trifluoromethanesulfonyl)imide

1-decyl-3-methylimidazolium bis(trifluoromethanesulfonyl)imide

1-ethyl-3-methylimidazolium trifluoromethanesulfonate

$\left[\mathrm{C}_{4} \mathrm{C}_{1} \mathrm{im}\right]\left[\mathrm{CF}_{3} \mathrm{O}_{3} \mathrm{~S}\right]$

1-butyl-3-methylimidazolium trifluoromethanesulfonate

$\left[\mathrm{C}_{10} \mathrm{C}_{1} \mathrm{im}\right]\left[\mathrm{CF}_{3} \mathrm{O}_{3} \mathrm{~S}\right]$

1-decyl-3-methylimidazolium trifluoromethanesulfonate

$\left[\mathrm{C}_{4} \mathrm{C}_{1} \mathrm{im}\right]\left[\mathrm{PF}_{6}\right]$

$\left[\mathrm{C}_{6} \mathrm{C}_{1} \mathrm{im}\right]\left[\mathrm{PF}_{6}\right]$

$\left[\mathrm{C}_{8} \mathrm{C}_{1} \mathrm{im}\right]\left[\mathrm{PF}_{6}\right]$

$\left.\left[\mathrm{C}_{4} \mathrm{C}_{1} \mathrm{im}\right][\mathrm{SCN}]\right)$

$\left[\left(\mathrm{C}_{2}\right)_{3} \mathrm{NC}_{4}\right] \mathrm{Br}$

$\left[\mathrm{C}_{4} \mathrm{NH}_{3}\right]\left[\mathrm{CH}_{3} \mathrm{COO}\right]$

1-butyl-3-methylimidazolium hexafluorophosphate

1-hexyl-3-methylimidazolium hexafluorophosphate

1-octyl-3-methylimidazolium hexafluorophosphate

1-butyl-3-methylimidazolium thiocyanate

Triethyl[2-ethoxy-2-oxoethyl]ammonium bromide

$\mathrm{N}$-butylammonium acetate

$\left[\mathrm{C}_{6} \mathrm{NH}_{3}\right]\left[\mathrm{CH}_{3} \mathrm{COO}\right] \quad$ N-hexylammonium acetate

$\left[\mathrm{C}_{8} \mathrm{NH}_{3}\right]\left[\mathrm{CH}_{3} \mathrm{COO}\right]$

$\mathrm{N}$-octylammonium acetate

$\left[\mathrm{C}_{4} \mathrm{NH}_{3}\right.$ ][oleate]

[ $\mathrm{C}_{6} \mathrm{NH}_{3}$ ][oleate]

[ $\mathrm{C}_{8} \mathrm{NH}_{3}$ ][oleate]

$\left[\left(\mathrm{C}_{1} \mathrm{OC}_{2}\right) \mathrm{C}_{1} \mathrm{im}\right][\mathrm{MsO}]$

$\left[\mathrm{C}_{2} \mathrm{OHC}_{1}\right.$ im $] \mathrm{Cl}$

[DDA] $\left[\mathrm{NO}_{3}\right]$

$\left[\mathrm{N}_{4,1,1,1}\right]\left[\mathrm{NTf}_{2}\right]$

Cholinium

[Ch][Ala]

[Ch][Ile]

[Ch][geranate $2(\mathrm{H})]$

[Ch][Glu]

[Ch][Gly]

[Ch][Leu]

$\mathrm{N}$-butylammonium oleate

N-hexylammonium oleate

$\mathrm{N}$-octylammonium oleate

1-methoxyethyl-3-methylimidazolium methanesulfonate

1-(2-hydroxyethyl)-3-methylimidazolium chloride

Didecyldimethylammonium nitrate

N-trimethyl-N-butylammonium bis(trifluoromethanesulfonyl)imide

Cholinium alaninate

Cholinium isoleucine

Cholinium geranate

Cholinium L-glutaminate

Cholinium glycinate

Cholinium leucinate

Cholinium phenylalanine

Cholinium prolinate

Cholinium serinate

[Ch][Se]

Cholinium tryptophan

[Ch][Try]

Morpholinium

[Nbmd][OH]

Phosphonium

4,4'-(butane-1,4-diyl)bis(4-dodecyl-morpholin-4-ium)hydroxide

$\left[\mathrm{P}_{444(14)}\right] \mathrm{Cl}$

$\left[\mathrm{P}_{6,6,6,14}\right] \mathrm{Cl}$

$\left[\mathrm{P}_{6,6,6,14}\right]\left[\mathrm{NTf}_{2}\right]$

Pyridinium

$\left[\mathrm{C}_{4} \mathrm{C}_{1}\right.$ py][DCI]

Tributyltetradecylphosphonium chloride

Trihexyltetradecylphosphonium chloride

Trihexyltetradecylphosphonium bis(trifluoromethylsulfonyl)imide

1-butyl-3-methylpyridinium dichloroiodate

$\left[\mathrm{C}_{6} \mathrm{C}_{6} \mathrm{OCOpy}\right]\left[\mathrm{N}(\mathrm{CN})_{2}\right]$ 1-hexyl-3-hexyloxycarbonylpyridinium dicyanamide

$\left[\mathrm{C}_{6} \mathrm{C}_{6} \mathrm{OCOpy}\right]\left[\mathrm{NTf}_{2}\right]$ 1-hexyl-3-hexyloxycarbonylpyridinium bis(trifluoromethylsulfonyl)imide 
Pyrrolidinium

$\left[\right.$ Pyrr $\left._{4,1}\right]\left[\mathrm{NTf}_{2}\right]$

API-ILs

[C $\mathrm{C}_{4} \mathrm{C}_{1}$ im] [Ibu]

[ $\left.\left(\mathrm{C}_{10}\right)_{2} \mathrm{C}_{1} \mathrm{C}_{1} \mathrm{im}\right][\mathrm{Doc}]$

$\left[\left(\mathrm{C}_{10}\right)_{2} \mathrm{C}_{1} \mathrm{C}_{1} \mathrm{im}\right][[\mathrm{Ibu}]$

[ $\left(\mathrm{C}_{10}\right)_{2} \mathrm{C}_{1} \mathrm{C}_{1}$ im][Pen $\left.\mathrm{G}\right]$

$\left[\left(\mathrm{C}_{10}\right)_{2} \mathrm{C}_{1} \mathrm{C}_{1}\right.$ im] $[\mathrm{Sal}]$

[Ch][Amp]

[Ch][BA]

[Ch][B3]

[Ch][B5]

[Ch][B6]

[Ch][Caf]

[Ch][Gal]

[Ch][Ibu]

[Ch][Ket]

[Ch][Nal]

[Ch][Nap]

[Ch][Nif]

[Ch][Sal]

[Ch $]_{2}[\mathrm{Ell}]$

[ $\mathrm{C}_{2} \mathrm{OHC}_{1}$ im][Amp]

$\left[\mathrm{C}_{2} \mathrm{OHC}_{1}\right.$ im] $[\mathrm{Ibu}]$

[C ${ }_{1}$ Pyrr][Sal]

[ $\left.\mathrm{HN}_{444}\right][\mathrm{Sal}]$

[Lid][Asp]

[Lid][Dicl]

[Lid][Doc]

[Lid][Eto]

[Lid][Ibu]

[Lid][Nap]

[Ran][Doc]

[mPEG $\left.\mathrm{m}_{3} \mathrm{~N}_{44}\right][\mathrm{Sal}]$

$\left[\mathrm{P}_{4444}\right][\mathrm{Ibu}]$

[P $\left.{ }_{666(14)}\right][$ Amp]

$\left[\mathrm{PBu}_{4}\right][\mathrm{Sal}]_{\mathrm{n}} \mathrm{H}_{\mathrm{m}-1}$

[ProOEt][Ibu]
Butylmethylpyrrolidinium bis(trifluorosulfonyl)amide

1-butyl-3-methylimidazolium ibuprofenate

Didecyidimethylammonium docusate

Didecyldimethylammonium ibuprofenate

Didecyldimethylammonium penicillin G

Didecyldimethylammonium salicylate

Cholinium ampicilate

Cholinium betulinate

Cholinium nicotinate

Cholinium pantothenate

Cholinium pyridoxylate

Cholinium caffeate

Cholinium gallate

Cholinium ibuprofenate

Cholonium ketoprofen

Cholinium nalixidixate

Cholinium naproxen

Cholinium niflumate

Cholinium salicylate

Dicholinium ellagate

1-hydroxy-ethyl-3-methylimidazolium ampicilate

1-ethanol-3-methylimidazolium ibuprofenate

1-methylpyrrolidinium salicylate

Tributylammonium salicylate

Lidocainium acetylsalicylate

Lidocainium diclofenac

Lidocainium docusate

Lidocainium etodolac

Lidocainium ibuprofenate

Lidocainium naproxenum

Ranitidine docusate

Triethylene glycol monomethyl ether tributylammonium salicylate

Tetrabutylphosphonium ibuprofenate

Trihexyl-tetradecyl phosphonium ampicilate

Tetrabutylphosphonium salicylates

Ethylester ibuprofenate

\section{References}

1. World Health Organization Medicines Strategy-Contries at the Core. Available online: https://apps.who.int/iris/bitstream/handle/10665/84307/WHO_EDM_2004.5_eng.pdf;jsessionid= 0F733DD987692B73A234E9FB8C10D40B?sequence=1 (accessed on 20 May 2020).

2. Ende, M.T.; Ende, D.J. Chemical Engineering in the Pharmaceutical Industry: Drug Product Design, Development and Modeling, 2nd ed.; Wiley: Hoboken, NJ, USA, 2019.

3. Shamshina, J.L.; Rogers, R.D. Overcoming the problems of solid state drug formulations with ionic liquids. Ther. Deliv. 2014, 5, 489-491. [CrossRef] [PubMed]

4. Byrn, S.; Pfeiffer, R.; Ganey, M.; Hoiber, C.; Poochikian, G. Pharmaceutical Solids: A Strategic Approach to Regulatory Considerations. Pharm. Res. 1995, 12, 945-954. [CrossRef] [PubMed]

5. Kalepu, S.; Nekkanti, V. Insoluble drug delivery strategies: Review of recent advances and business prospects. Acta Pharm. Sin. B 2015, 5, 442-453. [CrossRef] [PubMed]

6. Savjani, K.T.; Gajjar, A.K.; Savjani, J.K. Drug Solubility: Importance and Enhancement Techniques. ISRN Pharm. 2012, 2012, 195727. [CrossRef] [PubMed] 
7. Brittain, H.G.; Grant, D.J.R. Effects of Polymorphism and Solid-State Solvation on Solubility and Dissolution Rate. In Polymorphism in Pharmaceutical Solids; Taylor and Francis: Abingdon, UK, 2009; pp. 436-480.

8. Censi, R.; Di Martino, P. Polymorph Impact on the Bioavailability and Stability of Poorly Soluble Drugs. Molecules 2015, 20, 18759-18776. [CrossRef]

9. Bauer, J.; Spanton, S.; Henry, R.; Quick, J.; Dziki, W.; Porter, W.; Morris, J. Ritonavir: An Extraordinary Case of Conformational Polymorphism. Pharm. Res. 2001, 18, 859-866. [CrossRef]

10. Hulme, A.T.; Price, S.L.; Tocher, D.A. A New Polymorph of 5-Fluorouracil Found Following Computational Crystal Structure Predictions. J. Am. Chem. Soc. 2005, 127, 1116-1117. [CrossRef]

11. Florence, A.T.; Attwood, D. Physicochemical Principles of Pharmacy, 4th ed.; Pharmaceutical Press: London, UK, 2006.

12. Cue, B.W.; Zhang, J. Green process chemistry in the pharmaceutical industry. Green Chem. Lett. Rev. 2009, 2, 193-211. [CrossRef]

13. El-Yafi, A.K.E.Z.; El-Zein, H. Technical crystallization for application in pharmaceutical material engineering: Review article. Asian J. Pharm. Sci. 2015, 10, 283-291. [CrossRef]

14. Jain, N.; Kumar, A.; Chauhan, S.; Chauhan, S.M.S. Chemical and biochemical transformations in ionic liquids. Tetrahedron 2005, 61, 1015-1060. [CrossRef]

15. Olivier-bourbigou, H.; Magna, L. Ionic liquids: Perspectives for organic and catalytic reactions. J. Mol. Catal. A Chem. 2002, 183, 419-437. [CrossRef]

16. Cave, G.W.V.; Raston, L.; Scott, J.L. Recent advances in solventless organic reactions: Towards benign synthesis with remarkable versatility. Chem. Commun. 2001, 2001, 2159-2169. [CrossRef]

17. Ehrenström-Reiz, G.; Reiz, S.; Stockman, O. Topical Anaesthesia with EMLA, a New Lidocaine-Prilocaine Cream and the Cusum Technique for Detection of Minimal Application Time. Acta Anaesthesiol. Scand. 1983, 27, 510-512. [CrossRef] [PubMed]

18. Shamshina, J.L.; Kelley, S.P.; Gurau, G.; Rogers, R.D. Develop ionic liquid drugs. Nature 2015, 528, $188-189$. [CrossRef] [PubMed]

19. Freire, M.G.; Cláudio, A.F.M.; Araújo, J.M.M.; Coutinho, J.A.P.; Marrucho, I.M.; Canongia Lopes, J.N.; Rebelo, L.P.N. Aqueous biphasic systems: A boost brought about by using ionic liquids. Chem. Soc. Rev. 2012, 41, 4966-4995. [CrossRef]

20. Earle, M.J.; Esperança, J.M.S.S.; Gile, M.; Lopes, J.N.C.; Rebelo, L.P.N.; Magee, J.W.; Seddon, K.R.; Widegren, J.A. The distillation and volatility of ionic liquids. Nature 2005, 439, 831-834. [CrossRef] [PubMed]

21. Cláudio, A.F.M.; Neves, M.C.; Shimizu, K.; Canongia Lopes, J.N.; Freire, M.G.; Coutinho, J.A.P. The magic of aqueous solutions of ionic liquids: Ionic liquids as a powerful class of catanionic hydrotropes. Green Chem. 2015, 17, 3948-3963. [CrossRef]

22. Shamshina, J.L.; Barber, P.S.; Rogers, R.D. Ionic liquids in drug delivery. Expert Opin. Drug Deliv. 2013, 10, 1367-1381. [CrossRef]

23. Castro, L.; Pereira, P.; Freire, M.; Pedro, A. Progress in the Development of Aqueous Two-Phase Systems Comprising Ionic Liquids for the Downstream Processing of Protein- Based Biopharmaceuticals. Am. Pharm. Rev. 2019, 1-6.

24. Ventura, P.M.; Silva, F.A.; Quental, M.V.; Mondal, D.; Freire, M.G. Ionic-Liquid-Mediated Extraction and Separation Processes for Bioactive Compounds: Past, Present, and Future Trends. Chem. Rev. 2017, 117, 6984-7052. [CrossRef]

25. McQueen, L.; Lai, D. Ionic liquid aqueous two-phase systems from a pharmaceutical perspective. Front. Chem. 2019, 7. [CrossRef] [PubMed]

26. Egorova, K.S.; Ananikov, V.P. Biological Activity of Ionic Liquids Involving Ionic and Covalent Binding: Tunable Drug Development Platform. In Encyclopedia of Ionic Liquids; Springer: Berlin/Heidelberg, Germany, 2019; pp. 1-8. ISBN 9789811067396.

27. Egorova, K.S.; Gordeev, E.G.; Ananikov, V.P. Biological Activity of Ionic Liquids and Their Application in Pharmaceutics and Medicine. Chem. Rev. 2017, 117, 7132-7189. [CrossRef] [PubMed]

28. Tanner, E.E.L.; Curreri, A.M.; Balkaran, J.P.R.; Selig-wober, N.C.; Yang, A.B.; Kendig, C.; Fluhr, M.P.; Kim, N.; Mitragotri, S. Design Principles of Ionic Liquids for Transdermal Drug Delivery. Adv. Mater. 2019, 31, 1901103. [CrossRef] [PubMed] 
29. Dobler, D.; Schmidts, T.; Klingenhöfer, I.; Runkel, F. Ionic liquids as ingredients in topical drug delivery systems. Int. J. Pharm. 2013, 441, 620-627. [CrossRef] [PubMed]

30. Adawiyah, N.; Moniruzzaman, M.; Hawatulaila, S.; Goto, M. Ionic liquids as a potential tool for drug delivery systems. Med. Chem. Commun. 2016, 7, 1881-1897. [CrossRef]

31. Marrucho, I.M.; Branco, L.C.; Rebelo, L.P.N. Ionic Liquids in Pharmaceutical Applications. Annu. Rev. Chem. Biomol. Eng. 2014, 5, 527-546. [CrossRef]

32. Huang, W.; Wu, X.; Qi, J.; Zhu, Q.; Wu, W.; Lu, Y.; Chen, Z. Ionic liquids: Green and tailor-made solvents in drug delivery. Drug Discov. Today 2020, 25, 901-908. [CrossRef]

33. Frizzo, C.P.; Gindri, I.M.; Tier, A.Z.; Buriol, L.; Moreira, D.N.; Martins, M.A.P. Pharmaceutical Salts: Solids to Liquids by Using Ionic Liquid Design. In Ionic Liquids-New Aspects for the Future; IntechOpen: London, UK, 2013; pp. 557-579.

34. Moniruzzaman, M.; Mahmood, H.; Goto, M. Chapter 15: Ionic Liquid Based Nanocarriers for Topical and Transdermal Drug Delivery. In Ionic Liquid Devices; Royal Society of Chemistry: London, UK, 2017; pp. 390-403.

35. Sheldon, R.A. The E factor 25 years on: The rise of green chemistry and sustainability. Green Chem. 2017, 19, 18-43. [CrossRef]

36. Subhedar, D.D.; Shaikh, M.H.; Nawale, L.; Yeware, A.; Sarkar, D.; Kalam, F.A.; Sangshetti, J.N.; Shingate, B.B. Novel tetrazoloquinoline-Rhodanine conjugates: Highly efficient synthesis and biological evaluation. Bioorg. Med. Chem. Lett. 2016, 26, 2278-2283. [CrossRef]

37. Subhedar, D.D.; Shaikh, M.H.; Khan, F.A.K.; Sangshetti, J.N.; Khedkar, V.M.; Shingate, B.B. Facile synthesis of new N-sulfonamidyl-4- thiazolidinone derivatives and their biological evaluation. New J. Chem. 2016, 40, 3047-3058. [CrossRef]

38. Tao, Y.; Dong, R.; Pavlidis, I.V.; Chen, B.; Tan, T. Using imidazolium-based ionic liquids as dual solvent-catalysts for sustainable synthesis of vitamin esters: Inspiration from bio- and organo-catalysis. Green Chem. 2016, 18, 1240-1248. [CrossRef]

39. Siódmiak, T.; Marsza, M.P.; Proszowska, A. Ionic Liquids: A New Strategy in Pharmaceutical Synthesis. Mini Rev. Org. Chem. 2012, 9, 203-208. [CrossRef]

40. Hubbard, C.D.; Illner, P.; van Eldik, R. Understanding chemical reaction mechanisms in ionic liquids: Successes and challenges. Chem. Soc. Rev. 2011, 20, 272-290. [CrossRef] [PubMed]

41. Orrling, K.M.; Wu, X.; Russo, F. Fast, Acid-Free, and Selective Lactamization of Lactones in Ionic Liquids. J. Org. Chem. 2008, 8627-8630. [CrossRef] [PubMed]

42. Zang, H.; Su, Q.; Mo, Y.; Cheng, B. Ionic liquid under ultrasonic irradiation towards a facile synthesis of pyrazolone derivatives. Ultrason. Sonochem. 2011, 18, 68-72. [CrossRef] [PubMed]

43. Siddiqui, I.R.; Srivastava, A.; Shamim, S.; Srivastava, A.; Waseem, M.A. An Efficient One-Pot Regioselective Approach Towards the Synthesis of Thiopyrano [2,3-d] thiazole-2-thiones Catalyzed by Basic Ionic Liquid under Microwave Irradiation. J. Heterocycl. Chem. 2016, 53, 849-858. [CrossRef]

44. Yeung, K.; Farkas, M.E.; Qiu, Z.; Yang, Z. Friedel-Crafts acylation of indoles in acidic imidazolium chloroaluminate ionic liquid at room temperature. Tetrahedron Lett. 2002, 43, 5793-5795. [CrossRef]

45. Güzel, Ö.; Salman, A.; Güzel, Ö.; Salman, A. Synthesis and biological evaluation of new 4- thiazolidinone derivatives. J. Enzyme Inhib. Med. Chem. 2009, 24, 1015-1023. [CrossRef]

46. Kowsari, E.; Mallakmohammadi, M. Ultrasound promoted synthesis of quinolines using basic ionic liquids in aqueous media as a green procedure. Ultrason. Sonochem. 2011, 18, 447-454. [CrossRef]

47. Shi, F.; Gu, Y.; Zhang, Q.; Deng, Y. Development of ionic liquids as green reaction media and catalysts. Catal. Surv. Asia 2004, 8, 179-186. [CrossRef]

48. Bhatt, J.; Chudasama, C.; Patel, K.D. Microwave Assisted Synthesis of Pyrimidines in Ionic Liquid and Their Potency as Non-Classical Malarial Antifolates: Pyrimidines as Non-Classical Malarial Antifolates. Arch. Pharm. Chem. Life Sci. 2016, 349, 791-800. [CrossRef] [PubMed]

49. Valizadeh, H.; Vaghefi, S. One-Pot Wittig and Knoevenagel Reactions in Ionic Liquid as Convenient Methods for the Synthesis of Coumarin Derivatives One-Pot Wittig and Knoevenagel Reactions in Synthesis of Coumarin Derivatives. Synth. Commun. 2009, 39, 1666-1678. [CrossRef]

50. Rao, V.A.; Tiwari, R.; Chhikara, B.S.; Shirazi, A.N.; Parang, K.; Kumar, A. Copper triflate-mediated synthesis of 1,3,5- triarylpyrazoles in [bmim][PF6] ionic liquid and evaluation of their anticancer activities. RSC Adv. 2013, 35, 15396-15403. [CrossRef] [PubMed] 
51. Earle, M.J.; Mccormac, B.; Seddon, K.R. The first high yield green route to a pharmaceutical in a room temperature ionic liquid. Green Chem. 2000, 2, 261-262. [CrossRef]

52. Lai, R.; Wu, X.; Lv, S.; Zhang, C.; He, M.; Chen, Y.; Wang, Q.; Hai, L.; Wu, Y. Synthesis of indoles and quinazolines via additive- controlled selective $\mathrm{C}-\mathrm{H}$ activation/annulation of $\mathrm{N}$-arylamidines and sulfoxonium ylides. Chem. Commun. 2019, 55, 4039-4042. [CrossRef]

53. Mazzoni, O.; Diurno, M.V.; Bosco, A.M.; Novellino, E.; Grieco, P.; Esposito, G.; Calignano, A.; Russo, R.; Università, M.; Li, F.; et al. Synthesis and Pharmacological Evaluation of Analogs of Indole-Based Cannabimimetic Agents. Chem. Biol. Drug Des. 2010, 75, 106-114. [CrossRef]

54. Martins, M.A.P.; Frizzo, C.P.; Moreira, D.N.; Zanatta, N.; Bonacorso, H.G. Ionic Liquids in Heterocyclic Synthesis. Chem. Rev. 2008, 108, 2015-2050. [CrossRef]

55. Liu, B.K.; Wang, N.; Chen, Z.C.; Wu, Q.; Lin, X.F. Markedly enhancing lipase-catalyzed synthesis of nucleoside drugs ester by using a mixture system containing organic solvents and ionic liquid. Bioorg. Med. Chem. Lett. 2006, 16, 3769-3771. [CrossRef]

56. Kumar, V.; Malhotra, S.V. Synthesis of nucleoside-based antiviral drugs in ionic liquids. Bioorg. Med. Chem. Lett. 2008, 18, 5640-5642. [CrossRef]

57. Deshmukh, A.; Gore, B.; Thulasiram, H.V.; Swamy, V.P. Recyclable ionic liquid iodinating reagent for solvent free, regioselective iodination of activated aromatic and heteroaromatic amines. RSC Adv. 2015, 5, 88311-88315. [CrossRef]

58. Harrison, I.T.; Lewis, B.; Nelson, P.; Rooks, W.; Roszkowski, A.; Tomolonis, A.; Fried, J.H. Nonsteroidal Antiinflammatory Agents. I. 6- Substituted 2-Naphthylacetic Acids. J. Med. Chem. 1970, 13, $203-205$. [CrossRef] [PubMed]

59. Wan, K.T.; Davis, M.E. Asymmetric synthesis of naproxen by a new heterogeneous catalyst. J. Catal. 1995, 152, 25-30. [CrossRef]

60. Mena, S.; Santiago, S.; Gallardo, I.; Guirado, G. Sustainable and efficient electrosynthesis of naproxen using carbon dioxide and ionic liquids. Chemosphere 2020, 245, 125557. [CrossRef] [PubMed]

61. Dutta, A.; Damarla, K.; Kumar, A.; Saikia, P.J.; Sarma, D. Gemini basic ionic liquid as bi-functional catalyst for the synthesis of 2,3-dihydroquinazolin-4(1 H)-ones at room temperature. Tetrahedron Lett. 2020, 61, 151587. [CrossRef]

62. Kim, K.; Song, B.; Choi, M.; Kim, M. Biocatalysis in Ionic Liquids: Markedly Enhanced Enantioselectivity of Lipase. Org. Lett. 2001, 3, 1507-1509. [CrossRef]

63. Gamenara, D.; Domínguez, P.; María, D. Candida spp. redox machineries: An ample biocatalytic platform for practical applications and academic insights. Biotechnol. Adv. 2009, 27, 278-285. [CrossRef]

64. Fronza, G.; Fuganti, C.; Grasselli, P.; Mele, A. On the Mode of Bakers' Yeast Transformation of 3-Chloropropiophenone and Related Ketones. Synthesis of (2S)-[2-2H]Propiophenone, (R)-Fluoxetine, and (R)- and (S)-Fenfluramine. J. Org. Chem. 1991, 56, 6019-6023. [CrossRef]

65. Jeong, H.; Uhm, K.; Kim, H. Production of chiral compound using recombinant Escherichia coli cells co-expressing reductase and glucose dehydrogenase in an ionic liquid/water two phase system. J. Mol. Catal. B Enzym. 2011, 70, 114-118. [CrossRef]

66. Pleuvry, B.J. Factors affecting drug absorption and distribution. Pharmacology 2005, 6, 135-138. [CrossRef]

67. Food and Drug Administration (FDA). Dissolution Testing and Acceptance Criteria for Immediate-Release Solid Oral Dosage Form. Drug Products Containing High. Solubility Drug Substances (Guidance for Industry). Available online: https://www.fda.gov/regulatory-information/search-fda-guidance-documents/dissolutiontesting-and-acceptance-criteria-immediate-release-solid-oral-dosage-form-drug-products (accessed on 26 May 2020).

68. Grodowska, K.; Parczewski, A. Organic solvents in the pharmaceutical industry. Acta Pol. Pharm. Drug Res. 2010, 67, 3-12.

69. Mizuuchi, H.; Jaitely, V.; Murdan, S.; Florence, A.T. Room temperature ionic liquids and their mixtures: Potential pharmaceutical solvents. Eur. J. Pharm. Sci. 2008, 33, 326-331. [CrossRef] [PubMed]

70. Millard, J.W.; Alvarez-Núñez, F.A.; Yalkowsky, S.H. Solubilization by cosolvents: Establishing useful constants for the log-linear model. Int. J. Pharm. 2002, 245, 153-166. [CrossRef]

71. Chaudhari, S.P.; Dugar, R.P. Application of surfactants in solid dispersion technology for improving solubility of poorly water soluble drugs. J. Drug Deliv. Sci. Technol. 2017, 41, 68-77. [CrossRef] 
72. Faria, R.A.; da Ponte, M.N.; Bogel-Łukasik, E. Solubility studies on the system of trihexyl(tetradecyl)phosphonium bis[(trifluoromethyl)sulfonyl]amide) ionic liquid and pharmaceutical and bioactive compounds. Fluid Phase Equilib. 2015, 385, 1-9. [CrossRef]

73. dos Santos, A.D.; Morais, A.R.C.; Melo, C.; Bogel-Łukasik, R.; Bogel-Łukasik, E. Solubility of pharmaceutical compounds in ionic liquids. Fluid Phase Equilib. 2013, 356, 18-29. [CrossRef]

74. Goindi, S.; Arora, P.; Kumar, N.; Puri, A. Development of novel ionic liquid-based microemulsion formulation for dermal delivery of 5-fluorouracil. AAPS PharmSciTech 2014, 15, 810-821. [CrossRef] [PubMed]

75. Smith, K.B.; Bridson, R.H.; Leeke, G.A. Solubilities of pharmaceutical compounds in ionic liquids. J. Chem. Eng. Data 2011, 56, 2039-2043. [CrossRef]

76. McCrary, P.D.; Beasley, P.A.; Gurau, G.; Narita, A.; Barber, P.S.; Cojocaru, O.A.; Rogers, R.D. Drug specific, tuning of an ionic liquid's hydrophilic-lipophilic balance to improve water solubility of poorly soluble active pharmaceutical ingredients. New J. Chem. 2013, 37, 2196-2202. [CrossRef]

77. Williams, H.D.; Sahbaz, Y.; Ford, L.; Nguyen, T.H.; Scammells, P.J.; Porter, C.J.H. Ionic liquids provide unique opportunities for oral drug delivery: Structure optimization and in vivo evidence of utility. Chem. Commun. 2014, 50, 1688-1690. [CrossRef]

78. Manic, M.S.; Najdanovic-Visak, V. Solubility of erythromycin in ionic liquids. J. Chem. Thermodyn. 2012, 44, 102-106. [CrossRef]

79. Goindi, S.; Kaur, R.; Kaur, R. An ionic liquid-in-water microemulsion as a potential carrier for topical delivery of poorly water soluble drug: Development, ex-vivo and in-vivo evaluation. Int. J. Pharm. 2015, 495, 913-923. [CrossRef] [PubMed]

80. Alawi, M.A.; Hamdan, I.I.; Sallam, A.A.; Heshmeh, N.A. Solubility enhancement of glibenclamide in choline-tryptophan ionic liquid: Preparation, characterization and mechanism of solubilization. J. Mol. Liq. 2015, 212, 629-634. [CrossRef]

81. Melo, C.I.; Bogel-Łukasik, R.; Nunes da Ponte, M.; Bogel-Łukasik, E. Ammonium ionic liquids as green solvents for drugs. Fluid Phase Equilib. 2013, 338, 209-216. [CrossRef]

82. Forte, A.; Melo, C.I.; Bogel-łukasik, R.; Bogel-łukasik, E. A favourable solubility of isoniazid, an antitubercular antibiotic drug, in alternative solvents. Fluid Phase Equilib. 2012, 318, 89-95. [CrossRef]

83. Chowdhury, M.R.; Moshikur, R.M.; Wakabayashi, R.; Tahara, Y.; Kamiya, N.; Moniruzzaman, M.; Goto, M. Ionic-Liquid-Based Paclitaxel Preparation: A New Potential Formulation for Cancer Treatment. Mol. Pharm. 2018, 15, 2484-2488. [CrossRef]

84. Lourenço, C.; Melo, C.I.; Bogel-Łukasik, R.; Bogel-Łukasik, E. Solubility advantage of pyrazine-2-carboxamide: Application of alternative solvents on the way to the future pharmaceutical development. J. Chem. Eng. Data 2012, 57, 1525-1533. [CrossRef]

85. Jaitely, V.; Mizuuchi, H.; Florence, A.T. Current-stimulated release of solutes solubilized in water-immiscible room temperature ionic liquids (RTILs). J. Drug Target. 2010, 18, 787-793. [CrossRef]

86. Sintra, T.E.; Shimizu, K.; Ventura, S.P.M.; Shimizu, S.; Canongia Lopes, J.N.; Coutinho, J.A.P. Enhanced dissolution of ibuprofen using ionic liquids as catanionic hydrotropes. Phys. Chem. Chem. Phys. 2018, 20, 2094-2103. [CrossRef]

87. Sanan, R.; Kaur, R.; Mahajan, R.K. Micellar Transitions in Catanionic Ionic liquid-Ibuprofen Aqueous Mixtures, Effects of Composition and Dilution. RSC Adv. 2014, 4, 64877-64889. [CrossRef]

88. De Faria, E.L.P.; Shabudin, S.V.; Claúdio, A.F.M.; Válega, M.; Domingues, F.M.J.; Freire, C.S.R.; Silvestre, A.J.D.; Freire, M.G. Aqueous Solutions of Surface-Active Ionic Liquids: Remarkable Alternative Solvents to Improve the Solubility of Triterpenic Acids and Their Extraction from Biomass. ACS Sustain. Chem. Eng. 2017, 5, 7344-7351. [CrossRef]

89. Cláudio, A.F.M.; Cognigni, A.; de Faria, E.L.P.; Silvestre, A.J.D.; Zirbs, R.; Freire, M.G.; Bica, K. Valorization of olive tree leaves: Extraction of oleanolic acid using aqueous solutions of surface-active ionic liquids. Sep. Purif. Technol. 2018, 204, 30-37. [CrossRef] [PubMed]

90. Rodríguez-Hornedo, N.; Murphy, D. Significance of controlling crystallization mechanisms and kinetics in pharmaceutical systems. J. Pharm. Sci. 1999, 88, 651-660. [CrossRef] [PubMed]

91. Yu, Z.Q.; Chew, J.W.; Chow, P.S.; Tan, R.B.H. Recent advances in crystallization control: An industrial perspective. Chem. Eng. Res. Des. 2007, 85, 893-905. [CrossRef]

92. An, J.H.; Kim, J.M.; Chang, S.M.; Kim, W.S. Application of ionic liquid to polymorphic design of pharmaceutical ingredients. Cryst. Growth Des. 2010, 10, 3044-3050. [CrossRef] 
93. Desiraju, G.R. Crystal engineering: A holistic view. Angew. Chem. Int. Ed. 2007, 46, 8342-8356. [CrossRef]

94. Weber, C.C.; Kunov-Kruse, A.J.; Rogers, R.D.; Myerson, A.S. Manipulation of ionic liquid anion-solute-antisolvent interactions for the purification of acetaminophen. Chem. Commun. 2015, 51, 4294-4297. [CrossRef]

95. An, J.H.; Jin, F.; Kim, H.S.; Ryu, H.C.; Kim, J.S.; Kim, H.M.; Kim, K.H.; Kiyonga, A.N.; Jung, K. Investigation of the Polymorphic Transformation of the Active Pharmaceutical Ingredient Clopidogrel Bisulfate Using the Ionic Liquid AEImBF4. Cryst. Growth Des. 2016, 16, 1829-1836. [CrossRef]

96. An, J.H.; Jin, F.; Kim, H.S.; Ryu, H.C.; Kim, J.S.; Kim, H.M.; Kiyonga, A.N.; Min, D.S.; Youn, W.; Kim, K.H.; et al. Application of ionic liquid to polymorphic transformation of anti-viral/HIV drug adefovir dipivoxil. Arch. Pharm. Res. 2016, 39, 646-659. [CrossRef]

97. An, J.H.; Kim, W.S. Antisolvent crystallization using ionic liquids as solvent and antisolvent for polymorphic design of active pharmaceutical ingredient. Cryst. Growth Des. 2013, 13, 31-39. [CrossRef]

98. Weber, C.C.; Kulkarni, S.A.; Kunov-Kruse, A.J.; Rogers, R.D.; Myerson, A.S. The use of cooling crystallization in an ionic liquid system for the purification of pharmaceuticals. Cryst. Growth Des. 2015, 15, 4946-4951. [CrossRef]

99. Berry, D.A.; Dye, S.R.; Ng, K.M. Synthesis of Drowning-Out Crystallization-Based Separations. AIChE J. 1997, 43, 91-103. [CrossRef]

100. Viçosa, A.; Letourneau, J.J.; Espitalier, F.; Inês Ré, M. An innovative antisolvent precipitation process as a promising technique to prepare ultrafine rifampicin particles. J. Cryst. Growth 2012, 342, 80-87. [CrossRef]

101. Martins, I.C.B.; Gomes, J.R.B.; Duarte, M.T.; Mafra, L. Understanding polymorphic control of pharmaceuticals using Imidazolium-based ionic liquid mixtures as crystallization directing agents. Cryst. Growth Des. 2017, 17, 428-432. [CrossRef]

102. Reece, H.A.; Levendis, D.C. Polymorphs of gabapentin. Acta Crystallogr. Sect. C Cryst. Struct. Commun. 2008, 64, 105-108. [CrossRef]

103. Dempah, K.E.; Barich, D.H.; Kaushal, A.M.; Zong, Z.; Desai, S.D.; Suryanarayanan, R.; Kirsch, L.; Munson, E.J. Investigating gabapentin polymorphism using solid-state NMR spectroscopy. AAPS PharmSciTech 2013, 14, 19-28. [CrossRef]

104. Smith, K.B.; Bridson, R.H.; Leeke, G.A. Crystallisation control of paracetamol from ionic liquids. CrystEngComm 2014, 16, 10797-10803. [CrossRef]

105. Mirmehrabi, M.; Rohani, S. An approach to solvent screening for crystallization of polymorphic pharmaceutical and fine chemicals. J. Pharm. Sci. 2005, 94, 1560-1576. [CrossRef]

106. Hough, W.L.; Rogers, R.D. Ionic Liquids Then and Now: From Solvents to Materials to Active Pharmaceutical Ingredients. Bull. Chem. Soc. Jpn. 2007, 80, 2262-2269. [CrossRef]

107. Carson, L.; Chau, P.K.W.; Earle, M.J.; Gilea, M.A.; Gilmore, B.F.; Gorman, S.P.; Mccann, T.; Seddon, K.R. Antibiofilm activities of 1-alkyl-3-methylimidazolium chloride ionic liquids. Green Chem. 2009, 44, 492-497. [CrossRef]

108. Anvari, S.; Hajfarajollah, H.; Mokhtarani, B.; Enayati, M. Antibacterial and anti-adhesive properties of ionic liquids with various cationic and anionic heads toward pathogenic bacteria. J. Mol. Liq. 2016, 221, 685-690. [CrossRef]

109. Taylor, P.; Nancharaiah, Y.V.; Reddy, G.K.K.; Lalithamanasa, P.; Venugopalan, V.P. The ionic liquid 1-alkyl-3-methylimidazolium demonstrates comparable antimicrobial and antibiofilm behavior to a cationic surfactant. Biofouling J. Bioadhes. Biofilm 2012, 28, 1141-1149. [CrossRef]

110. Docherty, K.M.; Kulpa, C.F. Toxicity and antimicrobial activity of imidazolium and pyridinium ionic liquids. Green Chem. 2005, 7, 185-189. [CrossRef]

111. Cornellas, A.; Perez, L.; Comelles, F.; Ribosa, I.; Manresa, A.; Garcia, M.T. Self-aggregation and antimicrobial activity of imidazolium and pyridinium based ionic liquids in aqueous solution. J. Colloid Interface Sci. 2011, 355, 164-171. [CrossRef] [PubMed]

112. Benedetto, A.; Bingham, R.J.; Ballone, P. Structure and dynamics of POPC bilayers in water solutions of room temperature ionic liquids. J. Chem. Phys. 2015, 142, 03B622_1. [CrossRef] [PubMed]

113. Doria, O.F.; Castro, R.; Gutierrez, M.; Valenzuela, D.G.; Santos, L.; Ramirez, D.; Guzman, L. Novel Alkylimidazolium Ionic Liquids as an Antibacterial Alternative to Pathogens of the Skin and Soft Tissue Infections. Molecules 2018, 23, 2354. [CrossRef] 
114. Cho, C.; Stolte, S.; Yun, Y. Comprehensive approach for predicting toxicological effects of ionic liquids on several biological systems using unified descriptors. Sci. Rep. 2016, 33403, 1-9. [CrossRef]

115. Hodyna, D.; Kovalishyn, V.; Semenyuta, I.; Blagodatnyi, V.; Rogalsky, S.; Metelytsia, L. Imidazolium ionic liquids as effective antiseptics and disinfectants against drug resistant $\mathrm{S}$. aureus: In silico and in vitro studies. Comput. Biol. Chem. 2018, 73, 127-138. [CrossRef]

116. Zheng, W.; Huang, W.; Song, Z.; Tang, Z.; Sun, W. Insight into Structure-Antibacterial Activity of Amino Cation- based and Acetate Anion-based Ionic Liquids from the Computational Interaction with POPC Phospholipid Bilayer. Phys. Chem. Chem. Phys. 2020, 22, 15573-15581. [CrossRef]

117. Fister, S.; Mester, P.; Sommer, J.; Witte, A.K.; Kalb, R.; Wagner, M.; Rossmanith, P. Virucidal Influence of Ionic Liquids on Phages P100 and MS2. Front. Microbiol. 2017, 8, 1608. [CrossRef]

118. Bergamo, V.Z.; Donato, R.K.; Lana, D.F.D.; Donato, K.J.Z.; Ortega, G.G.; Schrekker, H.S. Imidazolium salts as antifungal agents: Strong antibiofilm activity against multidrug-resistant Candida tropicalis isolates. Lett. Appl. Microbiol. 2014, 60, 66-71. [CrossRef]

119. Hough-troutman, W.L.; Smiglak, M.; Griffin, S.; Reichert, W.M.; Mirska, I.; Jodynis-liebert, J.; Adamska, T.; Nawrot, J.; Stasiewicz, M.; Rogers, D.; et al. Ionic liquids with dual biological function: Sweet and anti-microbial, hydrophobic quaternary ammonium-based salts. New J. Chem. 2009, 33, 26-33. [CrossRef]

120. Petkovic, M.; Ferguson, J.; Bohn, A.; Trindade, J.; Martins, I.; Carvalho, M.B.; Leit, M.C.; Rodrigues, C.; Garcia, H.; Ferreira, R.; et al. Exploring fungal activity in the presence of ionic liquids. Green Chem. 2009, 11, 889-894. [CrossRef]

121. Suchodolski, J.; Feder-kubis, J.; Krasowska, A. Antifungal activity of ionic liquids based on (-)-menthol: A mechanism study. Microbiol. Res. 2017, 197, 56-64. [CrossRef] [PubMed]

122. Sintra, T.E.; Luís, A.; Rocha, S.N.; Ferreira, A.I.M.C.L.; Gonçalves, F.; Santos, L.M.N.B.F.; Neves, B.M.; Freire, M.G.; Ventura, S.P.M.; Coutinho, J.A.P. Enhancing the antioxidant characteristics of phenolic acids by their conversion into cholinium salts. ACS Sustain. Chem. Eng. 2015, 3, 2558-2565. [CrossRef] [PubMed]

123. Czerniak, K.; Walkiewicz, F. Synthesis and antioxidant properties of dicationic ionic liquids. New J. Chem. 2017, 41, 530-539. [CrossRef]

124. Ahmad, N.A.; Jumbri, K.; Ramli, A.; Ghani, N.A.; Ahmad, H.; Kassim, M.A. Synthesis, characterisation and antioxidant properties of ferulate-based protic ionic liquids: Experimental and modelling approaches. J. Mol. Liq. 2019, 278, 309-319. [CrossRef]

125. Ferreira, A.M.; Morais, E.S.; Leite, A.C.; Mohamadou, A.; Holmbom, B.; Holmbom, T.; Neves, B.M.; Silvestre, A.J. Enhanced Extraction and Biological Activity of 7- hydroxymatairesinol obtained from Norway Spruce knots using Aqueous Solutions of Ionic Liquids. Green Chem. 2017, 19, 2626-2635. [CrossRef]

126. Malhotra, S.V.; Kumar, V. A profile of the in vitro anti-tumor activity of imidazolium-based ionic liquids. Bioorg. Med. Chem. Lett. 2010, 20, 581-585. [CrossRef]

127. Kumar, V.; Malhotra, S.V. Study on the potential anti-cancer activity of phosphonium and ammonium-based ionic liquids. Bioorg. Med. Chem. Lett. 2009, 19, 4643-4646. [CrossRef]

128. Li, X.; Jing, C.; Lei, W.; Li, J.; Wang, J. Apoptosis caused by imidazolium-based ionic liquids in PC12 cells. Ecotoxicol. Environ. Saf. 2012, 83, 102-107. [CrossRef]

129. Hough, W.L.; Smiglak, M.; Rodríguez, H.; Swatloski, R.P.; Spear, S.K.; Daly, D.T.; Pernak, J.; Grisel, J.E.; Carliss, R.D.; Soutullo, M.D.; et al. The third evolution of ionic liquids: Active pharmaceutical ingredients. New J. Chem. 2007, 31, 1429. [CrossRef]

130. Dean, P.M.; Turanjanin, J.; Yoshizawa-fujita, M.; Macfarlane, D.R.; Scott, J.L. Exploring an Anti-Crystal Engineering Approach to the Preparation of Pharmaceutically Active Ionic Liquids. Cryst. Growth Des. 2009, 9, 1137-1145. [CrossRef]

131. Sastry, N.V.; Singh, D.K. Surfactant and Gelation Properties of Acetylsalicylate Based Room Temperature Ionic Liquid in Aqueous Media. Langmuir 2016, 32, 10000-10016. [CrossRef] [PubMed]

132. Suresh, C.; Zhao, H.; Gumbs, A.; Chetty, C.S.; Bose, H.S. New ionic derivatives of betulinic acid as highly potent anti-cancer agents. Bioorg. Med. Chem. Lett. 2012, 22, 1734-1738. [CrossRef] [PubMed]

133. Cherukuvada, S.; Nangia, A. Polymorphism in an API ionic liquid: Ethambutol dibenzoate trimorphs. CrystEngComm 2012, 14, 7840-7843. [CrossRef]

134. Tourne, C.; Judeinstein, P.; In, M.; Viau, L. Surfactant properties of ionic liquids containing short alkyl chain imidazolium cations and ibuprofenate anions. Phys. Chem. Chem. Phys. 2011, 13, 15523-15529. [CrossRef] 
135. Ferraz, R.; Branco, L.C.; Prudêncio, C.; Noronha, J.P.; Petrovski, Ž. Ionic liquids as active pharmaceutical ingredients. ChemMedChem 2011, 6, 975-985. [CrossRef]

136. Bica, K.; Rijksen, C.; Nieuwenhuyzen, M.; Rogers, R.D. In search of pure liquid salt forms of aspirin: Ionic liquid approaches with acetylsalicylic acid and salicylic acid. Phys. Chem. Chem. Phys. 2010, 12, 2011-2017. [CrossRef]

137. Rogers, R.D.; Daly, D.T.; Swatloski, R.P.; Hough-Troutman, W.L.; Hough-Troutman, J.J.H.L.; Marcin, S.; Juliusz, P.; Spear, S.K. Multifunctional Ionic Liquid Compositions for Overcoming Polymorphism and Imparting Improved Properties for Active Pharmaceutical, Biological, Nutritional and Energetic Ingredients. U.S. Patent No. 8,232,265; PCT/US2006/039454; WO 2007/044693 A2 (2007), 18 October 2012.

138. Frizzo, C.P.; Wust, K.; Tier, A.Z.; Vaucher, R.A.; Bolzan, L.P.; Terra, S.; Martins, M.A.P. Novel ibuprofenateand docusate-based ionic liquids: Emergence of antimicrobial activity. RSC Adv. 2016, 6, 100476-100486. [CrossRef]

139. Fernandez-Stefanuto, V.; Tojo, E. New Active Pharmaceutical Ingredient-Ionic Liquids (API-ILs) Derived from Indomethacin and Mebendazole. Proceedings 2018, 9, 48. [CrossRef]

140. Zhao, H.; Holmes, S.S.; Baker, G.A.; Challa, S.; Bose, H.S.; Song, Z. Ionic derivatives of betulinic acid as novel HIV-1 protease inhibitors. J. Enzyme Inhib. Med. Chem. 2012, 27, 715-721. [CrossRef] [PubMed]

141. Florindo, C.; Pereiro, A.B.; Vieira, N.S.M.; Matias, A.A.; Duarte, C.M.M.; Rebelo, P.N.; Marrucho, I.M. Cholinium-based ionic liquids with pharmaceutically active anions. RSC Adv. 2014, 28126-28132. [CrossRef]

142. Balk, A.; Wiest, J.; Widmer, T.; Galli, B.; Holzgrabe, U.; Meinel, L. Transformation of acidic poorly water soluble drugs into ionic liquids. Eur. J. Pharm. Biopharm. 2015, 94, 73-82. [CrossRef] [PubMed]

143. Branco, L.C.; Jorda, N. Dipolar motions and ionic conduction in an ibuprofen derived ionic liquid. Phys. Chem. Chem. Phys. 2015, 17, 24108-24120. [CrossRef]

144. Ferraz, R.; Branco, L.C.; Marrucho, I.M.; Araújo, J.M.; Rebelo, L.P.N.; da Ponte, M.N.; Petrovski, Ž. Development of novel ionic liquids based on ampicillin. Med. Chem. Commun. 2012, 3, 494-497. [CrossRef]

145. Florindo, C.; Araújo, J.M.; Alves, F.; Matos, C.; Ferraz, R.; Prudêncio, C.; Marrucho, I.M. Evaluation of solubility and partition properties of ampicillin-based ionic liquids. Int. J. Pharm. 2013, 456, 553-559. [CrossRef]

146. Ferraz, R.; Noronha, P. Advances Antibacterial activity of Ionic Liquids based on ampicillin against resistant bacteria. RSC Adv. 2014, 4, 4301-4307. [CrossRef]

147. Ferraz, R.; Costa-Rodrigues, J.; Fernandes, M.H.; Santos, M.M.; Marrucho, I.M.; Rebelo, L.P.N.; Prudêncio, C.; Noronha, J.P.; Petrovski, Ž.; Branco, L.C. Antitumor Activity of Ionic Liquids Based on Ampicillin. ChemMedChem 2015, 10, 1480-1483. [CrossRef]

148. Ferraz, R.; Noronha, J.; Murtinheira, F.; Nogueira, F.; Machado, M.; Prudêncio, M.; Parapini, S.; D'Alessandro, S.; Teixeira, C.; Gomes, A.; et al. Primaquine-based ionic liquids as a novel class of antimalarial hits. RSC Adv. 2016, 6, 56134-56138. [CrossRef]

149. Ferraz, R.; Pinheiro, M.; Gomes, A.; Teixeira, C.; Prudêncio, C.; Reis, S.; Gomes, P. Effects of novel triple-stage antimalarial ionic liquids on lipid membrane models. Bioorg. Med. Chem. Lett. 2017, 27, 4190-4193. [CrossRef]

150. Miwa, Y.; Hamamoto, H.; Ishida, T. Lidocaine self-sacrificially improves the skin permeation of the acidic and poorly water-soluble drug etodolac via its transformation into an ionic liquid. Eur. J. Pharm. Biopharm. 2016, 102, 92-100. [CrossRef] [PubMed]

151. Berton, P.; Di Bona, K.R.; Yancey, D.; Rizvi, S.A.A.; Gray, M.; Gurau, G.; Shamshina, J.L.; Rasco, J.F.; Rogers, R.D. Transdermal Bioavailability in Rats of Lidocaine in the Forms of Ionic Liquids, Salts, and Deep Eutectic. ACS Med. Chem. Lett. 2017, 8, 498-503. [CrossRef] [PubMed]

152. Johansson, K.M.; Izgorodina, E.I.; Forsyth, M.; Macfarlane, D.R.; Seddon, K.R. Protic ionic liquids based on the dimeric and oligomeric anions: [(AcO)xHx-1]-. Phys. Chem. Chem. Phys. 2008, 10, 2972-2978. [CrossRef] [PubMed]

153. Bica, K.; Rogers, R.D. Confused ionic liquid ions-A “"liquification”' and dosage strategy for pharmaceutically active salts. Chem. Commun. 2010, 46, 1215-1217. [CrossRef]

154. Stoimenovski, J.; Dean, P.M.; Izgorodina, E.I.; Macfarlane, D.R. Protic pharmaceutical ionic liquids and solids: Aspects of protonics. Faraday Discuss. 2012, 154, 335-352. [CrossRef]

155. Hajnal, K.; Gabriel, H.; Aura, R.; Erzsébet, V.; Blanka, S.S. Prodrug Strategy in Drug Development. Acta Med. Marisiensis 2016, 62, 356-362. [CrossRef] 
156. N'Da, D.D. Prodrug Strategies for Enhancing the Percutaneous Absorption of Drugs. Molecules 2014, 19, 20780-20807. [CrossRef]

157. Aguiar, A.J.; Krc, J.; Kinkel, A.W.; Samyn, J.C. Effect of polymorphism on the absorption of chloramphenicol from chloramphenicol palmitate. J. Pharm. Sci. 1967, 56, 847-853. [CrossRef]

158. Cojocaru, O.A.; Bica, K.; Gurau, G.; Narita, A.; Mccrary, P.D.; Shamshina, J.L.; Barber, S.; Rogers, R.D. Prodrug ionic liquids: Functionalizing neutral active ionic liquid form. Med. Chem. Commun. 2013, 4, 559-563. [CrossRef]

159. Staben, L.R.; Koenig, S.G.; Lehar, S.M.; Vandlen, R.; Zhang, D.; Chuh, J.; Yu, S.; Ng, C.; Guo, J.; Liu, Y.; et al. Targeted drug delivery through the traceless release of tertiary and heteroaryl amines from antibody-drug conjugates. Nat. Chem. 2016, 8, 1112-1119. [CrossRef]

160. Dias, A.M.A.; Cortez, A.R.; Barsan, M.M.; Santos, J.B.; Brett, C.M.A.; De Sousa, H.C. Development of greener multi-responsive chitosan biomaterials doped with biocompatible ammonium ionic liquids. ACS Sustain. Chem. Eng. 2013, 1, 1480-1492. [CrossRef]

161. De Almeida, T.S.; Júlio, A.; Mota, J.P.; Rijo, P.; Reis, C.P. An emerging integration between ionic liquids and nanotechnology: General uses and future prospects in drug delivery. Ther. Deliv. 2017, 8, 461-473. [CrossRef] [PubMed]

162. Halayqa, M.; Zawadzki, M.; Domańska, U.; Plichta, A. Polymer-Ionic liquid-Pharmaceutical conjugates as drug delivery systems. J. Mol. Struct. 2019, 1180, 573-584. [CrossRef]

163. Khan, A.B.; Ali, M.; Malik, N.A.; Ali, A.; Patel, R. Role of 1-methyl-3-octylimidazolium chloride in the micellization behavior of amphiphilic drug amitriptyline hydrochloride. Colloids Surf. B Biointerfaces 2013, 112, 460-465. [CrossRef] [PubMed]

164. Mehrdad, A.; Miri, A.H. Aqueous solubility of acetaminophen in the presence of 1-hexyl-3-methyl imidazolium bromide, ionic liquid as co-solvent. Fluid Phase Equilib. 2016, 425, 51-56. [CrossRef]

165. Oh, D.X.; Shin, S.; Lim, C.; Hwang, D.S. Dopamine-mediated sclerotization of regenerated chitin in ionic liquid. Materials 2013, 6, 3826-3839. [CrossRef]

166. Silva, S.S.; Popa, E.G.; Gomes, M.E.; Oliveira, M.B.; Nayak, S.; Subia, B.; Mano, J.F.; Kundu, S.C.; Reis, R.L. Silk hydrogels from non-mulberry and mulberry silkworm cocoons processed with ionic liquids. Acta Biomater. 2013, 9, 8972-8982. [CrossRef]

167. Meng, Z.; Zheng, X.; Tang, K.; Liu, J.; Ma, Z.; Zhao, Q. Dissolution and regeneration of collagen fibers using ionic liquid. Int. J. Biol. Macromol. 2012, 51, 440-448. [CrossRef]

168. De Carvalho, R.N.L.; Lourenço, N.M.T.; Gomes, P.M.V.; Da Fonseca, L.J.P. Swelling behavior of gelatin-ionic liquid functional polymers. J. Polym. Sci. Part B Polym. Phys. 2013, 51, 817-825. [CrossRef]

169. Pandey, P.K.; Rawat, K.; Aswal, V.K.; Kohlbrecher, J.; Bohidar, H.B. DNA ionogel: Structure and self-assembly. Phys. Chem. Chem. Phys. 2017, 19, 804-812. [CrossRef]

170. Rawat, K.; Aswal, V.K.; Bohidar, H.B. DNA-gelatin complex coacervation, UCST and first-order phase transition of coacervate to anisotropic ion gel in 1-methyl-3-octylimidazolium chloride ionic liquid solutions. J. Phys. Chem. B 2012, 116, 14805-14816. [CrossRef]

171. Barber, P.S.; Griggs, C.S.; Bonner, J.R.; Rogers, R.D. Electrospinning of chitin nanofibers directly from an ionic liquid extract of shrimp shells. Green Chem. 2013, 15, 601-607. [CrossRef]

172. Fu, R.; Ji, X.; Ren, Y.; Wang, G.; Cheng, B. Antibacterial blend films of cellulose and chitosan prepared from binary ionic liquid system. Fibers Polym. 2017, 18, 852-858. [CrossRef]

173. Murugesan, S.; Wiencek, J.M.; Ren, R.X.; Linhardt, R.J. Benzoate-based room temperature ionic liquids-Thermal properties and glycosaminoglycan dissolution. Carbohydr. Polym. 2006, 63, 268-271. [CrossRef]

174. Trivedi, T.J.; Srivastava, D.N.; Rogers, R.D.; Kumar, A. Agarose processing in protic and mixed protic-aprotic ionic liquids: Dissolution, regeneration and high conductivity, high strength ionogels. Green Chem. 2012, 14, 2831-2839. [CrossRef]

175. Viau, L.; Tourné-Péteilh, C.; Devoisselle, J.M.; Vioux, A. Ionogels as drug delivery system: One-step sol-gel synthesis using imidazolium ibuprofenate ionic liquid. Chem. Commun. 2010, 46, 228-230. [CrossRef] [PubMed]

176. Chen, J.; Xie, F.; Li, X.; Chen, L. Ionic liquids for the preparation of biopolymer materials for drug/gene delivery: A review. Green Chem. 2018, 20, 4169-4200. [CrossRef] 
177. Zhu, L.; $\mathrm{Xu}, \mathrm{H}$. The optimal choice of medication administration route regarding intravenous, intramuscular, and subcutaneous injection. Patient Prefer. Adherence 2015, 15, 923-942. [CrossRef]

178. Maddison, J.E.; Page, S.W.; Dyke, T.M. Chapter 2-Clinical Pharmacokinetics, 2nd ed.; Elsevier Ltd.: Amsterdam, The Netherlands, 2011.

179. Bharmoria, P.; Singh, T.; Kumar, A. Complexation of chitosan with surfactant like ionic liquids: Molecular interactions and preparation of chitosan nanoparticles. J. Colloid Interface Sci. 2013, 407, 361-369. [CrossRef]

180. Liu, Y.; Huang, Y.; Boamah, P.O.; Cao, L.; Zhang, Q.; Lu, Z.; Li, H. Homogeneous synthesis of linoleic acid-grafted chitosan oligosaccharide in ionic liquid and its self-assembly performance in aqueous solution. J. Appl. Polym. Sci. 2015, 132, 1-8. [CrossRef]

181. Tang, W.; Liu, B.; Wang, S.; Liu, T.; Fu, C.; Ren, X.; Tan, L.; Duan, W.; Meng, X. Doxorubicin-loaded Ionic Liquid-Polydopamine nanoparticles for combined chemotherapy and microwave thermal therapy of cancer. RSC Adv. 2016, 6, 32434-32440. [CrossRef]

182. Dong, H.; Xu, Q.; Li, Y.; Mo, S.; Cai, S.; Liu, L. The synthesis of biodegradable graft copolymer cellulose-graft-poly(l-lactide) and the study of its controlled drug release. Colloids Surf. B Biointerfaces 2008, 66, 26-33. [CrossRef] [PubMed]

183. Moniruzzaman, M.; Tahara, Y.; Tamura, M.; Kamiya, N.; Goto, M. Ionic liquid-assisted transdermal delivery of sparingly soluble drugs. Chem. Commun. 2010, 46, 1452-1454. [CrossRef] [PubMed]

184. Parsi, E.; Salabat, A. Comparison of O/W and IL/W Microemulsion Systems as Potential Carriers of Sparingly Soluble Celecoxib Drug. J. Solut. Chem. 2020, 49, 68-82. [CrossRef]

185. Demirkurt, B.; Cakan-akdogan, G.; Akdogan, Y. Preparation of albumin nanoparticles in water-in-ionic liquid microemulsions. J. Mol. Liq. 2019, 295, 111713. [CrossRef]

186. Esson, M.M.; Mecozzi, S.; Mecozzi, S. Preparation, Characterization, and Formulation Optimization of Ionic-Liquid-in-Water Nanoemulsions toward Systemic Delivery of Amphotericin B. Mol. Pharm. 2020, 17, 2221-2226. [CrossRef]

187. Taylor, P.; Hosseinzadeh, F.; Mahkam, M. Synthesis and characterization of ionic liquid functionalized polymers for drug delivery of an anti-inflammatory drug. Des. Monomers Polym. 2012, 15, 379-388.

188. Rasouli, S.; Davaran, S.; Rasouli, F.; Mahkam, M.; Salehi, S. Synthesis, characterization and pH-controllable methotrexate release from biocompatible polymer/silica nanocomposite for anticancer drug delivery. Drug Deliv. 2013, 1, 155-163. [CrossRef]

189. Banerjee, A.; Ibsen, K.; Brown, T.; Chen, R.; Agatemor, C.; Mitragotri, S. Ionic liquids for oral insulin delivery. Proc. Natl. Acad. Sci. USA 2018, 115, 7296-7301. [CrossRef]

190. Bica, K.; Rodríguez, H.; Gurau, G.; Cojocaru, O.A.; Riisager, A.; Fehrmann, R.; Rogers, R.D. Pharmaceutically active ionic liquids with solids handling, enhanced thermal stability, and fast release. Chem. Commun. 2012, 48, 5422-5424. [CrossRef]

191. Zhang, L.; Liu, J.; Tian, T.; Gao, Y.; Ji, X.; Li, Z. Pharmaceutically Active Ionic Liquid Self-Assembled Vesicles for the Application as an Efficient Drug Delivery System. ChemPhysChem 2013, 14, 3454-3457. [CrossRef] [PubMed]

192. Sahbaz, Y.; Williams, H.D.; Nguyen, T.; Saunders, J.; Ford, L.; Charman, S.A.; Scammells, P.J.; Porter, C.J.H. Transformation of Poorly Water-Soluble Drugs into Lipophilic Ionic Liquids Enhances Oral Drug Exposure from Lipid Based Formulations. Mol. Pharm. 2015, 12, 1980-1991. [CrossRef] [PubMed]

193. Benson, H.A.E.; Grice, J.E.; Mohammed, Y.; Namjoshi, S.; Roberts, M.S. Topical and Transdermal Drug Delivery: From Simple Potions to Smart Technologies. Curr. Drug Deliv. 2019, 16, 444-460. [CrossRef] [PubMed]

194. Prausnitz, M.R.; Langer, R. Transdermal drug delivery. Nat. Biotechnol. 2008, 26, 1261-1268. [CrossRef]

195. Caparica, R.; Júlio, A.; Rosadoand, C.; Santos, T. Applicability of Ionic Liquids in Topical Drug Delivery Systems: A Mini Review. J. Pharmacol. Clin. Res. 2018, 4, 555649-555655. [CrossRef]

196. Mahajan, S.; Sharma, R.; Mahajan, R.K. An Investigation of Drug Binding Ability of a Surface Active Ionic Liquid: Micellization, Electrochemical, and Spectroscopic Studies. Langmuir 2012, 18, 17238-17246. [CrossRef]

197. Pal, A.; Yadav, A. Binding interactions of anesthetic drug with surface active ionic liquid. J. Mol. Liq. 2016, 222, 471-479. [CrossRef] 
198. Moniruzzaman, M.; Tamura, M.; Tahara, Y.; Kamiya, N.; Goto, M. Ionic liquid-in-oil microemulsion as a potential carrier of sparingly soluble drug: Characterization and cytotoxicity evaluation. Int. J. Pharm. 2010, 400, 243-250. [CrossRef]

199. Islam, R.; Chowdhury, R.; Wakabayashi, R.; Kamiya, N. Ionic Liquid-In-Oil Microemulsions Prepared with Biocompatible Choline Carboxylic Acids for Improving the Transdermal Delivery of a Sparingly Soluble Drug. Pharmaceutics 2020, 12, 392. [CrossRef]

200. Yoshiura, H.; Tamura, M.; Aso, M.; Kamiya, N.; Goto, M. Ionic Liquid-in-Oil Microemulsions as Potential Carriers for the Transdermal Delivery of Methotrexate. J. Chem. Eng. Jpn. 2013, 46, 794-796. [CrossRef]

201. Wang, C.; Zhu, J.; Zhang, D.; Yang, Y.; Zheng, L.; Qu, Y.; Yang, X.; Cui, X. Ionic liquid-Microemulsions assisting in the transdermal delivery of Dencichine: Preparation, in-vitro and in-vivo evaluations, and investigation of the permeation mechanism. Int. J. Pharm. 2018, 535, 120-131. [CrossRef] [PubMed]

202. Morais, E.S.; Silva, N.H.C.S.; Sintra, T.E.; Santos, S.A.O.; Neves, B.M.; Almeida, I.F.; Costa, P.C.; Correia-Sá, I.; Ventura, S.P.M.; Silvestre, A.J.D.; et al. Anti-inflammatory and antioxidant nanostructured cellulose membranes loaded with phenolic-based ionic liquids for cutaneous application. Carbohydr. Polym. 2019, 206, 187-197. [CrossRef] [PubMed]

203. Chantereau, G.; Sharma, M.; Abednejad, A.; Neves, B.M.; Se, G.; Freire, M.G.; Freire, C.S.R.; Silvestre, A.J.D. Design of Nonsteroidal Anti-Inflammatory Drug-Based Ionic Liquids with Improved Water Solubility and Drug Delivery. ACS Sustain. Chem. Eng. 2019, 7, 14126-14134. [CrossRef]

204. Chantereau, G.; Sharma, M.; Abednejad, A.; Vilela, C.; Costa, E.M.; Veiga, M.; Antunes, F.; Pintado, M.M.; Sèbe, G.; Coma, V.; et al. Bacterial nanocellulose membranes loaded with vitamin B-based ionic liquids for dermal care applications. J. Mol. Liq. 2020, 302, 112547. [CrossRef]

205. Miwa, Y.; Hamamoto, H.; Hikake, S.; Kuwabara, Y. A Phase I, Randomized, Open-Label, Cross-Over Study of the Pharmacokinetics, Dermal Tolerability, and Safety of MRX-7EAT Etodolac-Lidocaine Topical Patch in Healthy Volunteers. J. Pain 2013, 14, S72. [CrossRef]

206. Abednejad, A.; Ghaee, A.; Morais, E.S.; Sharma, M.; Neves, B.M.; Freire, M.G.; Nourmohammadi, J.; Mehrizi, A.A. Polyvinylidene fluoride-Hyaluronic acid wound dressing comprised of ionic liquids for controlled drug delivery and dual therapeutic behavior. Acta Biomater. 2019, 100, 142-157. [CrossRef] [PubMed]

207. Júlio, A.; Caparica, R.; Lima, S.A.C.; Fernandes, A.S.; Rosado, C.; Prazeres, D.M.F.; Reis, S.; Almeida, S. De Ionic Liquid-Polymer Nanoparticle Hybrid Systems as New Tools to Deliver Poorly Soluble Drugs. Nanomaterials 2019, 9, 1148. [CrossRef]

208. Zhang, D.; Wang, H.; Cui, X.; Wang, C.; Zhang, D.; Wang, H.; Cui, X.; Wang, C. Evaluations of imidazolium ionic liquids as novel skin permeation enhancers for drug transdermal delivery. Pharm. Dev. Technol. ISSN 2016, 22, 511-520. [CrossRef]

209. Furukawa, S.Y.; Hattori, G.; Sakai, S.; Kamiya, N. Highly Efficient and Low Toxic Skin Penetrants Composed of Amino Acid Ionic Liquids. RSC Adv. 2016, 6, 87753-87755. [CrossRef]

210. Zavgorodnya, O.; Shamshina, J.L.; Mittenthal, M.; McCrary, P.D.; Rachiero, G.P.; Titi, H.M.; Rogers, R.D. Polyethylene Glycol Derivatization of the Non-active Ion in Active Pharmaceutical Ingredient Ionic Liquids Enhances Transdermal Delivery. New J. Chem. 2017, 41, 1499-1508. [CrossRef]

211. Zakrewsky, M.; Lovejoy, K.S.; Kern, T.L.; Miller, T.E.; Le, V.; Nagy, A. Ionic liquids as a class of materials for transdermal delivery and pathogen neutralization. Proc. Natl. Acad. Sci. USA 2014, 111, 13313-13318. [CrossRef]

212. Zech, O.; Thomaier, S.; Kolodziejski, A.; Touraud, D.; Grillo, I.; Kunz, W. Ionic Liquids in Microemulsions-A Concept To Extend the Conventional Thermal Stability Range of Microemulsions. Chem. Eur. J. 2010, 16, 783-786. [CrossRef]

213. Simon, L.S.; Zhao, S.Z.; Arguelles, L.M.; Lefkowith, J.B. Economic and Gastrointestinal Safety Comparisons of Etodolac, Nabumetone, and Oxaprozin from Insurance Claims Data from Patients with Arthritis. Clin. Ther. 1998, 20, 1218-1235. [CrossRef]

214. Jing, B.; Lan, N.; Qiu, J.; Zhu, Y. Interaction of Ionic Liquids with Lipid Bilayer: A Biophysical Study of Ionic Liquid Cytotoxicity. J. Phys. Chem. B 2016, 120, 2781-2789. [CrossRef] [PubMed]

215. Whitehead, K.; Mitragotri, S. Mechanistic Analysis of Chemical Permeation Enhancers for Oral Drug Delivery. Pharm. Res. 2008, 25, 1412-1419. [CrossRef] [PubMed] 
216. Agatemor, C.; Ibsen, K.N.; Tanner, E.E.; Mitragotri, S. Ionic Liquids for Addressing Unmet Needs in Healthcare. Bioeng. Transl. Med. 2017, 3, 7-25.

217. Kubota, K.; Shibata, A.; Yamaguchi, T. The molecular assembly of the ionic liquid/aliphatic carboxylic acid/aliphatic amine as effective and safety transdermal permeation enhancers. Eur. J. Pharm. Sci. 2016, 86, 75-83. [CrossRef]

218. Janus, E.; Ossowicz, P.; Klebeko, J.; Nowak, A.; Duchnik, W.; Klimowicz, A. Enhancement of ibuprofen solubility and skin permeation by conjugation with L -valine alkyl esters. RSC Adv. 2020, 10, 7570-7584. [CrossRef]

Publisher's Note: MDPI stays neutral with regard to jurisdictional claims in published maps and institutional affiliations.

(C) 2020 by the authors. Licensee MDPI, Basel, Switzerland. This article is an open access article distributed under the terms and conditions of the Creative Commons Attribution (CC BY) license (http://creativecommons.org/licenses/by/4.0/). 